https://theses.gla.ac.uk/

Theses Digitisation:

https://www.gla.ac.uk/myglasgow/research/enlighten/theses/digitisation/

This is a digitised version of the original print thesis.

Copyright and moral rights for this work are retained by the author

A copy can be downloaded for personal non-commercial research or study, without prior permission or charge

This work cannot be reproduced or quoted extensively from without first obtaining permission in writing from the author

The content must not be changed in any way or sold commercially in any format or medium without the formal permission of the author

When referring to this work, full bibliographic details including the author, title, awarding institution and date of the thesis must be given

Enlighten: Theses

https://theses.gla.ac.uk/

research-enlighten@glasgow.ac.uk 


\section{PHOTOPRODUCTION OF NEGATIVE PIONS IN DEUTERIUM}

BI

H. C. EVANS

PRESENTED TO THE UNIVERSITY OF GLASGOW AS A THESIS FOI THE DEGREE OF DOCTOR OF PIILOSOPHY, AUGUST, 1961. 
ProQuest Number: 10656256

All rights reserved

INFORMATION TO ALL USERS

The quality of this reproduction is dependent upon the quality of the copy submitted.

In the unlikely event that the author did not send a complete manuscript and there are missing pages, these will be noted. Also, if material had to be removed, a note will indicate the deletion.

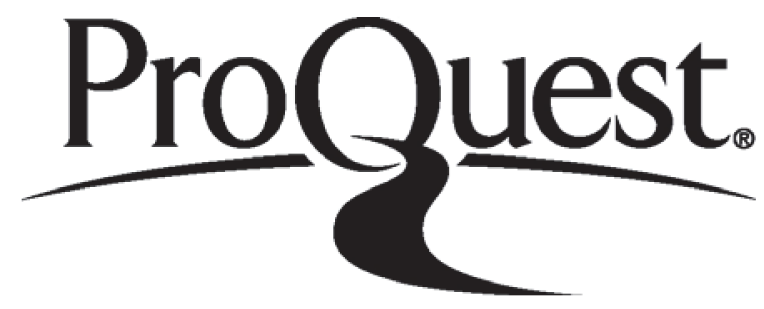

ProQuest 10656256

Published by ProQuest LLC (2017). Copyright of the Dissertation is held by the Author.

All rights reserved.

This work is protected against unauthorized copying under Title 17, United States Code Microform Edition (C) ProQuest LLC.

ProQuest LLC.

789 East Eisenhower Parkway

P.O. Box 1346

Ann Arbor, Ml $48106-1346$ 


\section{PREFACE}

Deuterium provides the most sultable target for otudying the basic process of negative pion photoproduction at a freo neutron. For photon energies well above threshold tho spectator model has been used to relate pion photoproduction in deutoriua to photoproduction at a Iroe noutron. In 1957 when the work described in thts thesis was initiated no experimental test of the Epectator model that cloarly supported its valldity for negative pion photoproduction in deuterium had boen reported. An experiment done ualng the brensetrahlune beam of the Glasgow electron synchrotron is described. A scintillation countor tochniquo was used, and tho energy epeotrum and angular distribution of tho recoll protono detected in coincidence with necative pione from deuterium were compared with the predietions of tho opectator model. Ireasonable agreement was obtained.

Charged pion photoproduction in hydrogen and deutertum 18 discused in Chaptor I. A dotalled discusolon of experifental teate of the apectator model and the lapulso approxination is civen.

The callbration of the response of cotwerclally avallablo plastic ocintillator io described in Chapter II. 
Th1 work was largely wy own.

The construction, tosting, and calibration of the ecintillation counter telescopos and the asociated electronics 10 glven in Chapter III. The proton teloscopo was constructed by wysolf. Tho plon teloscope wa adapted from an existing counter toleacope. The athor assisted in the construction of tho display unt and was entirely responatble for the counter teats descrtbed.

In Chapter IV tho moasurement of the recoll proton energy and angular distributions is doscribed and tho rosulte prozented. None of the work lincluded in the description of the eynchrotron was done by the author. The Ilquid targot was constructed and operated by Mr. D. Millax. I was assistod in the collection of deta by Mr. B. Patrick. The analyois of tho data was dono by mysels.

The rocoll proton onorgy opectra and angular diatributions for $r+n \rightarrow p+\pi^{-}$and for the opectator model description of $\gamma+d \rightarrow 2 p+\pi^{-}$are calculated in Chapter V. The computation of the spoctator model kinematics using Deuco was dono by $\mathrm{Hr}$. I.Barbour. The remainder of the work was done by the author. 
The discussion and the conclusions presented in Chaptar VI are my own.

I wish to thank Profossor P.I. Doo F.N.S. For the intorest ho he ohown in this work and for extending to we the privilege of working in his laboratory. I am grateful to Professor E.II. Bellany for oupervioton during the first 3 yoars of this work and to Dr. J. Rutherglon for his assistance and advice during the later stager. It to a pleasure to thank Dr. Herarlane and his eynchrotron crer for their invaluable assiatanco. I an also lndobted to :r. D. M110r, Mr. B. patrick and Mx. I. Darboux.

I wieh to acknowlodgo tho financial support given no by the National Rosearch Counc1l of Canada during ar firet 3 yeare, and to thank the University of olasgow for a Univerelty Research studentship awarded me during the fourth year. 
PREFACE

CHLAPTER I

(a) Introduction 1

(b) Positive Pion Photuproduction at Protons

(c) Charged PIon Photoproduction in Deuteriun

(d) Review of Publ1shed Ixperimental Work 21

(e) The Presont Experiment 37

CHAPTER II : RESPONSE OF PLASTIC SCINTILLATOR

CHAPTER III, THE DETECTION SYSTEM

(a) Introduction 50

(b) The Proton Telescope 52

(c) The pion Telescopo 62

(a) Detection of Protons in Colncidence
with Nogative Plons

CHAPTER IV, PHOTOPRODUCTION OF NEGATIVE PIONS IN DEUTERIUH.

(a) The Synchrotron 74

(b) The Target 79

(c) Experimental Procedure 81 
PAGE

CHAPTER V: CALCULATION OF ENERGY AND ANGULAR DISTRIBUTIONS

CIIAPTER VI: DISCUSSION AND CONCLUSIONS 106

PUBLICATIONS

REFERENCES 


\section{CHAPTER I}

(a) Introduction

The existence of tho pion was first postulated by Yukawa (1935) in his theory of nuclear forces. Their existence in cosmic radiation was confirmed by the Bristol group led by Powell in 1947 (Lattes et al., 1947) by observing the decay of the pion into $\mu-m e s o n s$ in nuclear emulsions. As high energy particle accelerators becarte avaliable the production of pions in the laboratory In nucleon-nucleon and photon-nucleon collisions made possible detalled investigation of their properties. Pions are zero spin particles. They form an isotopto spin triplet and have odd intrinsic parity with respect to the nucleon. The masses and principel decay modes of charged and neutral plons are given bolow.

$\begin{array}{llrr}\text { Pion } & \text { Decay Hode } & \begin{array}{r}\text { Life Time } \\ \left(8 \times 0_{0}\right)\end{array} & \begin{array}{r}\text { Mass } \\ (\text { MeV.) }\end{array} \\ \pi^{ \pm} & \pi^{ \pm} \rightarrow \mu^{ \pm}+v & 2.54 \times 10^{-8} & 139.6 \\ \pi^{0} & \pi^{0} \rightarrow 2 \gamma & 5 \times 10^{-16} & 135.0\end{array}$

Tho first observation of pions produced in photonnucleon collisions (photoproduction) were made at Berkoley (McHilian, 1949) using a carbon target. The Investigation of photoproduction of charged pions carried out since then has been largely directed towards 
understanding the basic processes for photoproduction of a single charged pion at a nucleon.

$$
\begin{aligned}
& r+p \rightarrow \pi^{+}+n \\
& r+n \rightarrow \pi^{-}+p
\end{aligned}
$$

Only the flrst of these can be observed for free nucloons due to the lack of a condensed noutron target. The most sultable nucleus for investigating (1.2) 1s the deuteron. The low blnding energy and loose structure of the deuteron lead one to expect that the nuclear binding has less effect on charged pion photoproduction from deuteriun than from heavier nucle1. The reactions for charged pion photoproduction in deuterium are

$$
\begin{aligned}
& r+d \rightarrow \pi^{+}+2 n \\
& r+d \rightarrow \pi^{-}+2 p
\end{aligned}
$$

The interpretation of $(1.3)$ and $(1.4)$ in terms of the freo nucleon reactions $(1.1)$ and $(1.2)$ is complicated by a number of effects.

The photon beans available for experiment are produced by allowing artiflclally accelerated electrone to strike a target. This produces a bremsstrahlung beam 
which contalns photons of all energles between zero and the maximum enerey of the incident electrons. The energy of a photon 1nvolved in production of a pion at a nucleus is in general unknown. In the special case of (1.1) which is a two body reaction. measurement of the angle of production and the energy of one of the final state particles uniquely defines the incident photon energy. This is due to the requirement of simultaneous energy and momentum conservation.

In the simplest model for reactions (1.3) and (1.4). photoproduction is considered to take place at a free nucleon, which is given a momentum distribution appropriate to a nucleon in deuterium. This is the spectator model, so called because the other nucloon takes no part in the 1nteraction. In this model the measurement of the angle of production and energy of a pion allows one to define a range $\stackrel{\text { of }}{\wedge}$ energy for the 1ncident photon. The interaction of the 3 particles in the final state can be expected to introduce additional effects. In reaction (1.4) there are 3 charged particles in the rinal state and Coulomb-interaction. which is absent in (1.3) is important at low energy. In most experiments involving pion photoproduction from deuterium, only the plon 1 s detected and the results 
are interpreted in terras of free nucleon kinematics. Experiments in which more than one final state particlo are observed allow one to investigate tho validity of the various models used to interpret observations of (1.3) and (1.4). The purpose of this thesis $1 \mathrm{~s}$ to describe an experiment done using the bremstrahlung bean of the Glasgow electron synchrotron, In which a recoil proton was detected in colnctdence with negative plons from deuterium using a scintillation counter technique. Before discussing the detalled Investigation of reactions (1.3) and $(1.4)$ a brief account of pion photoproduction in hydrogen is givon for the energy region up to $350 \mathrm{MeV}$ in which pions are produced singly.

(b) Positive Plon Photoproduction at Protons

Photoproduction of positive plons at protons has been thoroughly investigated and the main features of this reaction are well known. The total cross section rises as the photon energy Increases above threshold and reaches a maximum value in the region of 290 to $300 \mathrm{MeV}$. At hicher energles the cross section decreases rapldiy. Th1 o behaviour is due to a strong resonance in the 


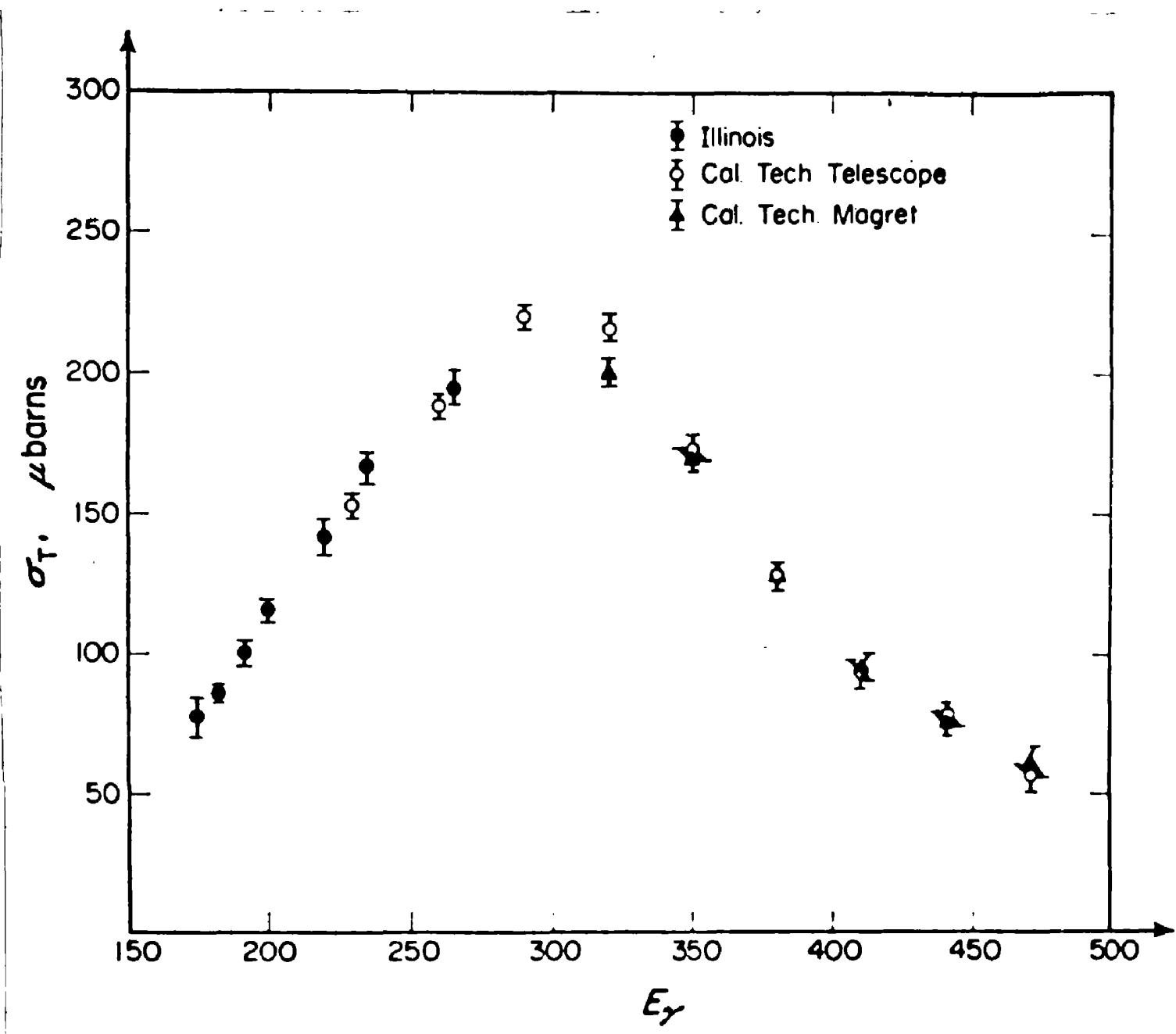

Total cross-section $\gamma+p \rightarrow \pi^{+}+n$.

FIgure 1.1 . 
$T=3 / 2, J=3 / 2$ pion nucleon state, where $T$ and $J$ are the isotopic spin and total angular momentum respectirely. The total cross section 1s shown as a function of photon energy in figure 1.1, which has been taken from a review article by Bellamy (1960). The low energy data of Benerentano et al. (2956) obtalned using nuclear emulsions at Illinols and that of the Cal. Tech. Groups (Tollestrup et al, 1955 and Walker et al.,1955) are plotted together. The agreement between the three seto of data is good. Measurements of the angular distribution show that plong are emited almost lsotropically in the centre of mass aystem near threshold. As the photon energy is Increased an excess of production at backward angles becomes apparent. At $290 \mathrm{MeV}$ a large maximum in the angular alstribution is observed in the region between 90 and 120 degrees, the angle belng measured w1th respect to the Incident photon direction. This maximum decreases as the photon energy is Increased further. At $380 \mathrm{MeV}$ the angular distribution rises towards forward angles. For photon energies below $350 \mathrm{MeV}$ it 18 reasonable to assume that only $S$ and $P$ wave production are important. This assumption has led to an analysis of the angular distribution in the centre of mass system in terms of 
a quadratio expression in $\cos \theta$,

$$
\frac{d \sigma}{d \Omega}=A+B \cos \theta+C \cos ^{2} \theta
$$

whero $\theta$ is the angle of pion omisolon noasured from tho Incident photon direction. Horavcsik (1956) pointed out that the direot interaction botween the photon and the aeson current introduces a tern contalniag $(1-\beta \cos \theta)^{2}$ In the donominator into the differential cross section. Iie has suggested that the analygls of the angular diotribution be done using the fourth order polynomial in $\cos \theta$,

$$
\begin{array}{r}
(1-\beta \cos \theta)^{2} \frac{d \sigma}{d \Omega}=A+B \cos \theta+C \cos ^{2} \theta+D \cos ^{3} \theta+E \cos ^{4} \theta \\
(1.6)
\end{array}
$$

In the analyeio the coofficients $A$ to $E$ are to bo determined from the detalis of the theory and the rooulting curve is compared with tho moasured angular d1etribution.

Recent angular distribution measurements (Halmbere ot al., 1958, Urotaly et a1., 1958, and Knapp ot al., 1957. and 1959) have boen cotspared with dispersion relation calculations of Chow et al. (1957) using this recipe. The angular distributions obtalned by Urotsky t al. for 

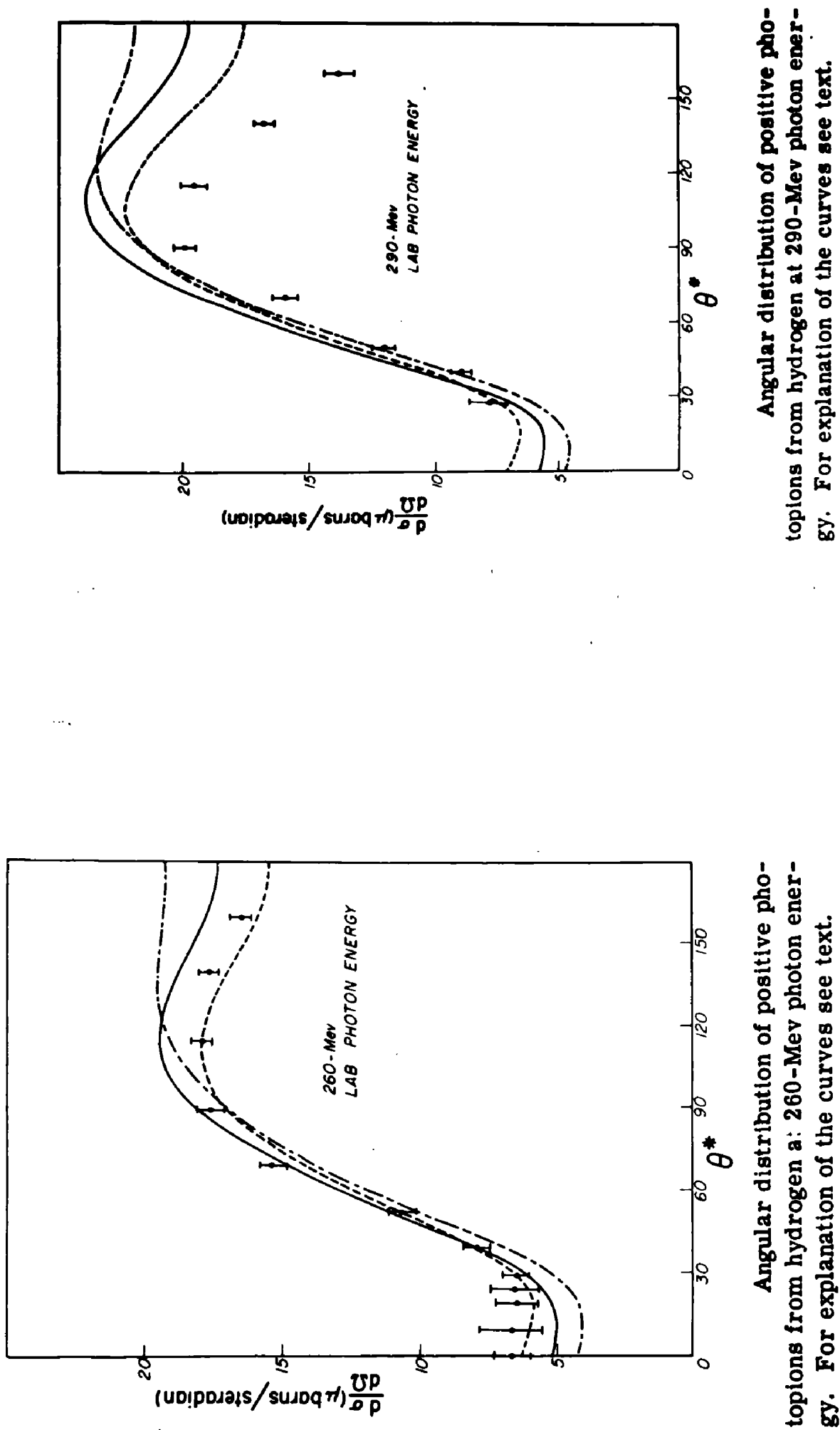

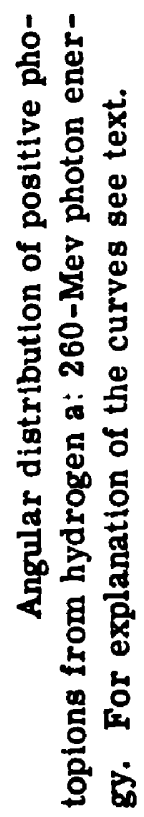

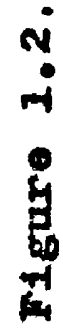


260 and $290 \mathrm{MeV}$ photon energies are shown in figure 1.2. The various curves are obtained for different assumed values of the small plon-nucleon phase shifts, $\delta 11$. $\delta 13$ and $\delta 31$. The subscript are twice tho 1sotopic spin and total angular momentum respectively. The agreewent ohown between the experimental values and the theoretical predictions in figure 1.2 is reasonable. A preclse knowledge of the values of the small phase shifts will be required before a detalled comparieon with the theory can be made.

An interesting relationship exists between various threshold values in pion physies. It depends upon the well established principles of charge independence and detalled balance, The quantities Involved in this relationship. that can be measured experimentally are;

1. the Panofsky rat10, $R=\frac{\omega\left(\pi^{-}+p \rightarrow \pi^{0}+n\right)}{\omega\left(\pi^{-}+p \rightarrow \gamma+n\right)}$

2. the charge exchange scattering transition rate, $\omega\left(\pi^{-}+p \rightarrow \pi^{0}+n\right)$

3. the threshold photoproduction transition rate $\omega\left(\gamma+p \rightarrow \pi^{+}+n\right)$

4. the rat10, $r=\frac{\omega\left(\gamma+n \rightarrow \pi^{-}+p\right)}{\omega\left(\gamma+p \rightarrow \pi^{+}+n\right)}$ 


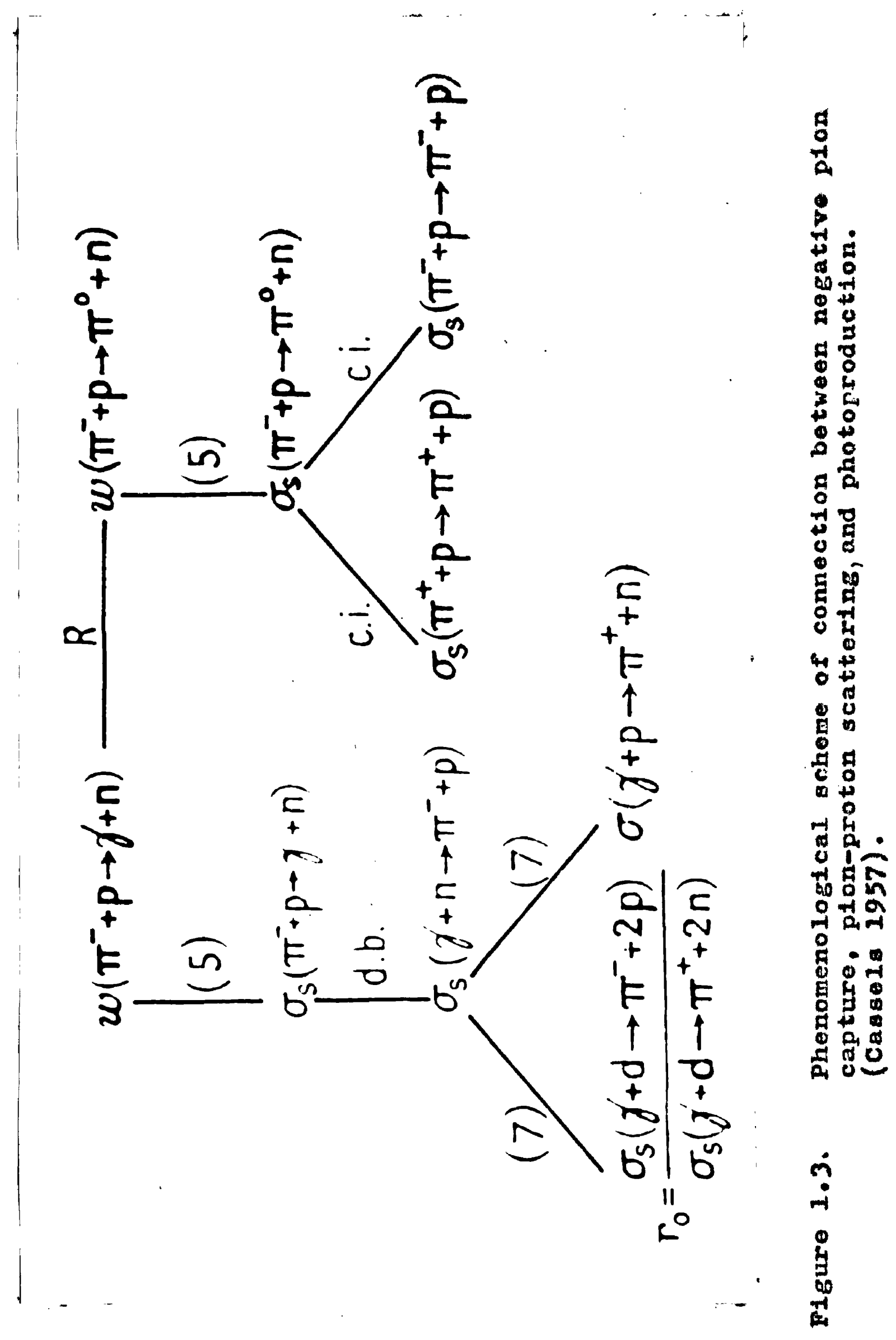


The rolationship betwoen these quantities is shown in f1gure 1.3. The Panofeky ratio 18 measured for zero energy pions. The experimental observation of 2,3 . and 4 are made at positive energy and must be extrapolated to threshold. Initially the measured values of 2,3 and 4 led to a prediction of 2.5 for the Panofsky ratio as conpared with $1.5 \pm .1$ for the experimentally observed rat1o. Cinl of al. (1958) showed that the discrepancy may be resolved, If the extrapolation to zero energy of pion photoproduction and chargo exchange ocattering are done in a manner consistent with the theoretical energy dependence for these processes.

The measurement of the 90 degree differentlal cross section as a function of photon energy provides an experimental test of the Cinf extrapolation. The coefficient a is plotted in figure 1.4. where a 18 related to A in equation 1.5 by

$$
a_{0}=A / W \text { where } W=\mu \mu_{0}(1+V / M)^{-2}
$$

where $\mu$ and $\mu_{0}$ are the pion momentiu and enorey respectively. $V 1$ the photon momentur and $M 1 s$ the nucleon mass. The experimental points are those of Rutherelen and 


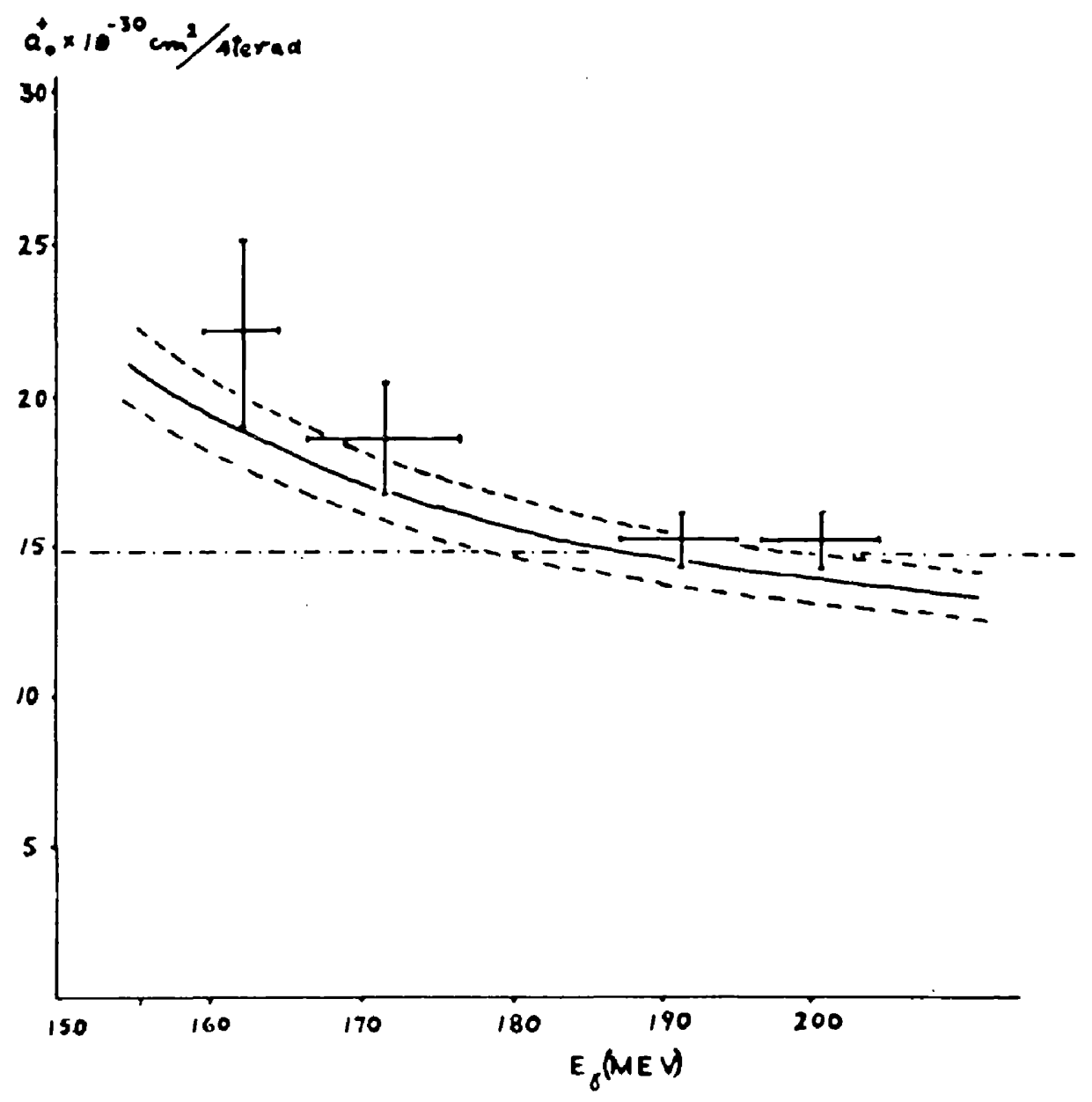
et a] ${ }^{15}$

$\mid\left. M^{+}\left(90^{\prime}\right.$ c.m.s. $)\right|^{2}$ from the measurements of Rutherglen

Figure 1.4. The solid curve is the cint extrapolation. 
Walker reported at the Rochester Conference (1960). They provide experimental confirmation of the dispersion relation predictions.

Tho minus - plus ratio, $r$. for pion photoproduction that is measured experimentally is that for deutorium. It must be correctad for the effect of nuclear binding before it is introduced into the threshold relationship. A discussion of charged pion photoproduction in devterium the next section.

(c) Chargod P1on Photoproduction in Deuterium.

It was pointed out above, that one of the maln reasons for the interest in pion photoproduction in deuterium is that it is the most practical target for studying the basic Interaction (1.2), for pion photoproduction at a noutron. The many measurements of the negative to positive ratio for pion production are the best example of this approach. The study of pion photoproduction in deuterium may also be directed towards understanding the effect of nuclear binding on the fundamental pion production reactions. An example of this approach 18 the measurement of the ratio of positire pion photo- 
production crose sections in deuterium and hydrogen.

The Investigations directed towards the understanding of 1.2 require a model to relate the measurements of pion photoproduction at the bound neutron to photoproduction at a froe neutron at rest. The simpleat model 1 s the phenomenologtcal epectator modol in which the photoproduction takes place at one nucleon only. The other nucleon leaves the interaction with momentum equal to its inftial internal monentum. Photoproduction in deuterium may then be reduced to production at a free nucleon. This nucloon is not at rest and must be given a momentun distribution appropriate to the bound nucleon. The effect of the binding energy may be included In this mode1. The measurement of the angle of emlssion and enerey of the pion say, permit the complote golution of the two body kinematics involved in the spectator model for assumed values of the intial nucleon momentum. Thus the energy spectrum of photons that can produce a pion at particular angle and energy may be ovaluated for any assumed nucleon momentum distribution. In the Interprotation of experimental rosults for pion photoproduction in deuterium the kinematics for production at 
a free nucleon at rest have often been used to relate photon energy to pion energy and angle. This procedure Implicitly assumes the validity of the spectator model and in addition that the spread in photon energies due to nucleon momentum is not large. Although the spectator model has generally been assumed to be valld in the energy region well above threshold (Er>200 HoV) no experimental work clearly supporting it had been published unt1l a yoar ago.

At photon energles below $200 \mathrm{MeV}$ the spectator model 1s not expected to give good description of pion photoproduction in deuterium. Th1s model ignores final state interactions which become increasingly 1nportant at low energiea. In the energy region near threshold and up to $200 \mathrm{MeV}$ the impulse approximation $1 \mathrm{~s}$ useful. It was suggested by Chew (1950) and was first used by him to deduce free neutron-neutron scattering cross sections from neutron-deuteron lnelastic scattering data. The application of the 1mpulse approximation to pion photoproduction in deuterium has been discussed in detali In a series of papers by Chew and Lewis (1951). Chew and Wtok (1952), and by Lax and Feshback (1951, 1952). 
The fundamental assumption of the Impulse approximation is that the pion production amplitudes from various nucleons are linearly superposable to form the production amplitude for the whole nucleus. The conditions required for the validity of the impulso approximation are threefold. They are stated below in the form Eiven by Chew and Wick.

1. The Incident particle never interacts strongly with more than one nucleon at the same time. 2. The amplitude of the incldent ware falling on each nucleon 16 elmost the same as it would be If the nucleon were alone.

3. The binding forces between the nucleons are negligible during the declsive phase of the Interaction when the Incident particle Interacts strongly with the nucleus.

Conditions 1 and 3 mugt be satisfied if the many body features of the problem are to be evolded. The transparency condition 2 , is not essent1al but permits a considerable simplification. The third condition is sometimes restated in an alternative form, namely that the collision time is short compared to the period 
of the nucleon system.

The above conditions are expected to be well satisfied for pion photoproduction in deuterium. Condition 1 is certainly satisfied for the incldent photon due to the emalineas of the fine structure constant.

The transparency condition for the two nucleon system may be restated in terms of the probability of a moson produced at one nucleon belng scattered at the second. Unless this probability is small the effect of multiple scattering will be important. A simple indication of the magnitude of the multiple scattering error may be obtalned by considering the ratio of the plon-nucleon scattering cross section, to the size of the deuteron, 1.0.

$$
\sigma_{s} / \pi \bar{R}^{2}
$$

where $\bar{R}$ is the dean nucleon separation. If wo assure 20 m1111barns for $\sigma_{s}$ and use the ralue taken by Chew (1952) for $\bar{R}=3.2 \times 10^{-13} \mathrm{~cm}$., the above expression gives a multiple scattering error of 7 percent. This is In good agreement with the estimate of 5 percent obtained by MacDonald (1959) from detalled calculations. The collision time is expected to be small compared 
to the nuclear period since the onergy conservation violation in the intermediate state is on the average equal to the pion rest nass.

The determination of the cross section in the Impulse approximation is done by evaluating the transition matrix eloment for free nucleon photoproduction between initial and final nucleon states. The nucleon blinding forces determine the initial and final states, and do not eneter the calculations directly. The procedure 18 illustrated by giving the calculation of Chew and Lowlo (1951) In some detall.

They express the differential cross section for pion photoproduction in deuterium in the form

$$
\frac{d \sigma_{f}}{d \mu d D}=(2 \pi)^{-2}|Q|^{2} \delta\left(\mu_{0}+\epsilon+D^{2} / 4 M-v_{0}\right)
$$

where $\mu$ and $\mu_{0}$ are the pion momentum and energy. $v$ and $v_{0}$ are the photon momentum and energy. D Is the total momentum of the recoling nucleon system.

and $M$ is the nucleon mass. $\epsilon=\epsilon_{f}-\epsilon_{i}$ where $\epsilon_{f}$ is the internal energy of 
the final state nucleon system and $-\epsilon i$ the deuteron binding onergy.

Q is the matrix element whtch is to be evaluated in the impulse approximation. In 1.8, $\hbar=C=1$ and the pion rest mass 18 set equal to 1.

The matrix is to be approxinated by $T=T_{1}+T_{2}$ where $T_{j}$ is the part of the matrix element which describes photoproduction from the $j$ th nucleon acting alone.

$$
T_{j}=\left(\sigma_{j} \cdot K+L\right) \exp \left[i(v-\mu) \cdot r_{j}\right] \tau_{j}^{T}
$$

where $r_{j}, \sigma_{j}$ and $\gamma_{j}$ are the nucleon position, spin, and isotopic spin respectively. The matrix element is written in two parts. $\sigma_{j} \cdot K$ represents the spin dependent production in which the spin of one nucleon is reversed. 1.0. spin-fl1p occurs. L represents the spin Independent part in which the nucloon spin state remalns unchanged. The matrix element 18 evaluated between the initial deuteron state and the final symetric and antisymetric states. The matrix element 1s squared, summed over final nucleon states, and averaged over Initial spin states and photon polarization 


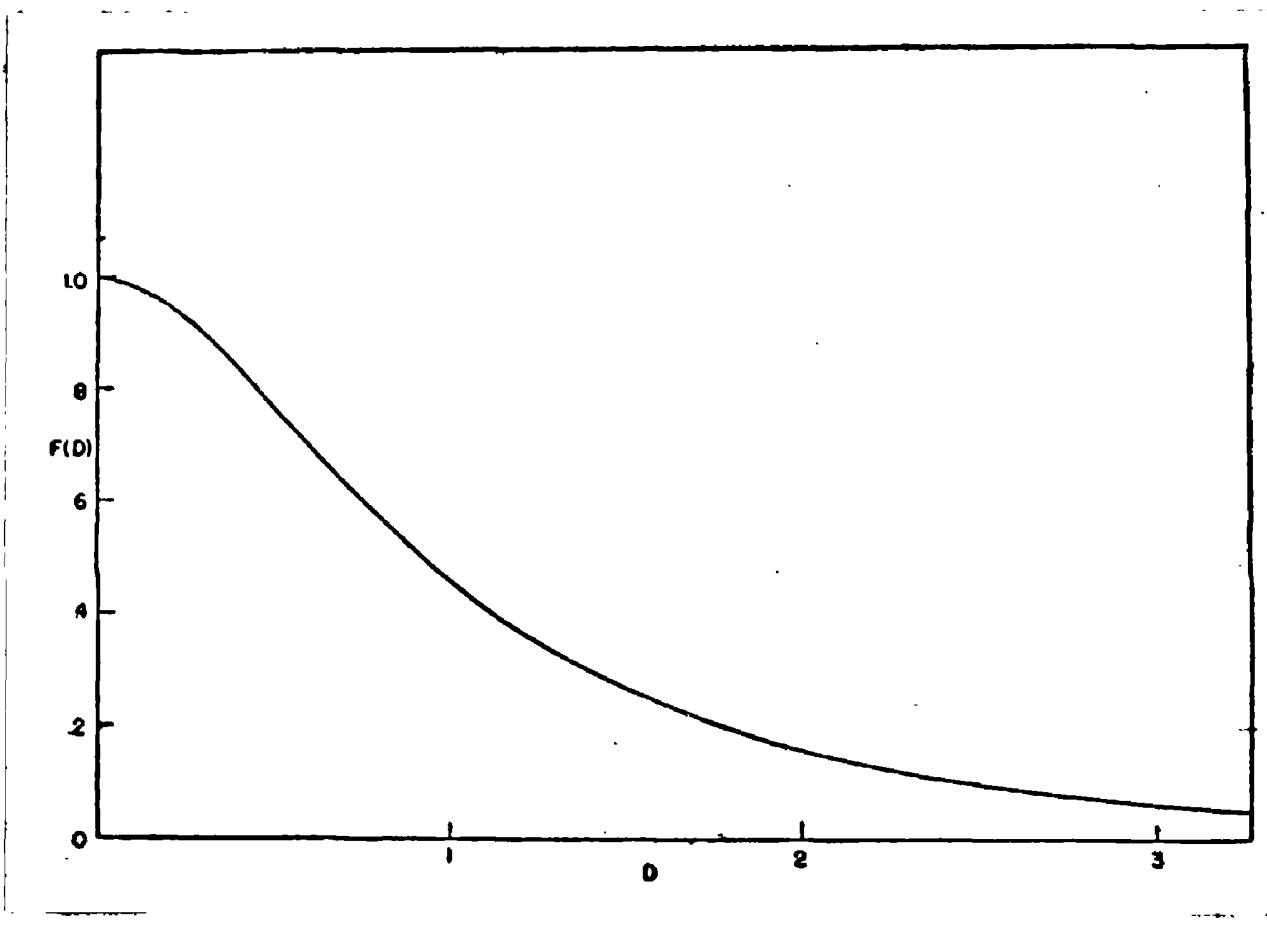

Figure 1.5. Exclusion principle function $F(D)$ calculated by Chow and Lew1s (1951). 
$-16=$

Giving,

$$
\begin{aligned}
|Q|^{2}= & \frac{2}{3}\left\langle\left|K^{2}\right|\right\rangle_{\operatorname{avg}}\left|E_{f}\right|^{2} \\
& +\left[\frac{4}{3}\left\langle\left|K^{2}\right|\right\rangle_{\text {avg. }}+2|L|^{2}\right]\left\langle|O|^{2}\right\rangle_{f}
\end{aligned}
$$

where the $K$ and $L$ are the same as $\ln (1.9)$ and $E_{f}$ and $O_{f}$ are defined by the integrals

$$
\begin{aligned}
& E_{f}=\int u_{f e}^{*}(\rho) \exp \left(i k_{0} \rho\right) u_{i}(\rho) d \rho \\
& O_{f}=\int u_{f o}^{*}(\rho) \exp \left(i k_{0} \rho\right) u_{i}(\rho) d \rho
\end{aligned}
$$

where $U_{f e}$ and $U_{f o}$ are the symmetrical and antisymetrical final state wave functions and $U_{i}$ is the deuteron wave function.

When the dependence on the pion momentum is eliminated, the cross section may be expressed as a function of $\mathrm{D}^{2}$ In the form

$$
d \sigma / d D^{2}=\left[1-\frac{1}{3} F(D)\right] \frac{d \sigma_{k}}{d D^{2}}+[1-F(D)] \frac{d \sigma L}{d D^{2}}
$$

In which the spin-filp part $d \sigma_{k} / d D^{2}$ and the non spinflip part $d \sigma_{L} / d D^{2}$ are written separately. The function $F(D)$ is shown in figure 1.5. The corresponding 
oxprossion for photoproduction at a free proton is

$$
\frac{d \sigma}{d D^{2}}=\frac{d \sigma_{k}}{d D^{2}}+\frac{d \sigma_{L}}{d D^{2}}
$$

The effect of paull exclusion principle is llistrated by 1.12. Whon $D=O F(D)=1$ and tho non spin-121p production 1 s suppressed wh10 $2 / 3$ of the apin-filp production 18 hllowed. Thls may also be seen from a oleple consideration of the initial and final aucleon etatos Involved. Tho initial state is tho ground state of tho deuteron which $18 \mathrm{a}^{3} \mathrm{~S}$ state. The pauli principle allows transitions to ${ }^{1} S,{ }^{3} P, 1_{D}$ states otc.. but forbids transitions to ${ }^{3},{ }^{1} p, 3_{D}$ states. Near throshold whero the enorgy available is not sufficlent for the nucleons to be in a f state the transition will be inhibited is opin-filp production does not occur. In the region near threshold D will always bo small, and tho dopondence on D obtained by Chow and Lewls is expected. Their analyeis showed that small valuos of $D$ correspond to ealseion of the pion at small angles to tho Incident photon direction. It follows that experimente desiened to dotermino tho nucleon epin dependence must be done at forward angles where the excludion principlo 
effect 18 large. In principle a meesurement of tho ratio of positive pion photoproduction from deuterium to that from hydrogen at small angles wij.1 determine the spin dependence. Experimonts at small forward angles are difficult to perform due to the high electron background and the results of experiments of this type are not conclustre.

The final state interaction of the particles in positive and negative plon photoproduction from deuterium (1.3 and 1.4) are considered in detall by Bald1n (1958) for photon energies near threshold. He expresses the cross section in the form

$$
\frac{d \sigma}{d p d q}=A(p, q)|K|^{2}+B(p, q)|L|^{2}
$$

where $p=\frac{1}{2}\left(p_{1}-p_{2}\right)$.

$$
q=\frac{1}{2}\left(p_{1}+p_{2}\right) \text {. }
$$

and $p_{1}$ and $p_{2}$ are the momentum of the two final state nucleons in the laboratory system. $|K|^{2}$ and $|L|^{2}$ aro the squared spin-fIIp and non epin-flip matrix elemento for pion photoproduction at free nucleons.

$A$ and $B$ aro functions of $p$ and $q$ and express the dependence of the cross section measured for deuterium 
on the initial and final nucleon states. For positive pion production they are the equivalent of the $1-\frac{1}{3} F(D)$ and $1-F(D)$ obtained by Chew and Lew1s. Baldin has evaluated $A$ and $B$ in $a$ detalled manner approprlate to the threshold region. The Coulomb Interaction between the two protons is included in the evaluation of $A$ and $B$ for negative plon production. The Coulomb interaction between the negative pion and the protons is introduced separately. Theso calculations represent the most rigorous treatment of the final state interaction, that ha yet been done for negative pion photoproduction in deuterium. The effect of the Coulomb correction near threshold is to increase $\sigma^{-}$ measured for a deuterium target relative to the value for photoproduction from a froe neutron. The Coulomb corrections in the threshold region are summarized in the table below.

$\begin{array}{lcc}\text { Pion Energy } & \begin{array}{l}\text { Positive Coulomb } \\ \text { Correction } \\ \text { p-x interaction }\end{array} & \begin{array}{l}\text { Negative Coulomb } \\ \text { Correction } \\ \text { p-p Interaction }\end{array} \\ <10 \mathrm{MeV} & \text { can be }>10 \% & \text { negligible } \\ >10 \mathrm{MeV} & \text { negligible } & \text { can be appreciable. }\end{array}$

baldin concludes that the final state Coulomb corrections 
can not be neglected in the evaluation of $\sigma^{-}$for free neutrons from the deuterium data. The results of Baldin's calculations have been used to interpret the result of an experiment done by Adamovic et al. (1959) in whlch negative pion photoproduction was investigated near threshold. This experigent wil be discussed in detall later.

Photodisintegration of the deuteron

$$
r+d \rightarrow n+p
$$

w111 compete with pion photoproduction. W11son (1956) has developed a theory in which the photodisintegration of the deuteron tales place through a process of pton emission and reabsorption. He assumed that the pion 18 reabsorbed and that photodisintegration 13 the result, if the nucleons are within a pion Compton wave length of each other. He obtalned good agreement with the measured photodisintegration cross sections for deuteriun above $100 \mathrm{MeV}$, when ho used reasonable values for pion photoproduction cross sections. Even at high energies where the spectator model is expected to be valid the competition of photodisintegration may be expected to reduce the cross section for positive pion production from deuterium below that for hydrogen. 
The preceding constderation of charged pion photoproduction in deuterium Indicates that a careful consideration of the experimental conditions that obtain for any particular experiment is required if pion production in deuterium is to be related to reactions $(1.1)$ and $(1.2)$

(d) Review of Published Experimental Work.

The experimental investigation of charged pion photoproduction in deuteriun may be divided into two categories, experiments in which only one final state particle is detected, and those in which two or all three particles are detected. Experiments in the first category have the advantage of belng sultable to the use of counter techniques and good statistico are in general possible. The interpretation of the results of these experiments requires model to relate plon photoproduction In deuterium to that in hydrogen. Experiments in the second category auffer from poor statistical accuracy. whother the experiment employs a visual technlque where the analysis is tedious, or a counter technique requiring the simultaneous detection of more than one particle where counting rates will be low. These experiments 
allow an Investigation of the validity of the various models for pion photoproduction in deuterium in addition to measuring pion photoproduction cross sections. Experiments in which one particle only is detected will be discussed first.

The negative to postive pion ratio from deuterium (hereafter called the $-/+$ ratio) was measured by Benerentano et al. $(1954,56,58)$. A 11quid deuterium target was Irradiated by the $300 \mathrm{MeV}$ bremsstrahlung beam of the IIIInols betatron. The plons were detected in pelifcles which were lmmersed in a large block of emulsion. This arrangement compensated for scattering losses, and the effective oolid angle was defined by the pellicle s1ze. The pellicles were underdeveloped to reduce tho effect of the large electron background present near the photon beam. Identification of the negative and positive plons depended upon the track endings. A knowledge of the star-prong frequency of negative plon endings was required. Th1s wa obtalned from plates exposed to a negative pion beam from the Chicago cyolotron. Several exposures were made in whtch the electron background was greatly reduced. This allowed normal development. and the positive pions could be identified by the $\mu-e$ 


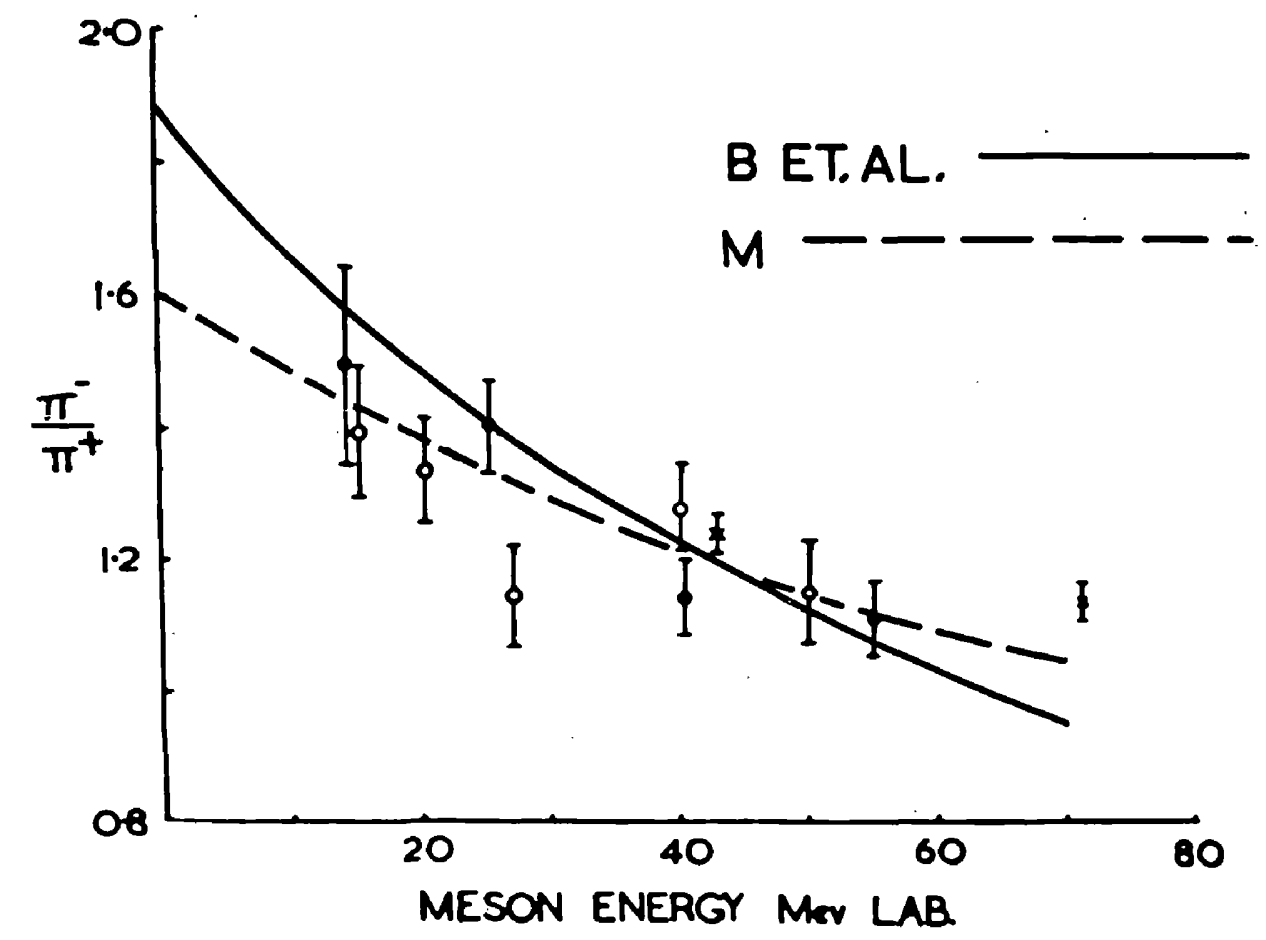

$\pi^{-} / \pi^{+}$Ratio Fron DEUTERIULI AS A FUTICTION OF PION ENERGY, ANGLES MEASURTD IN THE LAB. SYSTEM. $\times 73^{\circ}$ Sands et al, 1954. - $75^{\circ}$ Beneventano et al, 1956. - $75^{\circ}$ HOgg \& Bellamy

Figure 1.6. 
decays. The prong-frequency for the negative pion endings obtalned from these exposures agreed well with that obtalned from the plates exposed to the cyclotron pion beam. The uncertainty in the negative to positive ratio due to pion identification was small, The $-1+$ ratio obtained by Beneventano et al. at 75 degrees in the laboratory system is shown in figure 1.6.

The - /t ratio from deuterịm has been moasured by a number of groups using various types of counters as detectors and magnetic deflection to separate negative and positive pions. Sands et al. (1954) measured the $-/+$ ratio for pions produced in a cooled high prossure gas target at 3 angles in the laboratory eystem.

Their measurement extended over pion kinetio energies from 30 to $200 \mathrm{MeV}$. Hogg and Bellamy (1958) detected 15 to $70 \mathrm{HeV}$ plons produced in a liquid deuterium targot at 75 degrees in the laboratory. The measurement of Sands et a1. and Hogg and Bellamy are shown with those of Beneventano et al. In figure 1.6 The agreement between the three sets of data $1 \mathrm{~s}$ good. The solld curre 1s the extrapolation to threshold used by Beneventano which gives a value of 1.87 for the $-/+$ ratio at threshold. The Coulomb corrections reduce the cross section at a freo 
neutron by about 10 percent. Moravesik (1958) has shown that by applying small but reasonable correctlons to the parameters used by Beneventano a significant difference in the extrapolation is obtained. The dashed curve is duo to Ioravcsik. H1s extrepolation implies a $-/+$ ratio from free nucleons of 1.4 in good agreement with the theoretically predicted threshold ratio of 1.3.

Adamovic ot al. (1959) measured the negative plon production cross soction in deuterlus very noar threshold. Tho sape workers also measured positive plon cross sections from hydrogen (Adamovic, 1960). They obtain a threshold value for the $-1+$ ratio of $1.3 \pm .15$ for photoproduction at free nucleons. The agrement among the various sets of data 18 good, and the threshold $-/+$ ratio from free nucleons may be regarded as well established.

It 18 Interesting to note that the three sets of data shown In figure 1.6 were obtalned with very different poak photon energies namely, $235 \mathrm{MeV}$ Hogg and Bellamy, $300 \mathrm{HeV}$ Beneventano et al, and $500 \mathrm{MeV}$ Sands et al. The agreement between these measurements indicates that the $-1+$ ratio 13 not strongly dependent upon peak photon energy at these energies. Near threshold howerer the measured $-1+$ ratio from deuterlum may be strongly effected 
by the maximum photon energy avallable due to the different threshold energies for negative and positive pion photoproduction (Kharlomor, 1959). The offect w111 be large if the maxtmun photon energy is close to the threshold.

Recently Land (1959) has measured the $-1+$ rat1o from deuterium due to monoenergetic photons using a photon difference method. The M.I.T. synchrotron was operated wth maximum energy $\mathrm{E}$ nax at 307 and $292 \mathrm{MeV}$. The pion ylelds measured at these values of $\mathrm{E}_{\max }$ are norralized and subtracted to sive the yield due to monoenergetic photons at $292 \pm 8 \mathrm{MaV}$. The pions were, detected using magnetic deflection and a scintillation counter telescope. The $-1+$ ratios obtalned for monoenergetic photons are. $0.90 \pm .23$ at 73 degrees for $98 \mathrm{MeV}$ pions and $1.07 \pm .16$ at 120 degrees for 30 to $90 \mathrm{MeV}$ pions. These values are below those obtalned in this experiment, and below values obtained by other workers for the $-1+$ ratio measured using bremstrahlung beams. Land sugęsts that for production due to a bremsitrahlung bean, plons w111 be counted due to photons outside the $292 \pm 8 \mathrm{MeV}$ interval. Since the ratio rises with decreasing energy and little contribution can be expected from higher energy 
photons ( $E_{\max } 307$ ) the contribution from lower photon energies will tend to increase the ratio measured using bremsstrahlung beams. Thls suggestion is surprising, considering the agreement between the various measurements shown In figure 1.6. The errors assigned to the monenergetic measurement need to be reduced before a definite disagrement can be said to exist.

A convenient sumnary of the experimental data from $-/+$ ratio measurement prior to 1957 is given by Moravcsik (1957). He compares the $-/+$ ratio calculated using various approximations with the measured ratio over a wide range of photon energy and pion production angles. The -1+ ratio 1s always greater than one. Except at backward angles it decreases with increasing photon energy. The $-/+$ ratio rises towards backward angles at all energies.

The ratio of positive pion photoproduction from deuterium and hydrogen (hereafter called the $D / I I$ ratio) has been measured in a number of experinents (Benerontano et a1.,1958. Hagerman et a1.,1957. Wh1te ot a1.,1952). The techniques used are similar to those employed in the $-1+$ rat10 measurements. The measurement by Beneventano for photon energles up to $230 \mathrm{MeV}$ shows that the $\mathrm{D} / \mathrm{H}$ 
ratio is less than unity and that it decreases towards forward angles and low energy. Thls behaviour is predicted by the Chew and Lewl s calculations, ance low photon energies end forward angles is the region of small D. Attempts to obtain spin dependence of pion production from measurement of the $D / H$ ratio have led to inconclusive results.

Photoproduction of negative plons in deuterium near threshold has been Investigated by Adamovic ot al. (1959). This experiment is the most complete study of this reaction that has been reported. It will be described in dotall.

Nuclear emulsions loaded with heavy water were exposed to 200 and $250 \mathrm{MeV}$ bremsetrahlung beams from the Lebedev Physics Institute synchrotron. In this experiment the loaded emulsions acted as target and detector. Plons up to $30 \mathrm{MeV}$ kinetic energy could be registered in the heavy water loaded emulelons allowing measurement of the cross section for photon energies up to $174 \mathrm{MeV}$. Just orer $2000 \mathrm{~cm}^{2}$ of emulsion were scanned and 720 events due to photons between $174^{\wedge}$ and threshold were found. A few more sensitive plates were used to measure the crose section for photons between 174 and 202 
MeV.

The three final state charged particles were registered in the emulsion. Tho Identification of particles that stopped in the emulsion presented no problem. Some tracks which left the emulsion were ldentified by multiple scattering and grain counting techniques. A small fraction of the ovents $(8 \%)$ in which one or two particles left the emulsion were Identified using tho momentum and energy conservation conditions for reaction (1.4). All 3 prong stars were analysed using this condition and an error $\triangle P$ was obtained for each star. The star distribution was plotted as a function of $\Delta P$ for the heavy water loaded emulsion, and compared with the distribution in $\Delta P$ obtained from plates loaded with water. No ovents were found in the latter set of plates In the range of $\Delta P$ where events were ascribed to reaction (1.4). The Identification of stars due to (1.4) was considered to be unamblguous.

For each event the photon energy, pion energy and angle of emsssion, $p=\frac{1}{2} p_{1}-p_{2}$, and $q=\frac{1}{2} p_{1}+p_{2}$ were determined. The Impulse approximation calculation of Baldin gives the cross section for reaction (1.4) as a function of $p$ and $q$. A detalled comparison between 


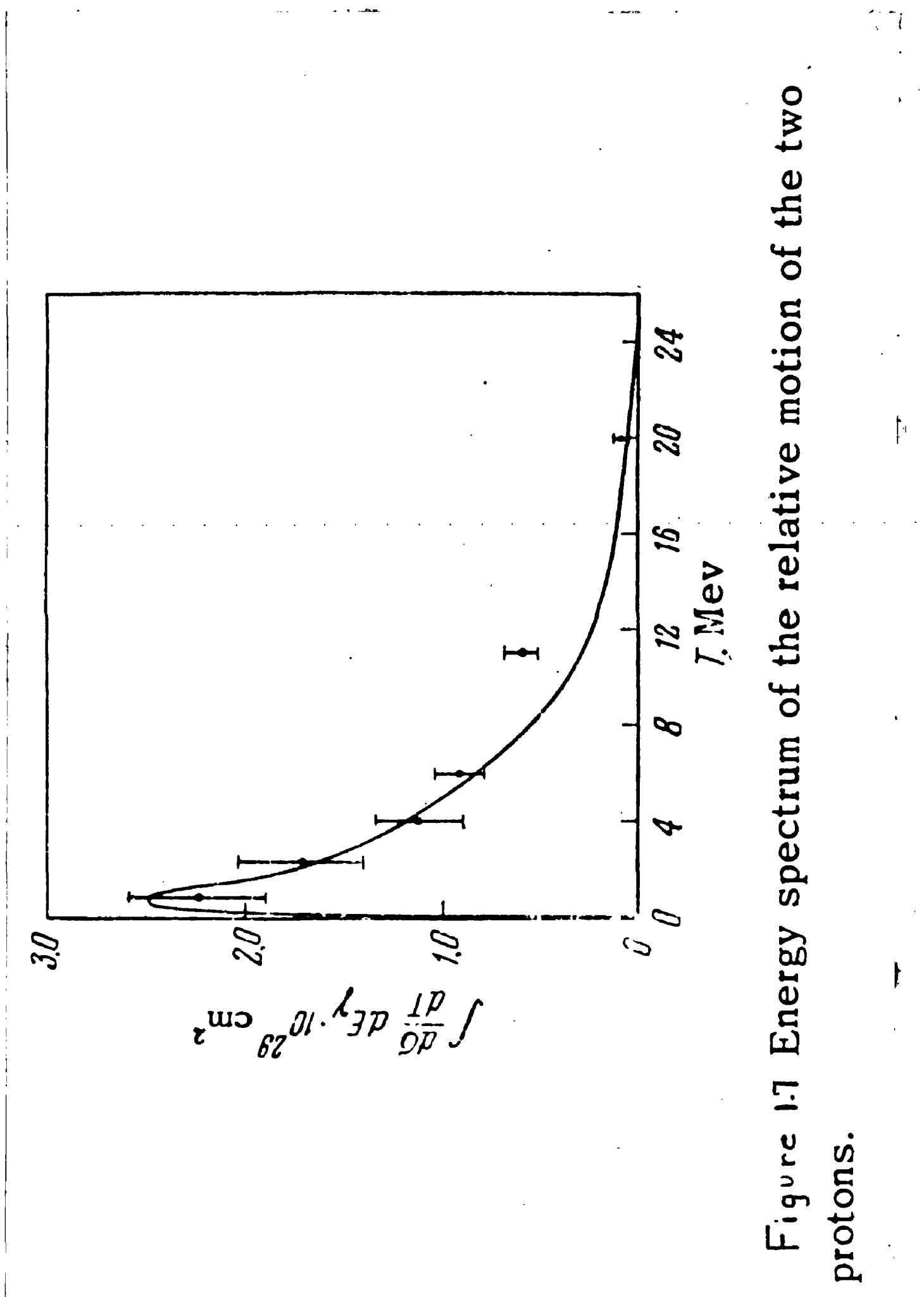



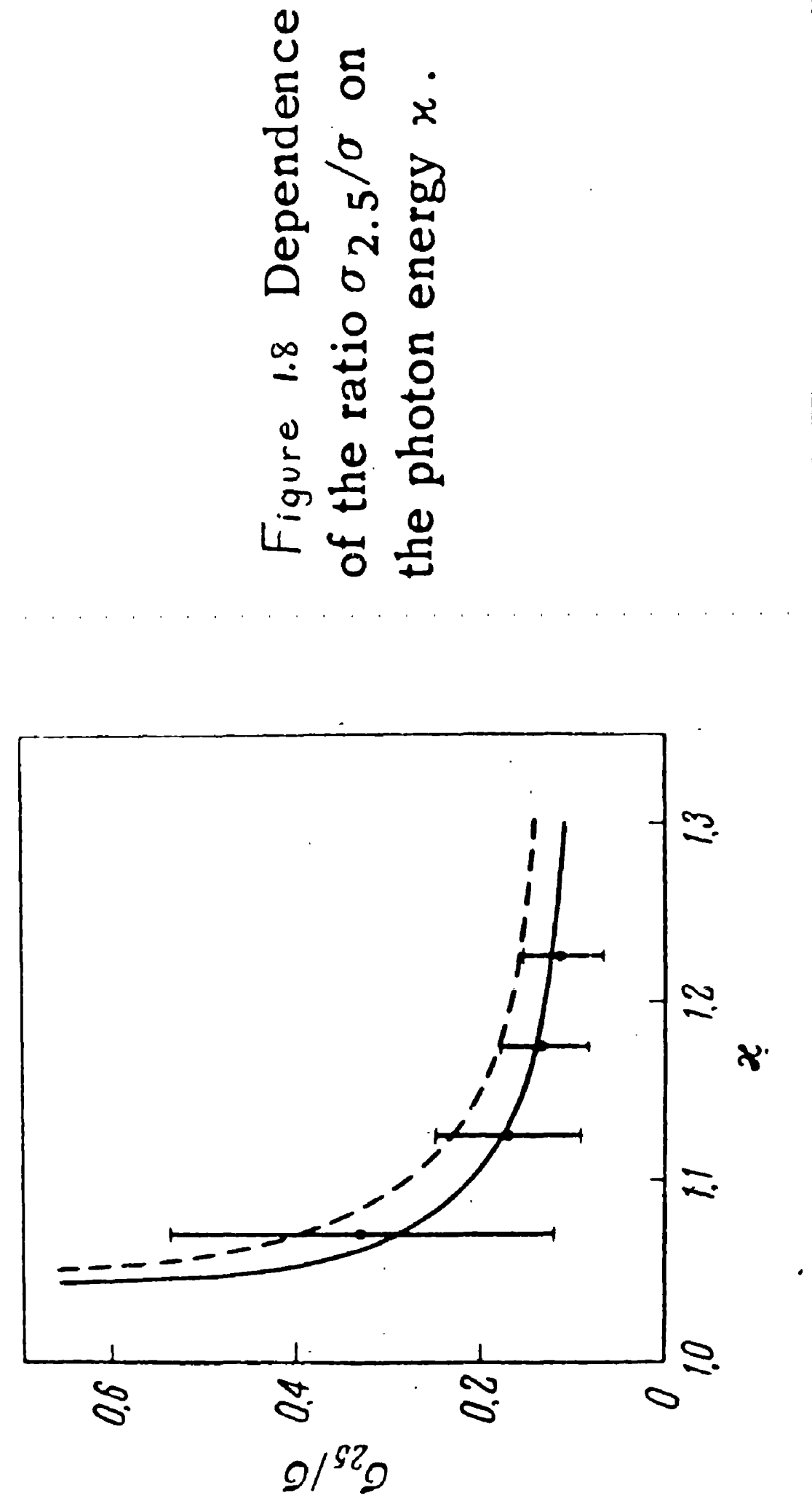
the predictions of Baldin's calculations and the experimental results was made. The energy spectrum of relative motion of the two protons 18 shown in Iigure 1.7. The theoretical spectrum is calculated for $L=0$, and value of $\left|x_{n}\right|^{2}$ obtalned from the positive pion cross aection from hydrogen and the theoretical value of 1.3 for the $-1+$ ratio. In f1gure 1.8 the ratio $\sigma_{2.5} / \sigma$ 18 shown as a function of photon energy. Here $\sigma$ is the total crose section and $\sigma_{2.5}$ is the cross section for production of a pion when $q / p \geqslant 2.5$. The solid curve represents the theoretical ratio $\sigma_{2.5} / \sigma$ the dashed curve was calculated omitting the Coulomb interaction.

The observed cross section 18 isotropic in the centre of mass system, and shows an $\eta_{\max }^{2}$ dependence, where $n_{\max }$ 1s the maximum possible pion romentum. Adamovic (1959) compares these properties of the data with the dependence predicted for various transitions.

Finally the squared matrix element for pion photoproduction at a free nucleon $\left|\mathrm{K}_{n}\right|^{2}$ is obtalned from a careful conolderation of the experimental and calculated cross sections for values of $p$ and $q$ where the calculations of Baldin are known to be accurate. In a subsequent experiment Adamovic et al. (1960) measured the cross 
section for positive pion production near threshold. The statistical accuracy of the data 1 sot sufficiently good to enable the cholce to be made between $\left|x_{p}\right|^{2}$ and $\left|K_{n}\right|^{2}$ constant and the cinl extrapolation. $\left|K_{p}\right|^{2}$ and $\left|\mathrm{x}_{\mathrm{n}}\right|^{2}$ were extrapolated to threshold using the cinl method to obtain the threshold $-/+$ ratio. Th1s ratio should bo independent of eystematic errors in beam monltoring.

The results of these experiment may be summarlzed as follows:

1. The Impulso approximation 1s valid for thls interaction provided the Coulomb interaction. In the final state 1 s included.

2. Near threshold the transition occurs through electric dipole absorption of the photon, the pion is enittod in an $S$ state and the nucleons are left in a singlet s sate, 1.0. spin-filp production occurs.

3. The $-1+$ ratio at threshold $1 \mathrm{~s} 1.3 \pm .15 \mathrm{in}$ good agreoment with the predicted value of 1.3 . An experiment in which the bremsstrahlung beam of the Berkeley electron synchrotron was passed through a 4 Inch deuterium bubble chamber 18 reported by Swanson 


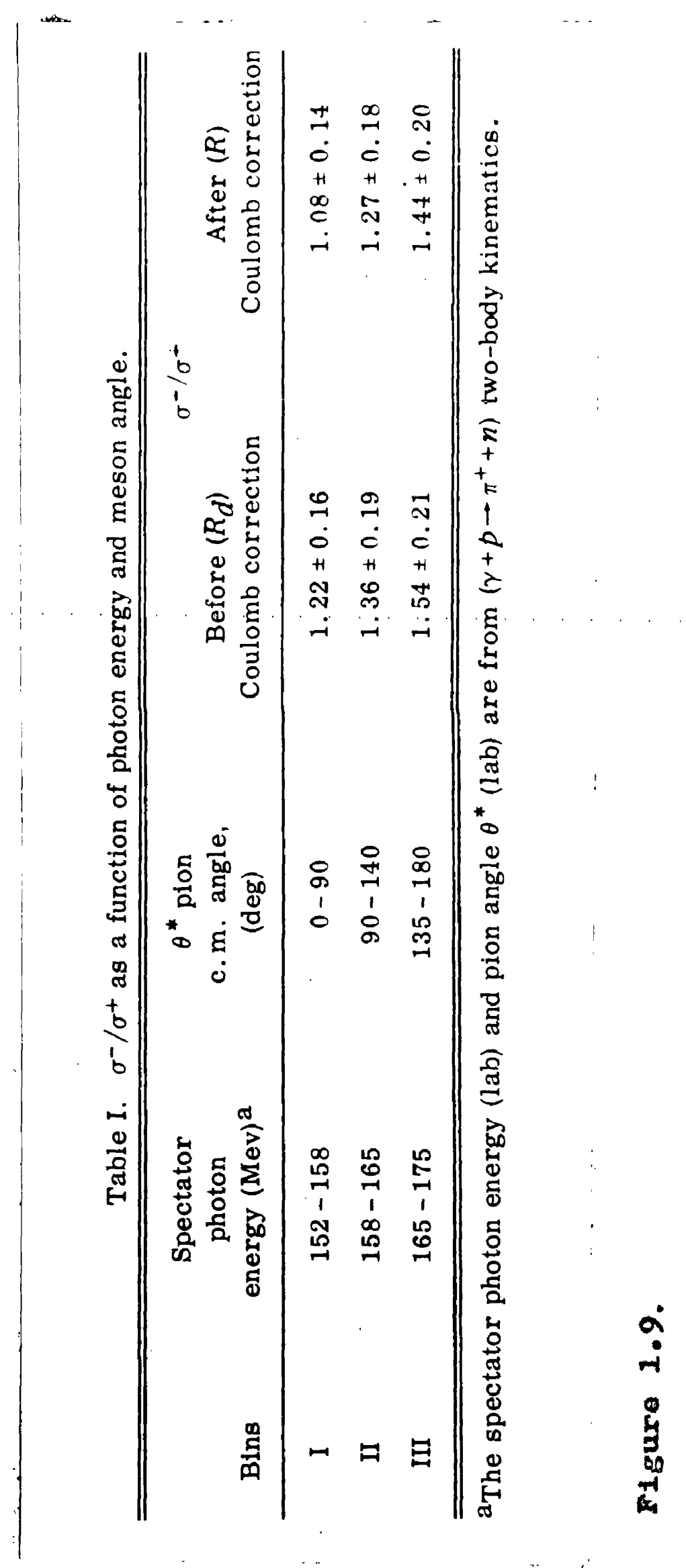


(1960). Negative and positivo pion production in deuterium were observed. The former reaction was ldentifled using energy and momentur conservation conditicens, the latter by the characterlstic range of the decay p meson. The $-/+$ ratio for deuterium obtalned by Swanson is shown In figure 1.9. The photon energy and centre of mass pion angle were assigned using the twobody kinematics for both reactions sinco the true photon energy was not determined for positive pion production. The negative pion yleld was corrected for coulozb effects to obtain the $-/+$ ratio for freo nucleons. The ratio for the lowest energy "bin" is below the theoretical value. The average value for tho $-/+$ ratio for deuterium and froe nucleons are $1.38 \pm .12$ and $1.27 \pm .11$ respectively. The distribution of photon energlos contributing to negative pion production for events in "bin" 2 is presented. The distribution is peaked about the trobody photon enerey, but extended $10 \mathrm{MeV}$ below and $20 \mathrm{MeV}$ above that value. The width of this distribution Indicates that considerable uncertainty may be introduced by use of two body kinematics to assign photon energles. Although separate measurement of negative plon production in deuteriur and positive pion production in hydrogen can introduce uncertainty in beam monitoring, 
this procedure $1 \mathrm{~s}$ to be preferred to that of Swanson et al. since the kinematics are then completely defined for both reactions.

Keck and Littauer (1952) have Investigated the opectator model for plon photoproduction in deuterium using a scintiliation connter technique. In this experiment $\mathrm{D}^{2} 0$ and $\mathrm{H}^{2} 0$ targets were irradiated by 310 HeV bremsstrahlung. A three counter telescope detected plons emitted at $90 \pm 10$ degrees with an energy of $56 \pm 9$ HeV. The pions wer Identified by their epecific lontzation and range, the first two oounters were operated in colncidence and in inticoincidence with the third counter. The protons were detected in a NaI(TI) crystal that could stop $69 \mathrm{MeV}$ protons. The proton energy was measured using a pulse helght analyser. The engular distribution and energy spectrum of the protons detected in colncidence with the plons are shown in figure 1.10. Curves A wore calculated for pion production at a free neutron at rest. The angular resolution and energy acceptance of the counter system is included. Curves B reprosent the distributions expected if the spectator model is assumed. Once again the resolution of the counter system is Included.

The agreement between the observed angular distribution 


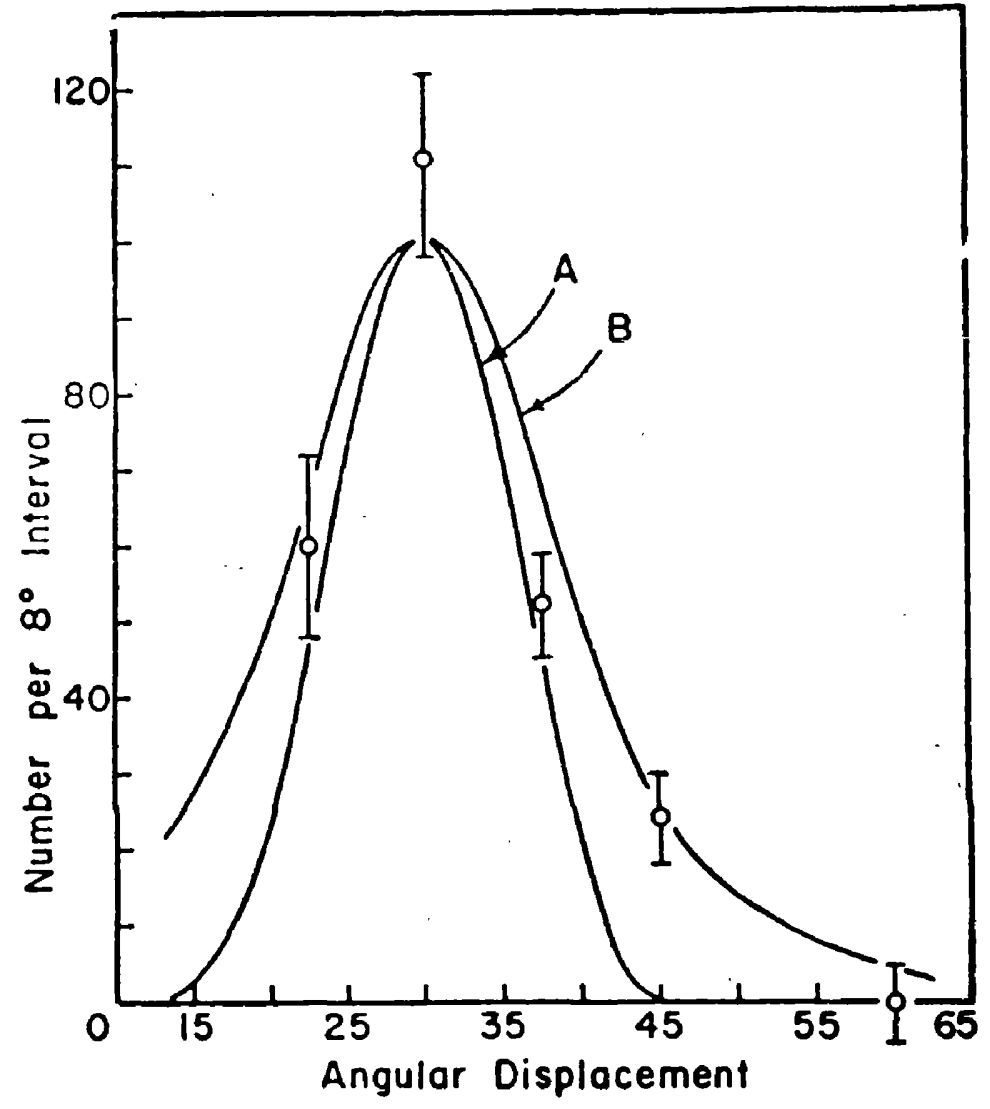

Angular distribution of recoils counted in coincidence with a 56-Mev meson at $90^{\circ}$. See text for explanation of curves.

FIgure 1.10a. 


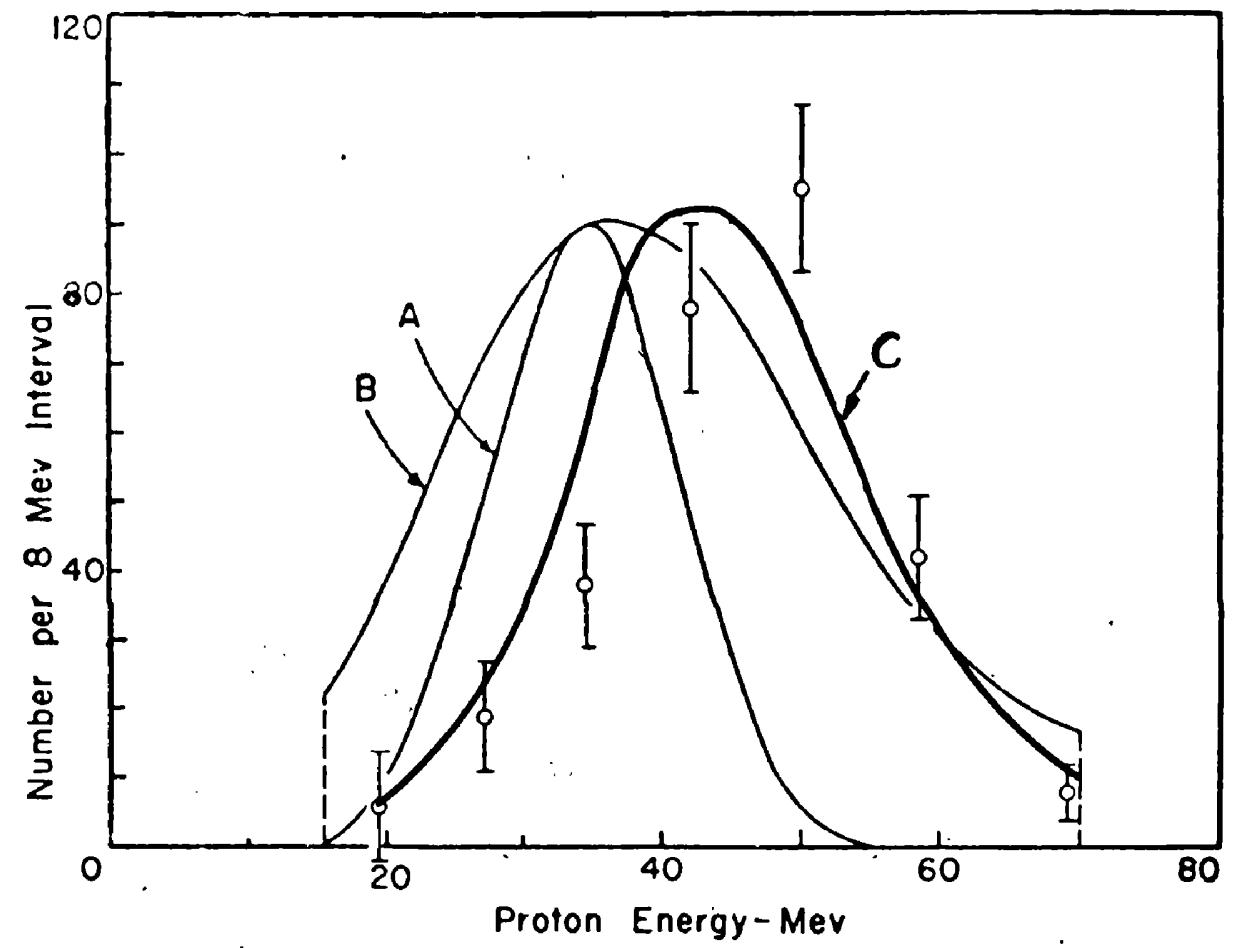

linergy distribution of recoils at $30^{\circ}$ counterl in coincicience with a $50-\mathrm{Al} \in \mathrm{V}^{\circ}$ mesion at $90^{\circ}$. See text for explanation of curves.

FIgure 1.10b. 
and that predicted by the spectator model 1. oatisfactory. The experimentel points for the proton energy spectrum do not agree with elther curve $A$ or B. They appear to be shifted towards higher energy by 12 to 15 MoV. This ditscrepancy was not resolved. The energy cal1bration of the proton counter wrs done using three different methods. The pulse holght in the proton counter was measured for the Cs 137 photopeak at $.67 \mathrm{MeV}$. The pulse helght produced by cosmic-ray mesone at $9.5 \mathrm{HeV}$ was measured. The number-bias curve obtalned using a beam of inhomogeneous protons was extrapolated to hlgh energy cut off at $69 \mathrm{MeV}$. These methods agreed to within \pm 5 percent. 0ther sources of error were considered. The effect of plons scattering around the third counter in the pion telescope was shown to be negligible. Multiple scattering of the protons in the targets, and possible variations in the pion cross section were shown to be small effects.

The differentiel cross section for negative pion photoproduction accompanted by a correlated recoll proton was calculated using curve for the angular distribution. This gave $10.8 \pm 1 \times 10^{-30} \mathrm{~cm}^{2}$. per steradian in good agreement with the value $11.8 \pm 1.2 \times 10^{-30} \mathrm{om}^{2}$. per steradian obtalned from the total pion counting rate and the $-/ t$ ratio for 
deuterium measured by Littauer and Walker (1952).

The Impulse approximation theory of Chew end Lewls was used by Thle (1952) to derive an expression for tho cross section for detection of a pion and recoll proton in colncidence. The expression is

$$
\frac{d \sigma}{d \Omega_{\mu} d E_{p} d \Omega_{p}}=\frac{M P \mu \mu_{0}\left[\mu\left(\mu_{0}+2 M\right)-\mu_{0} v_{0} \cos \theta_{\mu}\right]}{32 \pi^{2}\left|\mu\left(\mu_{0}+M\right)+\mu_{0} P \cos \left(\theta_{p}+\theta_{\mu}\right)-\mu_{0} v_{0} \cos \theta_{\mu}\right|} ₹
$$

where $P$ is the nucleon momentum.

$$
\begin{aligned}
& E_{p}=P^{2 / 2 M,} \\
& \tilde{f}=\left[\frac{1}{3}\left|E_{f}\right|^{2}+\frac{2}{3}\left|O_{f}\right|^{2}\right] K^{2}+\left|O_{f}\right|^{2} L^{2} .
\end{aligned}
$$

$\theta_{\mu}$ and $\theta_{p}$ are the pion and proton angles respectively. $d \Omega_{\mu}$ and $d \Omega_{p}$ are the sol1d angle for the pion and proton respectively, and the remaining symbols have been defined. Curve $c$ in figure 1.10 was obtalned from the above expression by a numerical integration. Although the maximum occurs at higher energy than for curves A and $B$ it does not agree with the experimental points. Reaction (1.4) was studied by White et al. (1960) for photon energles between 200 and $1000 \mathrm{MeV}$. They used a large diffusion cloud chamber fliled with deuterium gas at 14 atmospheres and operated in a magnetic field of 6 k1logauss. The 1040MeV bremsetrahlung bean from the 
Cornoll synchrotron was hardened using 1ithing hydride to reduce the relative number of low enerey photons and passed through the chamber. Reaction (1.4) was distinguishod from other three prong events, multiplo plon production for example. by a detalled kinematical analysis of each event.

The spectral shape of the hardened bean was known so that the cross section for negative pion production In deuterium was obtained. The cross section for photoproduction at a free neutron at rest was derived from the measured cross section, by first transforming each event into the centro of mass system to obtain the cross soction for a bound neutron at rost and then by dividing this quantity by the $D / 1$ ratio. The crose section derived in this way agrees well with that obtained by the more conventional method of multiplying the positive pion crosn section at a proton by tho $-1+$ ratio.

A direct comparion is made between the observed momentum distribution of the spectator proton and the momentum distribution of tho nucleon bound in the douteron. 1 gure 1.11 shows a histogram of the laboratory distribution of the spectator momenta. The observed distribution has been corrected for a cross section bias 


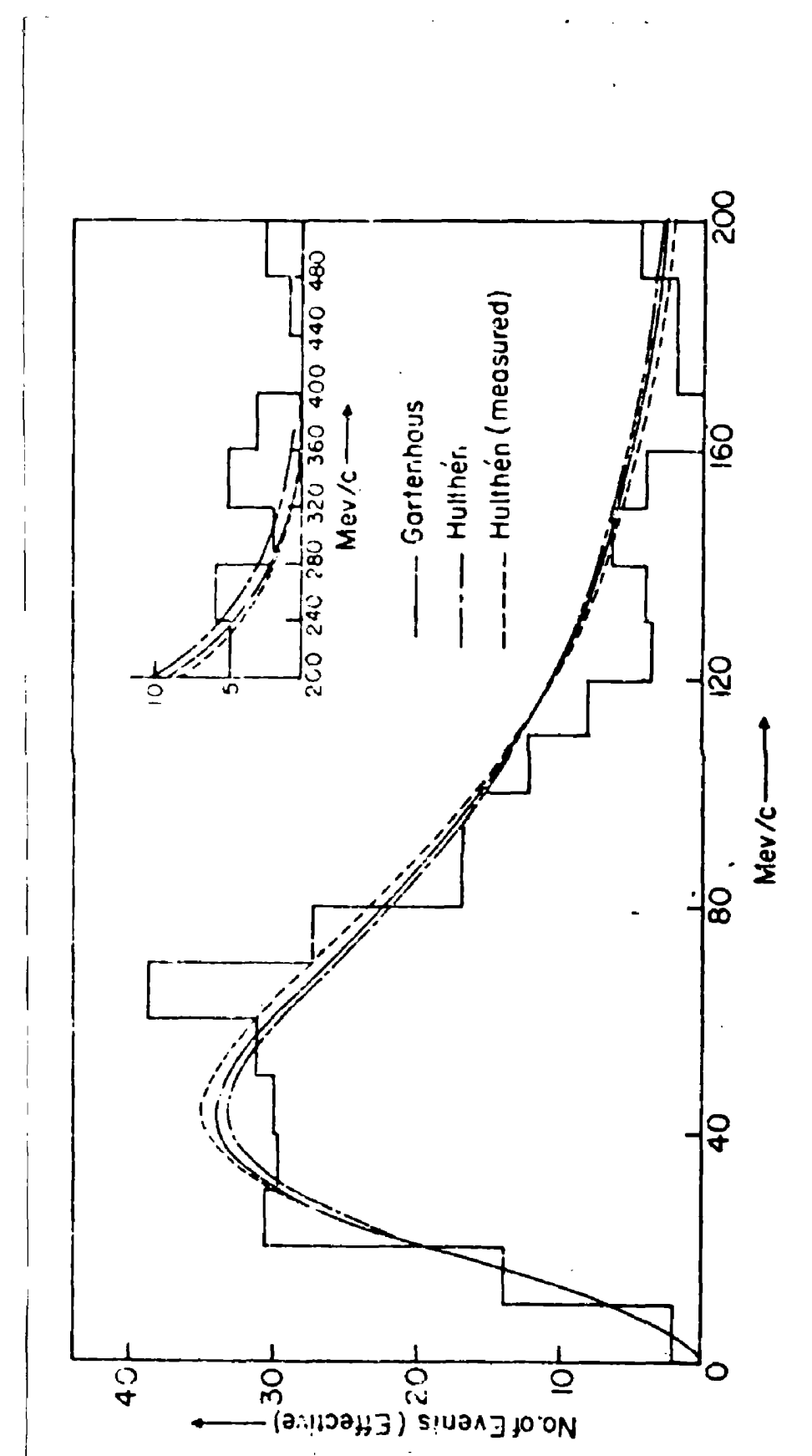

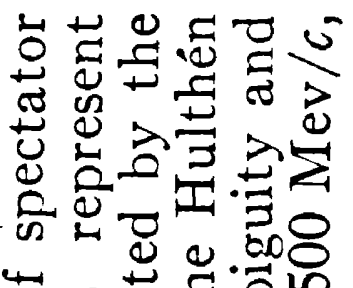

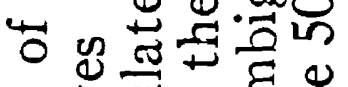

-

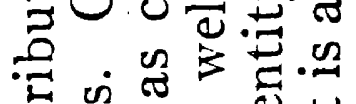

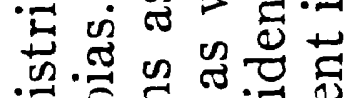

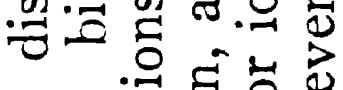

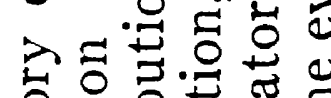

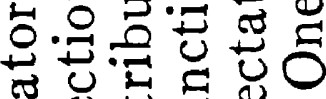

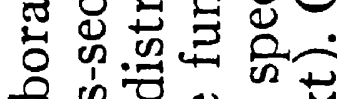

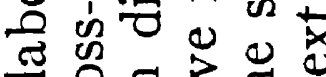

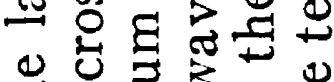

开焉焉

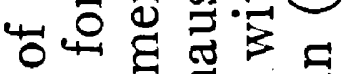

घ

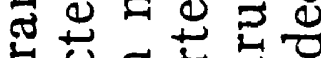

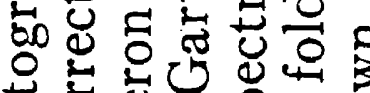

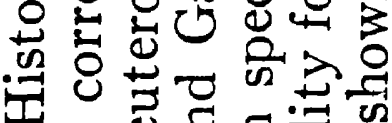

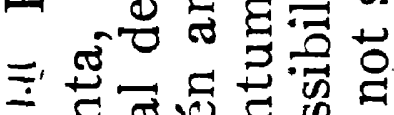

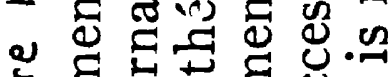

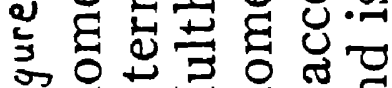

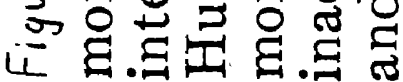


due to the nucleon momentum. Tho curves aro the momentum distributions calculated from the Gartenhaus and flulthén wave functions. The spectator model has an Inherent amblguty in 1dentifying the lower momentum proton as the spectator. This effect will be greatest for large spectator momenta. The "measured" curre Includes the effect of this ambiguity on the shape of the momentum distribution. The agreement shown in figure 1.11 is good. A few protons of high momentum were observed and must be considered to have interacted in the final state. White attributes the deficiency in the 100 to $200 \mathrm{MeV} / \mathrm{C}$ region to the competing photodisintegration process. The number of events did not permit a detalled analysis of the angular distribution. A definite excess of spectator protons was observed in the forward direction for photon energies above $250 \mathrm{HeV}$. Th1s could be Interpreted by asuming an average momentum transfer to the spectator proton of $10^{\circ} \mathrm{MeV} / \mathrm{C}$.

The work of White ot al. elves strong oupport to the validity of the spectator model description of pion photoproduction in deuterium in the region from 200 to $500 \mathrm{MeV}$. At higher energy the data 18 scarce. On the other hand the discrepancy observed by Keck and Littauer 
In the recoll proton enerey compared to the poctator model predictions would Indicate that the spectator model 1. subpot. The experimental study of nogativo pion photoproduction in douterium described in this thests was directed towardo Inveatigating thi diecrepancy from the oxperimental side.

\section{(e) The Prosent Experiment.}

The experimental method consisted of elrultaneous detection and measurement by scintillation counter telescopes of tho proton and negatiro plon produced in the roaction $r+d \rightarrow p+p+\pi^{-}(1.4)$. A thin 11quid deuterium target was irradiated by the $307 \mathrm{MeV}$ breasstrehlung boam of tho Glasgow eloctron synchrotron. pons wore dotected at $90 \pm 3.7$ degroos in the labozatory and in an enercy range from 46 to $60 \mathrm{HeV}$ using a scintiliation countor teloscopo. Tho coincident protons wero dotected in a second scintiliation counter telescope. The ancular distribution and onerey spectrum of tho colncidentprotons wero moasured.

The pion telescope consiated of 4 ecintillation countero operated in a $1+2+3-4$ colncidenceantlcolnctdenco equance. The plons were identifled 
by tholr pocific Ionization in counters 1 and 2 and by thelr rango. The tiro counter deteratnation of specific Ionization porratted nuch better soparation of plons from other charged particles than is possible with a aingle counter.

The proton toloscope had three scintillation counters. The front scintillator was thin, the socond had a rango equal to that of 81 lloV protong. Th1e counter toleacopo Identified protons in the enexgy range from 12 to $81 \mathrm{KoV}$. by coans of theif opocific Ionization and energy.

The dotaction of a pion by tho firat counter tolescope tribeored the sweop of an osc11loscopo. The pulsos from counters 1 and 2 in tho proton telescope ware dieplayed on tho oec11203cope trace which was photograpked. The position of tho pulses on the osc1I10scope trace were used to eliminato the backeround ovents. The energy spectrum of the protons wes obtalned frow tho pulso holeht distribution of the puloes from counter 2. Tho ability to ldentify both the pion and tho proton Erently reduced tho possibility of including ovente due to Interactiono other than $(1,4)$. The use of the liquid doutorium targot marko a defint to laprovenent over tho $D^{2} 0-U^{2} 0$ subtraction techniquo. 


\section{CILAPTER II.}

Tho Rosponso of plastic scintilintor.

In may exportaonts in nuclear physice the puleo height producod by charged particlos in scintiliation countoro 18 used to measure the energy $100 \mathrm{~s}$ in tho scintillator. The present investigation la an exapalo of ouch an experimont. Scint111ators having a linoar response to particlo enerey are to bo proforred in such applications. The Inorganic ocintiliators, sodium iodide and caosium lodide, are often used for this renson. Whon intenso pulsed sourcos of rediation are used tho long ocintiliation decay time combon to lnorganic scintidjators (of the order of $\mu$ second) makes their use difficult. Organic seintillators havo decay times of a fou nanosecondo, and may be used where very high instantaneous counting rates are expected (e.e. $10^{7}$ per sec.). Tho responso of organdc ecint1110toro tolheavily lonlaing particles to known to be non-11near. The response to a particular particle,protons or plons say, must be deternined before callbration at one or tro energies only w11 permit accurate measurement of particle energies. Tho comercially araliable platic sclntillator is the most convenient scintiliator for use in counter experinents in 
Which largo aron counters aro required. Sinco tho response of plastic scintiliator to protons had not been neasurod a direct calibration was dono (Evans and Bollamy, 1959).

B1rk. (1953) has developed a theory deacriblng the ccintilution process in oranic acintillatora. To Interprets the scintillation phenowena in terms of endasion of prisary photons by nolecules that are tontzed of oxcited by the tncidont particle. These photons aro In tho ultrartolot region and are reabsorbed. Tho reausorption may be accompanled by fluorescence in the viaiblo or near ultraviolet reclon. Non-radietivo capturo is a compoting process, and the relative inportance of the two procesees will lareely detemine the scintillation officiency of a particular matorial. The saturation observod in the rosponso of organic scintilintors to hoevily lonizing particles is explained by nolocular dnmage in the Ionization columin. Let $\mathrm{A} \mathrm{dE} / \mathrm{dx}$ represent the number of lonized or excited molecules por untt path length capable of priary photon emlasion, where dE/dx is the epocific lontation. The number of damaged nolecules 18 also proportional to dL/dz, 1.0. I $d E d x$. If the probabli1ty for capture by a damaged 
woloculo for tho prisary photon is k tiaes that for capture and fluorescence by an undamaged one then the spectfic fluoreaconce is

$$
\frac{d S}{d x}=\frac{A d E / d x}{1+k B d E / d x}
$$

For 6 all value of $d E / d x, k B d y / d x \ll 1$ and $(2.1)$ reduco to

$$
d s / d x=A d E / d x
$$

In aereement with the linear response observed for eloctrons in organic scintilintor. For vory heavily lonizing part1cles, leBde/d $\gg 1$ and $(2.1)$ boconos

$$
\mathrm{ds} / \mathrm{dx}=\mathrm{A} / \mathbf{k B}
$$

Indicating that the specific fluorescenco epproachos a limiting value for hoavily lonlaing particles.

In organic solution phosphors or phosphor-plastic Eixtures, tho primary caiesion 1 by tho solvent $c r$ baso. and the values of $A$ and $k B$ would be oxpected to depond upon tho nature of tho baso and the fluorescent matorial and its concontration.

The response of a plastc scintillator has been Invost1gated by Boroll and Grimolend (1955), They 
assumed equation $(2.1)$ to be true and measured $d S / d x$ for electrons and polonium 210 alpha particlos. Using (2.2) and (2.3) they obtained a value of $\mathrm{kB}=10.5 \mathrm{~cm}$ air equivalent per MeV. The scintillator they uod was of different manufacture than those currently arallable. The calibration of plastic scintillator described below does not depend upon the assumption that (2.1) correctly described the spectefc lontzation and is the first direct calibration of plastic scintillator response to protons reported. Protons of an Inttial energy of $14.8 \mathrm{MeV}$ were obtained from the reaction $\mathrm{d}+\mathrm{He}^{3} \mathrm{i} \rightarrow \mathrm{p}+\mathrm{He}^{4}$ using deuterons accelerated in a Cockroft-Walton high roltage machine. The $\mathrm{He}^{3}$ was present as a decay product in a tritium target 60 that the reaction $\mathrm{d}+\mathrm{H}^{3} \rightarrow \mathrm{n}+\mathrm{He}^{4}$ also occurred producling $14 \mathrm{MeV}$ neutrons. The yleld of protons relative to neutrons increases as the energy of the incident deuterons $1 \mathrm{~s}$ realsed above $120 \mathrm{KeV}$ where a resonance in the neutron production occurs. The high roltage machine was operated at 400 kilovolts near the resonance for proton production. To further reduce the background due to knock on protons from the hich neutron flux the protons were detected using a coincidence 


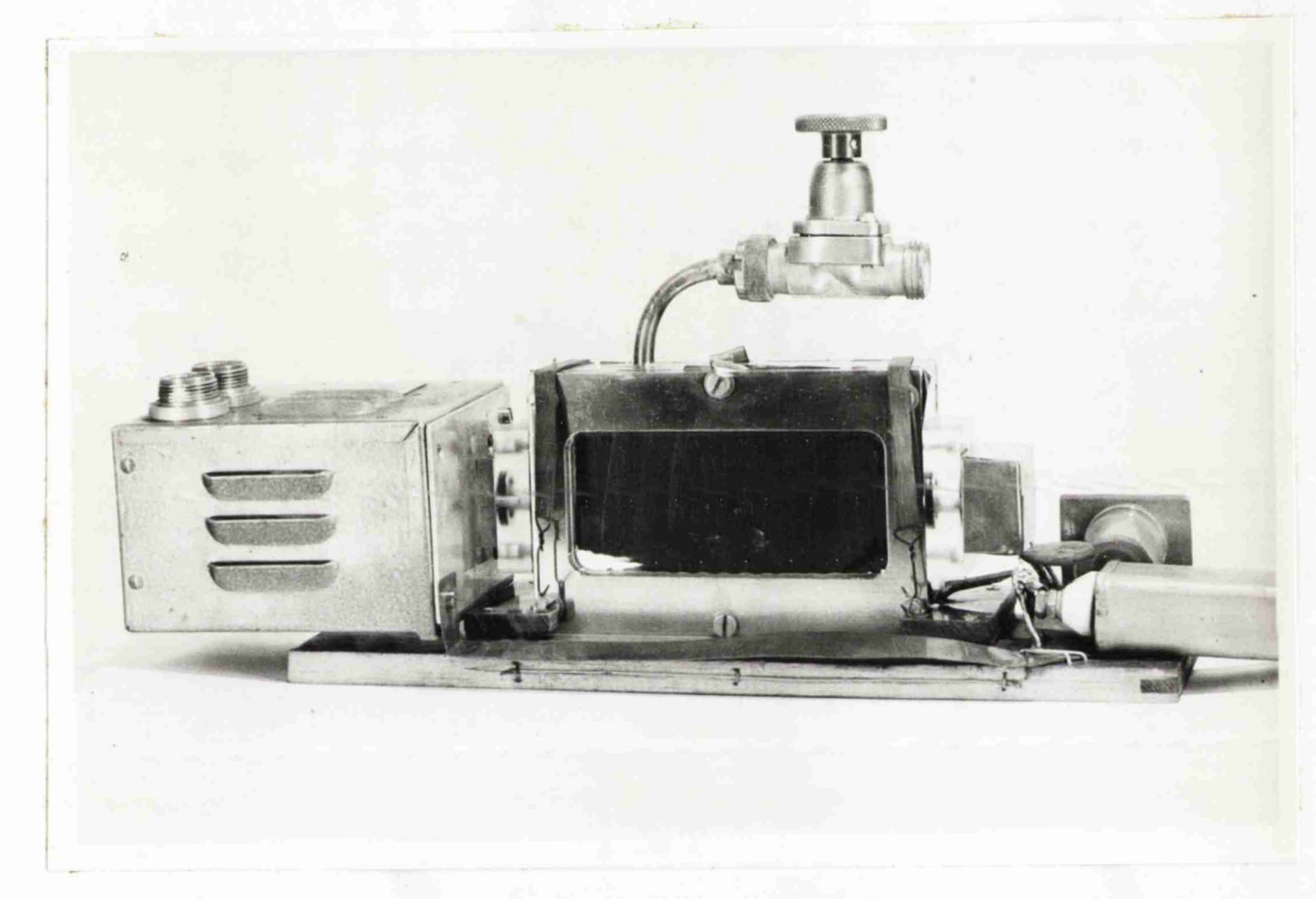

Figure 2.1. Thin proportional counter and head amplifier. 
counter telescope.

The front counter wa a thin gas rilled counter operatod in the proportional region bhom in ficure 2.2. It was constructed by aliling 4 by 2 Inch hole out of a 1 inch thick plece of brass. The central whe was 3 thou tungaten. Since only the central portion of the counter was used no special precautions were taken to eliminate end effecto. Celophano aluminized on the Instde was usod for tho windowe. The colophane shooto wore sealed against "O" rince by peans of clapping platea. The counter was fillud with a 93 percent argon 7 percent athane mixture at a pressure of one atmoophere. The response of this countor was tested using protons and polonium a-particlea and shown to be approximatoly proportional to the partielo onergy lost in the counter. The uso of tho counter to diecriminate agalnst noutrons however did not depend upon this property.

In the socond counter tho solntillator under test was viowed by an R.C.A. 6810 photomultiplier. A short length of lucite we interpoed between the scintillator and the photomultiplier to reduco offects due to uneven reaponse over the area of tho photocathode, The photomultiplier output was integrated at the collector 
so that the counter pulses corresponded to the total ocintiliation response.

The proportional counter was used to gate the output from the scintiliation counter. The latter was amplified and displayed on a 100 channel klckeorter. A delay uas introducod betwoen the scintillation counter and the kickeorter to allow the klckeorter gate time to operate. Tho amplitude of the 1nput pulso to the kicksorter was adjusted so that the poak in the puloo holght distribution occurred near the middle of the klckeorter rango. This was done uging en attenuator In the amplifier. whtch was adjustabla in $2 \mathrm{db}$ steps. The accuracy of the attenuator settings was checked and found to be correct to within 2 percent. No correction was made for thlo orror. The pulso holght at the collector of the photomultiplier was nover groater than .3 volts so that saturation in the photomultiplier was avolded. A blocl diagram of tho clrcult is ghom in figuro 2.2 . The experiaental arrangewent is shown in figure 2.2 . A 1 thou mylar window allowed the protons to leave the vacula ayoted of the high voltage machine with alnimus 1088 of energy. The ecintiliator was $11 \mathrm{~cm}$ from the ex1t window and the mazimum proton cnorgy entering the 


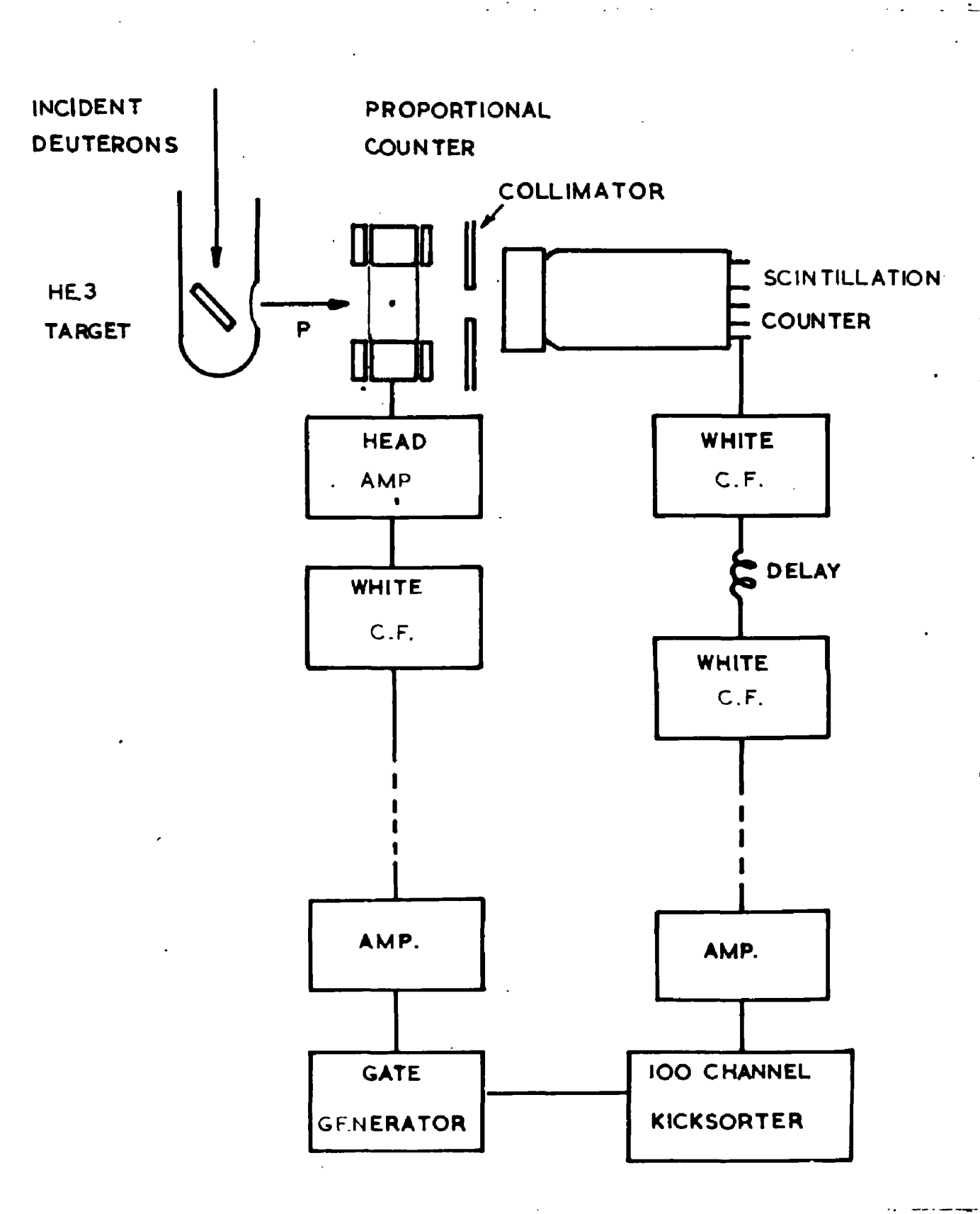

Figure 2.2. Experimental arrangenent and blocls diagrax of circuit uaed in callbration of plastic scintillator. 
scintillator at that position was $14.0 \mathrm{MeV}$. The energy of protong ontering tho scintillator was variod by interposing aluminium absorbers between the two counters. The pulse helght distributions for protons at nine onergles between $14.0 \pm .05 \mathrm{MoV}$ and $3.08 \pm .18 \mathrm{HeV}$ wero determined. The protons entering the scintiliator were collimated by a $1 \frac{1}{2}$ Inch holo in a $1 / 16$ inch sheot of aluminium to reduco the spread in energy due to protong traversing the absorber at large anglos. The pulse helght distribution for protons of onergy $1.2 \pm .1$ HeV was obtalned using protons from the reaotion $c^{12}+a \rightarrow c^{13}+p$.

The response of the scintillator to protons was normalized to the electron response using the Compton edges for $2.62 \mathrm{MeV}$ thorlum gamma rays and the $1.28 \mathrm{MeV}$ sodium 22 gamma rays.

The pulse helght distributions obtained for $14.0 \pm .05$ Hev protons 18 shown in figure 2.3. The two curves A and $B$ are the distributions obtalned with and without the gate. The pulse helght distributions for protons

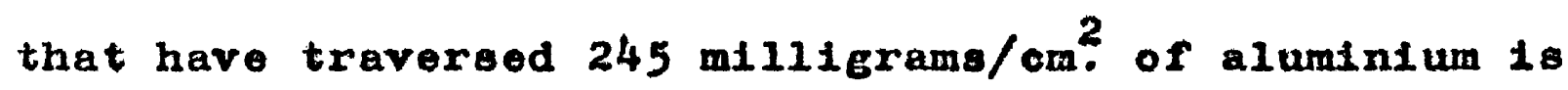
also shown. Considerable deterioration in pulso helght resolution is evident. 

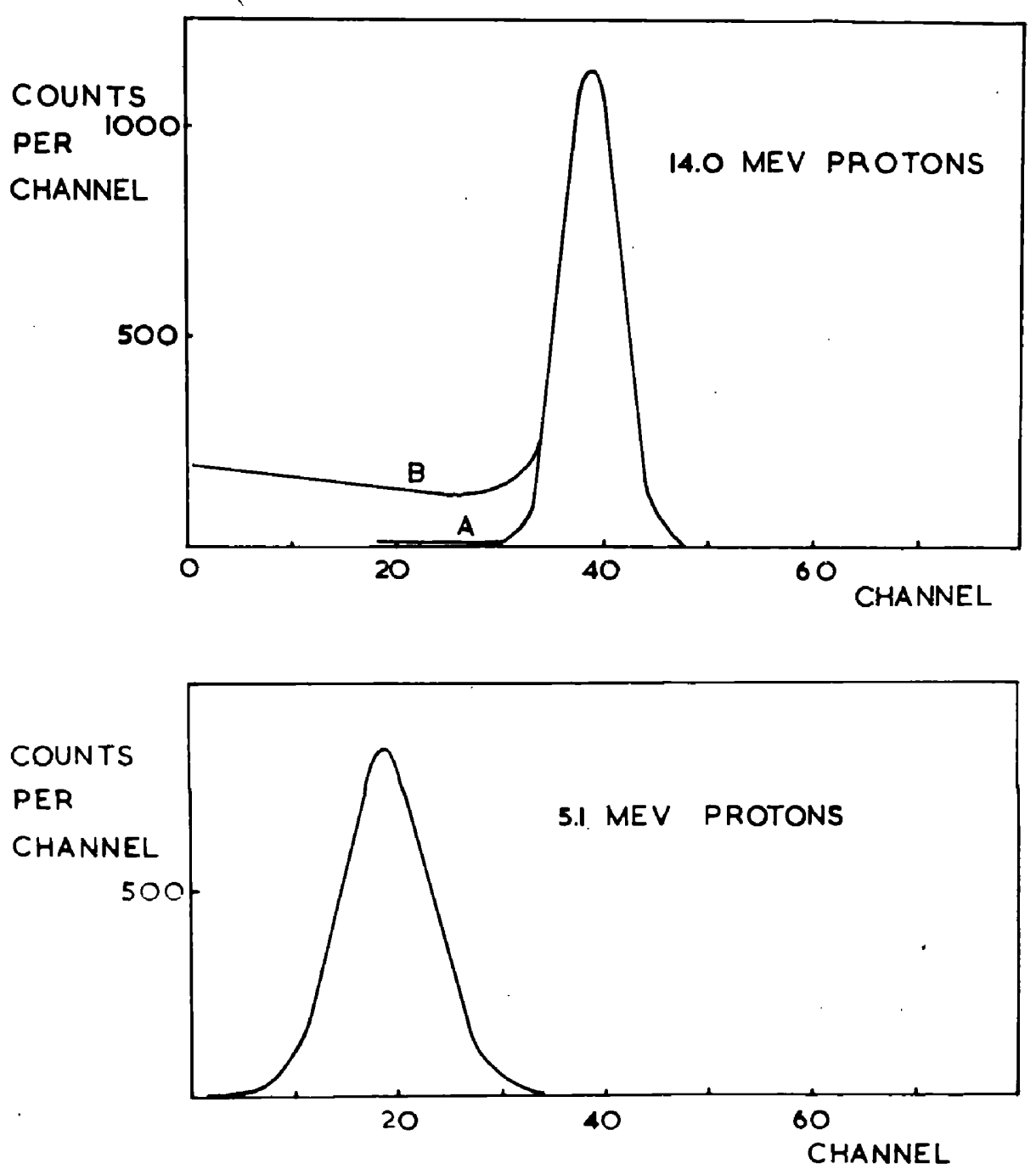

F1gure 2.3. Pulse helght distributions obtainod for protons in scintillator callbration. 
The response of two comerctally avallable plastic scintillators was measured. A 2 1nch diameter $\frac{1}{2}$ inch thick samplo of HE 102 produced by Nucloar Enterprizes G.D. Ltd., and a 3 1nch dianoter 2 1nch thick sapplo sanufactured by Mossrs. Jash and Thompoon Ltd. wero used. Both scintillators havo a polyvinyltoluene baso.

The rosults of tho measurements are given in table 2.1. The thickness of the alunintum Absorber to given in the first column. The rango onorgy tables of Atlinson and W11118 (1957) were used to deteralne tho residual energy of the proton entering the scintillator. The proton enercy is etron in the second column. The orrors includo uncertainty in absorber thekneso and in intilal proton enorey. In the third coluran tho pulso helght relative to that for 1 Nov electron is given. The half width at half maxinug of the pulso helght distribution obtalned at each energy 18 also eiven.

The response of plastic eclntillator INE 102 is shown In flguro 2.4. The exporinental points are taken from table 2.1. The callbration point obtalned from the Compton edges for thorlum and sodius 22 carre rays aro shown. The 1ndicated errors are the epread in pulse holeht from to height on the compton edge. 
Table 2.1a,

Response of Plastle Scintillator NE 102 to Protons.

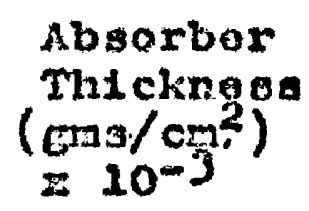

0

$$
27.0 \pm .2
$$$$
74.5 \pm .2
$$

$147.3 \pm .4$

$172.6 \pm .5$

$219.2 \pm .6$

$244.5 \pm .7$

$259.5 \pm .7$

$274.5 \pm .8$

$c^{12}(d . p) c^{13}$

\section{Proton}

Energy

( $\mathrm{geV})$

$$
14.0 \pm .05
$$

$13.2 \pm .05$

$12.8 \pm .05$

$9.4 \pm .08$

$8.4 \pm .10$

$6.4 \div .12$

$5.1 \pm .14$

$4.2 \pm .15$

$3.03 \pm .18$

$1.2 \pm .13$
Pulso Nolcht

Relative to

1 lov

Electrons.

$6.08 \pm .55$

$7.46 \pm .6$

$6.30 \pm .5$

$4.73 \div .4$

$4.07 \pm .5$

$2.84 \pm .4$

$1.80 \pm .4$

$1.37 \pm .4$

$.82 \pm .4$

$.25 \pm .2$ 
Tablo 2.1b.

Feaponse of Wash and Thonpson plastic Scintillator to Protons.
Absorber
Thicknesg
( $\mathrm{Cos} / \mathrm{cm}^{2}$ )
Proton
inorgy
(Mov)
0

$$
\begin{aligned}
& 25.3 \pm .1 \\
& 72.8 \pm .2 \\
& 90.1 \pm .3
\end{aligned}
$$
$144.7 \pm .4$
$170.0 \pm .5$

\begin{tabular}{|c|c|}
\hline $\begin{array}{l}\text { Proton } \\
\text { Enorgy } \\
\text { (Miov) }\end{array}$ & $\begin{array}{l}\text { Pulae llelght } \\
\text { Relative to } \\
\text { I NeV } \\
\text { Eloctrons. }\end{array}$ \\
\hline $23.0 \pm .05$ & $7.33 \pm .7$ \\
\hline $13.1 \pm .05$ & $6.83 \pm .6$ \\
\hline $11.7 \pm .05$ & $5.89 \pm .6$ \\
\hline $10.9 \pm .05$ & $5.26 \pm .5$ \\
\hline $9.3 \pm .08$ & $4.37 \pm .5$ \\
\hline $0.3 \pm .08$ & $3.52 \pm .5$ \\
\hline $6.15 \pm 1.1$ & $2.31 \pm .4$ \\
\hline $4.8 \pm 1.2$ & $1.39 \pm .4$ \\
\hline
\end{tabular}
$219.0 \pm .6$
$244 . \pm .7$
Puloe HeIght Relative to
1 Met
Eloctrons.
$7.33 \pm .7$
$6.83 \pm .6$
$5.89 \pm .6$
$5.26 \pm .5$
$4.37 \pm .5$
$3.52 \geq .5$
$2.31 \pm .4$
$1.39 \pm .4$ 


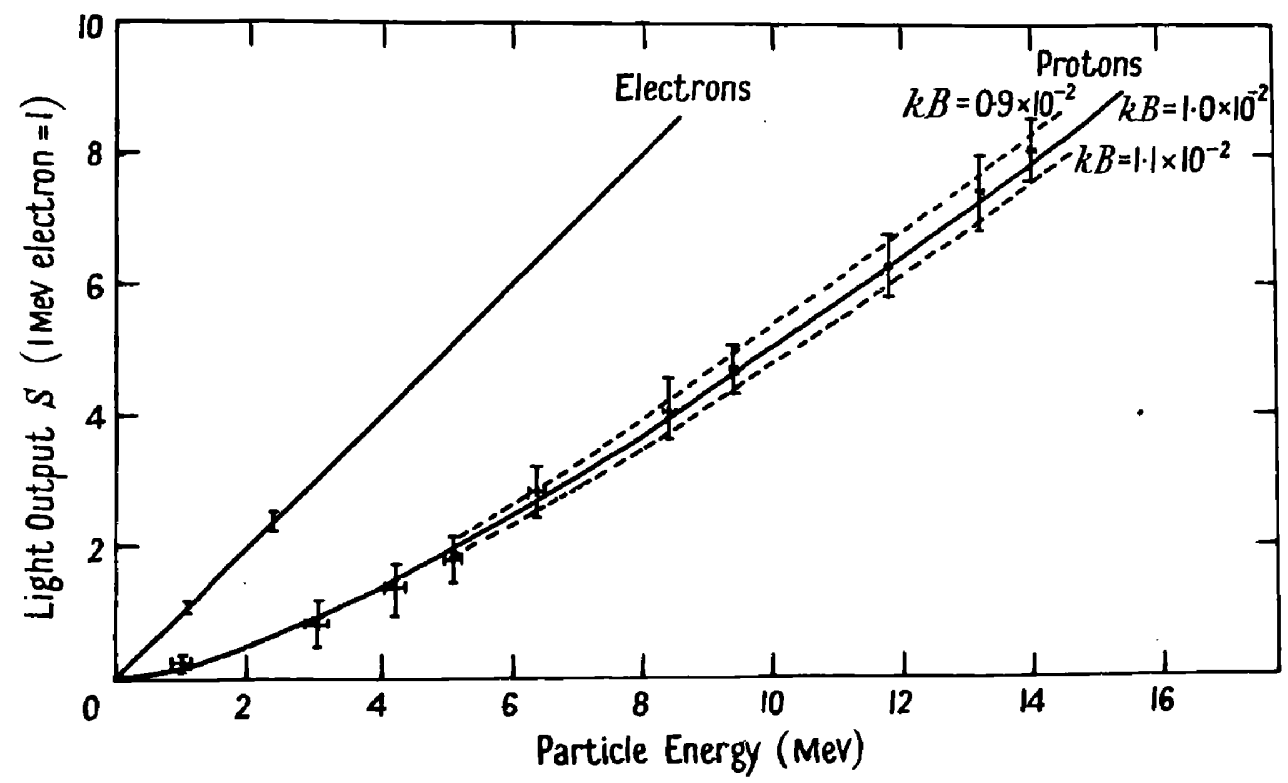

Figure 2.4. Response of plastic scintiliator to protons. The curves were calculated using Dirks' expression for spectfio fluorescence in organic seintillator for the values of $\mathrm{kJl}$ shown. 
The response of the scintillator predicted by Birks' expression, (2.1), may be obtalned by integrating tho specific fluorescence over the particlo range.

$$
\begin{aligned}
S(E)=\int_{0}^{R} \frac{d s}{d x} d x= & \int_{0}^{R} \frac{d E / d x}{1+k B d E / d x} d x \\
& \approx \sum_{0 i}^{E} \frac{\Delta E_{i}}{1+k B(d E / d x)_{i}}
\end{aligned}
$$

where A 1 corresponalng to normalizing the pulse helght to $1 \mathrm{MeV}$ electrons. $(\mathrm{dE} / \mathrm{d} x)_{\text {i }}$ is the specific lontzation eppropriate to a proton of chergy $\mathrm{D}_{j}$ and $\mathrm{n}$ lo the particle range. The last expression in (2.4) was used to calculate the curves in figure 2.4 for various assumed valus of $\mathrm{k}$. The rango energy relationship in plastic was taken as that for CE given by the tables of Rich and Madey (1954). The composition of plastic scintillator is given by the manufacturers as $\mathrm{CH} / .105$ Since the difference between the range energy relationship for CH and $\mathrm{CH}_{2}$ ie small, the error in assuming CH for plastic is negligible.

It 18 evident that a 10 percent variation in $k B$ does not Introduce a large change in the calculated response. The experimental point for IVE 102 are best fitted when $\mathrm{kB}=1.0 \times 10^{-2} \mathrm{sis} \cdot \mathrm{cm}^{-2} \mathrm{MeV}^{-1}$. A value of 
$1.1 \times 10^{-2}$ gms. $\mathrm{cal}^{-2} \mathrm{ISO}^{-7}$ was adopted for the Wash and Thompson sarplo.

Those values afree woll with that obtalned by Boreli and Grimoland which was equivalent to $1.1 \times 10^{-2}$ cons. $\mathrm{cs}^{-2} \mathrm{HeV}^{-1}$ if tho air equivalent range is dofinod at $15^{\circ} \mathrm{C}$ and 760 HC.

liecently Gooding and lugh (2960, and private corcunication) have coasurod the response of plastic scintillator IF 102 to protons up to 160 MoV and to deuterons up to $120 \mathrm{hoV}$. They compared their measurements to the reoponse calculated for these particlos by Integrating the foraula

$$
a S / d r=10 g(1+a d E / d x)
$$

for the speolfic fluoresconce due to Wright (1953). The neasurements described above lmply a value of $25 \pm 2$ me. $\mathrm{cm}^{-2} \mathrm{MeV}^{-1}$ for a. Gooding and Fugh obtatn a bost rit to thetr measured responso for $a=28 \pm 5 \mathrm{ag} \cdot \mathrm{ca}^{-2} \mathrm{MeV}^{-1}$. There is cood agreement among the various measurenenta. Sinoo the concentration of fluorescost matorial used by the manufacturers is eenerally chosen to optimize the 11ght output, and since samples using both polyotyrene and polyvinyltoluene basos behave slatlarly it is plausible 
that efmliar values of $\mathrm{kB}$ would apply to all such plastlo acintillators. Uncertainties in the value of kB of about 10 percent lead to mall inaccuracios in proton enercy moasurement ueling electron calibration. Th1o can be soen from the table below.

Eloctron Equivalent Pulse Holght from Protons

$\begin{array}{lllll}\text { Proton Ener6y } & 1 & 10 & 50 & 100 \\ s\left(k B=1.1 \times 10^{-2}\right) & .19 & 4.82 & 37.26 & 82.70 \\ s\left(k B=1.0 \times 10^{-2}\right) & .20 & 5.03 & 39.96 & 83.70\end{array}$

The results of the cellbration of plastic ecintillator are shituartided below.

1. Dirko" expression (2.1) for spectfic fluoreacence of organic scintillator accurately predicts the response of plastlo scintillator to protons.

2. The value of the coeffictent $\mathrm{kr}$ 10 close to $1.0 \pm .1 \mathrm{x} 10^{-2}$ gus. $\mathrm{cm}^{-2} \mathrm{Hov}^{-1}$ for comerelally avallable plastio selntillators.

It 16 reasonablo to assume that $(2.1)$ may bo used to obtaln the reoponse for plastic to other hoevily ionialng particleo. 


\section{CIAPTER III}

The Detection System

(a) Introduction.

lany erperimento in nuclear physics require the detection and identification of charged partieles. An experiment in which a bean of particles are incident on a target is a typical example. The identification of particles of a particular mass among a flux of different particleg emitted by the target is an essential requirement In nost experiments of this type. In general the particle identification w111 require simultaneous measurement of two properties of the particle which have different dependence on particle mass. The specific lonization and range, or specific ionization and enorey are often used. (Wolfe et al,1955. Keck, 1955. Rutherelen and Walker, 1,960).

The dependence of opecific lonization on energy for non relativistic particles may be expreseed as

$$
d E / d x \propto \frac{M^{.8} Z^{2}}{E^{.8}}
$$

where $M, Z$, and $E$ are the particle mass, charge and energy. The specific lonization for single charged 
particles is nearly proportional to particle mass. Tho specific lonization for pions, protons, and deuterons of the same onergy are in the ratio .2281 .1 .7 .

Wolfe showed that the specifle lonlzation and residual range. $R$ of a particle are ralated by

$$
d E / d x \propto \frac{M^{.45} Z^{1.1}}{R^{.45}}
$$

The relative opecific lonlzation for plons, protons, and deutercns having the sakio rosidual Iange $10.4: 1.1 .3$ respectively.

Scintillation counter tolescopes are sultablo for Idcatifying chargad particles by olther of the abovo methods. The specific icnization and erergy can be weasured usine a thin frort scintiliator and $e$ thick scintillator in which the particles stop. particlo range nay be defined by pulse helght selection in the second counter or by introducing a third counter operated in anticolncidence with the other two. The separation of charged particles obtainable in practice is not as good as indicated by (3.1) and (3.2). The need to have reasonable pulse height resolution in the $\mathrm{dE} / \mathrm{dx}$ measurement means that the energy loss must not bo 
too small. The pulse height is then not strictly proportional to $d E / d x$. Then organle scintillators are used the saturation of specific fluorescence for heavily Lonizing particles makes particle ldentiflcation more difficult. A comparison of (3.1) and (3.2) Indicates that the method of specific ionization and energy is to be preferred.

Two scintillation counter telescopes have been constructed to identify and neasure the energy of protons end piens. They are described in the foliowing sections.

(b) The proton Telescope.

The scintillation counter telescope used to detect the protons (here after callod the proton telescope) consists of 3 counters in which plastic scintillators are vlewed by R.C.A. 6810 photomultipllers. The front scintillator was 26 thou. thick and 3 by $23 / 8$ inches in area. The second and third sclntillators were cylindrical in shape being 3 and $4 \frac{1}{2}$ inches in diameter and 2 and $\frac{1}{2}$ inch thick respectively. plastio scintillator 15E 102 was used in counters 1 and 3 . The seoond ecintillator was the sample, manufactured by Nash and Thompson Ltd.. used in the scintillation calibration. 
Good optical coupling between the scintillators and porspex 11ght guides and between the light guides and photomultipliers was obtained using silicone fluid.

This counter telescope ldentified protons by means of $d E / d x$ and $E$. The derelopment of a thin $d E / d x$ scintillation counter was crucial to the experimental technique used. Thls counter wlll be described in detail.

Tho thin plastic scintillator was made by heating and presilng piece of plastic. It was carefuliy cloaned and placed on a clean pioce of plate glass. A second plece of plate glase was supported above the scintillator. The glase plates and scintillator were heated in an oven to $150^{\circ} \mathrm{C}$. After about an hour the supports for the top glass plate were removed and lead blocks loaded on to press the scintillator. The thlckness of the pressed scintillator was determined by spacers placed between the glass plates. When the top glass plate appeared to be resting on the spacers the oven was switched off and allowed to cool slowly with the door closed. The slow cooling annealed the scintillator. The scintillator was removed from the glass plates by placing them under water and waiting for 


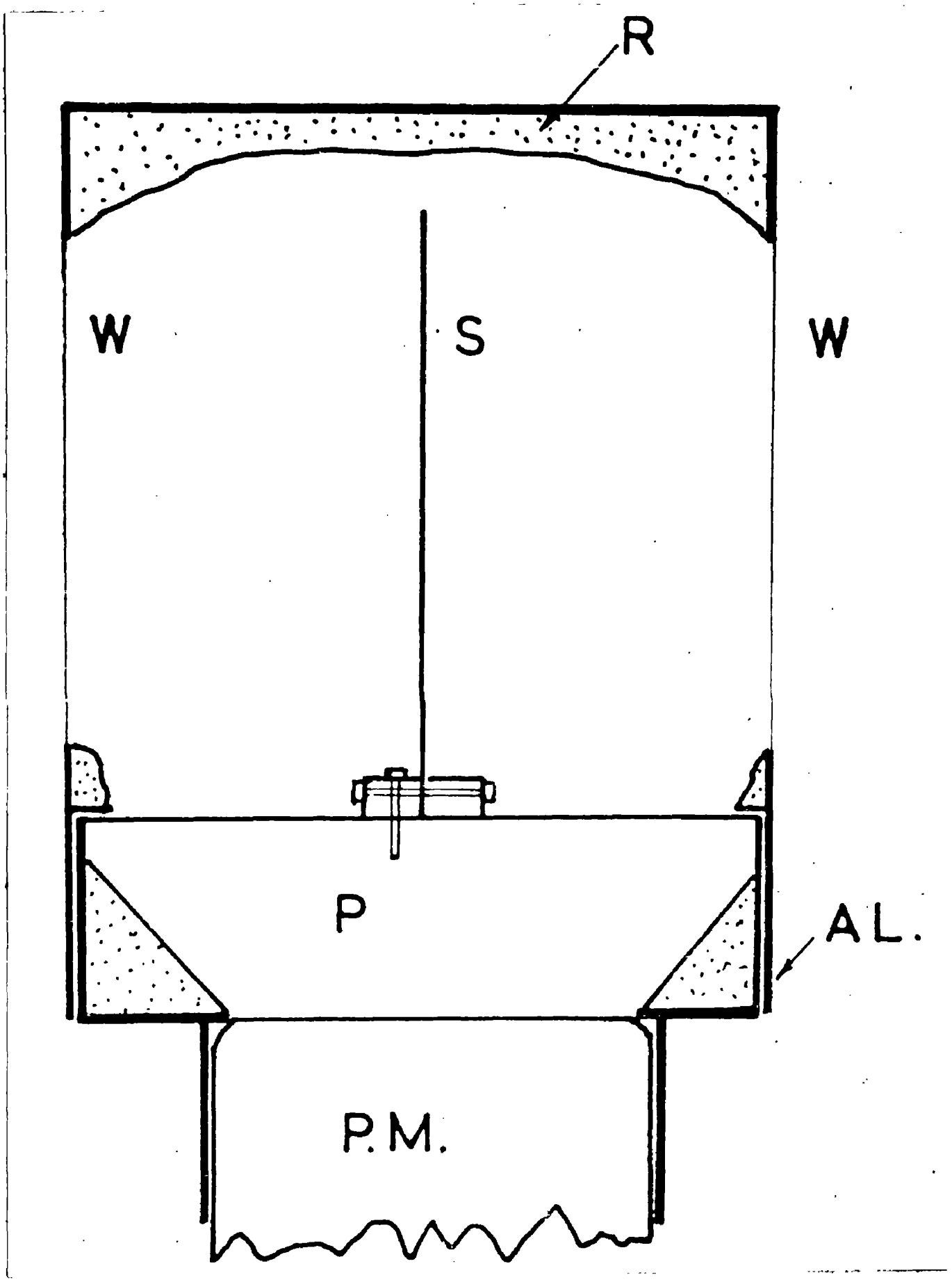

Figure 3.1. Thin sointillator Mounting

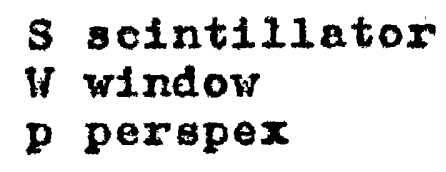

Al aluminium

PM photomult1plier

$R$ magnesium oxide reflector 
the to separate. In order to obtain high quality scintillator it was necessary to produce a large sheot and to cut the required scintillator from the best part. The scintillator mounting is shown in figure 3.1. The scintillator was clamped by the perspex strips. The aluminium enclosure surrounding the scintillator has two windows covered with $\frac{1}{2}$ thou aluminized mylar and a double layer of 0.2 thou aluainium foll: The interior shape of the enclusure was moulded usting plaster of paris, and coated with megnesium oxide by burning magnesium ribbon inside tho enclosure. The photomultiplier uged in this counter was selected for low noise level. The pulse height and resolution obtained with this counter were satisfactory.

The pulse height calibration was obtalned using $160 \mathrm{KeV}$ internal converaion olectrons from an Indium 114 source. The source vas collimated and placed close to the counter window. The electron energy incident on the scintillator was $96 \mathrm{KeV}$. The pulse helght distribution due to the indium electrons was obtained using a 100 channel kicksorter. A typical pulse height distribution is shown in flgure 3.2. The background, which was mainly due to photomultiplier nolse, is also shown. The spectra shown in figure 3.2 were obtained by counting for one 


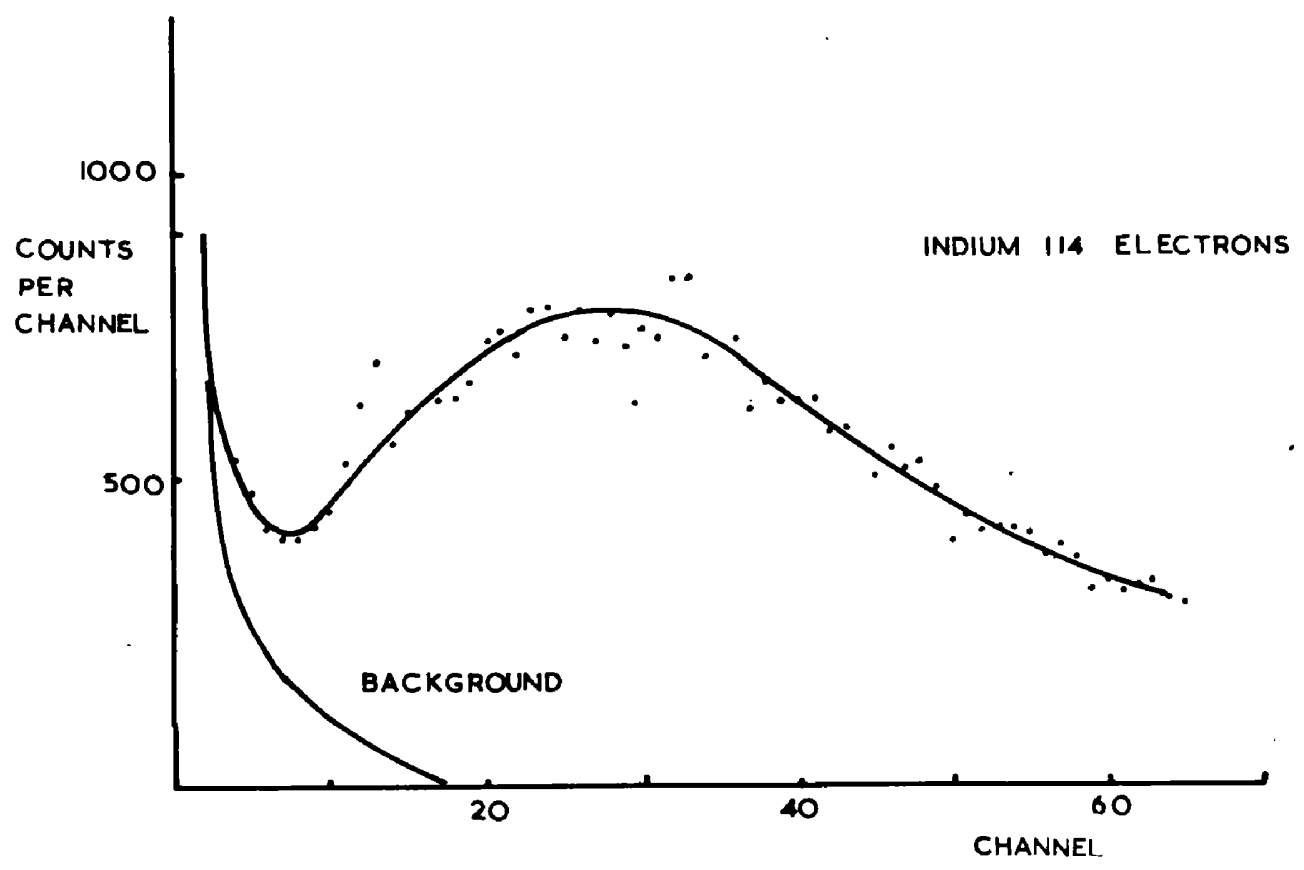

F1gure 3.2. Puise heleht distribution obtalned with the thin sclntiliation counter for indium 114 intornal conversion olectrons. The upper curve includes the backeround. 


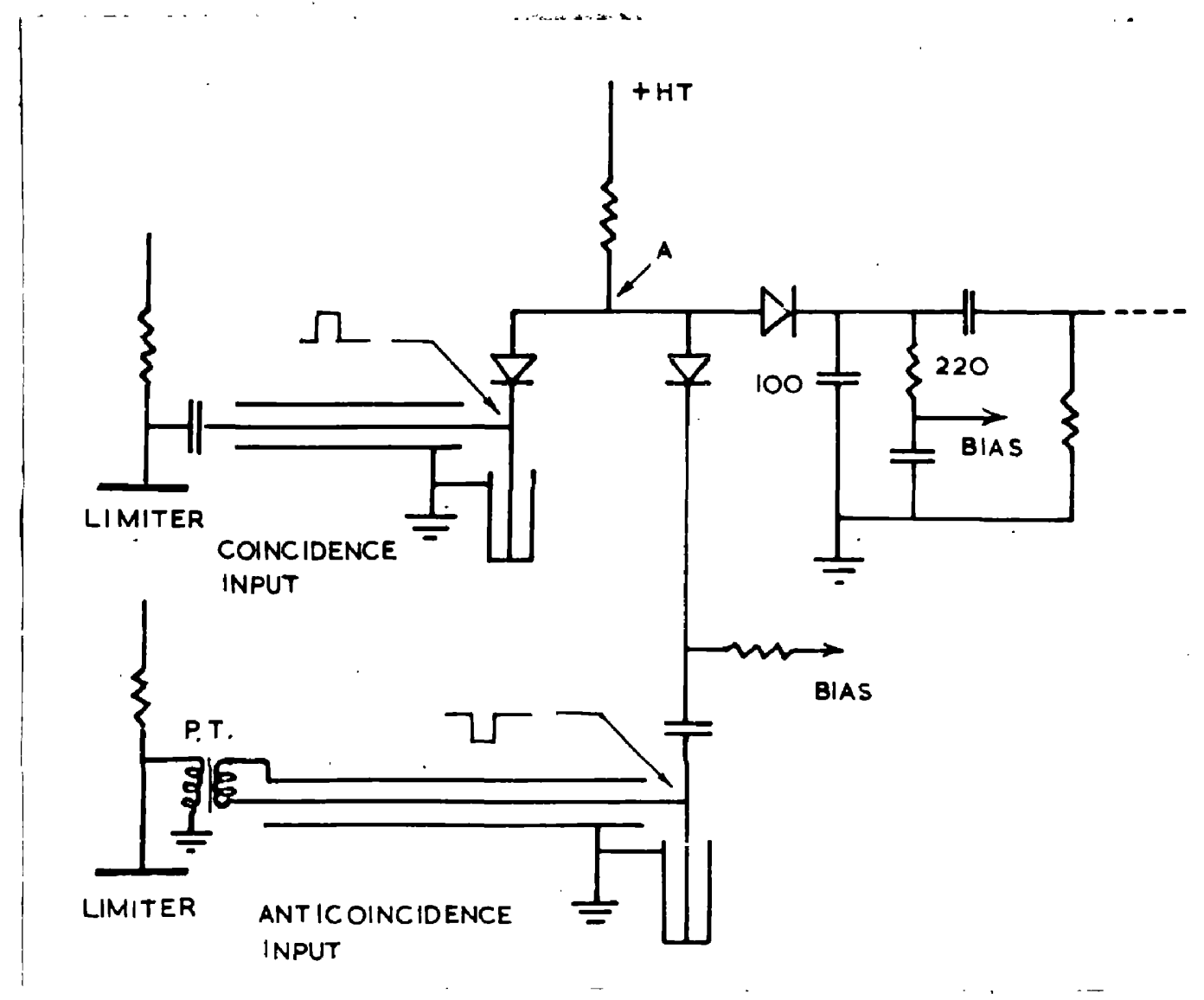

F1gure 3.3. Coincidence circult used with proton telescope. One colncidence and one unticoincidence input are shown. 
minute. When the kicksorter blas is allowed for an the background subtracted the resolution of the peak $1 \mathrm{~s}$ 60 percent half width at half heicht.

The proton telescope was operated in a $1+2-3$ coincidence - anticolncidence sequence. The modified form of the Bell colncidence clrcuit shown in figure 3.3 was used. Each input is terminated in a shorted 100 ohm Iine, and is connected to the common point A through a gertiantus diode. For colncidence inputs the diode 10 normally conducting. When the colncldence blas is properly adjusted a coincidence to singles ratio of 20 to 1 is possible. with this circult. The diode at tho anticolncidence input is normally biased off. A negative pulse causes the dlode to conduct and prevents a large colncidence pulso from being formed at A. Tho negative input is obtalned by Inverting the linited pulses using a pulse transformer. Conventional ilmiter clrcuits using $E 180$ ralves are employed. When 1.5 metre shorted line were used the colncidence resolving tIme wos $5 \times 10^{-9}$ eeconds. A non Inverting output from the limiter valve of counter 3 was used to determine the correct delay relative to the other counters. The principal advantage of this circult lies in the separate 


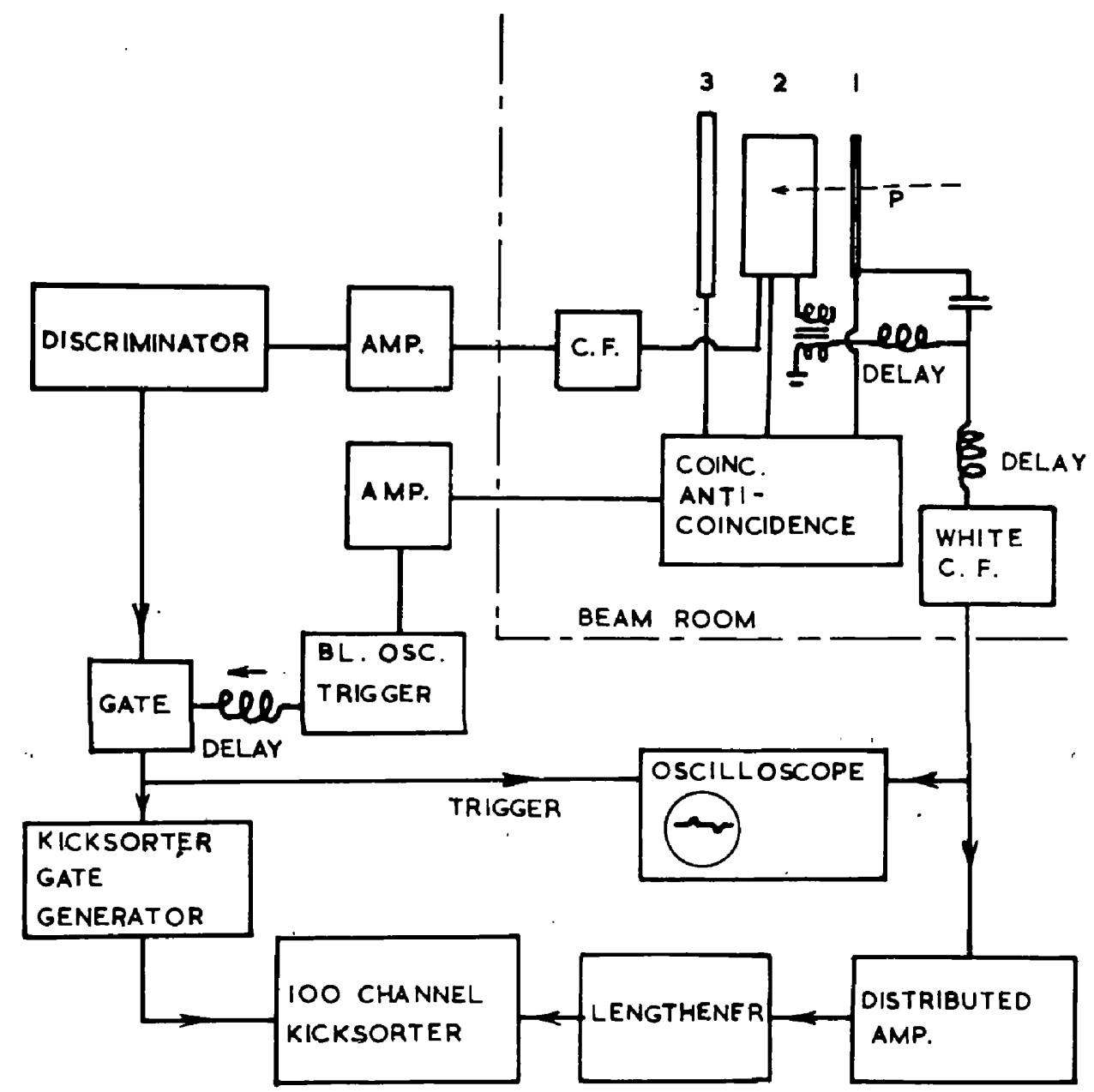

F1gure 3.4. Block diagram of c1rcult used for testing and calibration of tho proton telescope. 
rafnute. When the kiclsorter bias is allowed for an the background subtracted the resolution of the peak $1 \mathrm{~s}$ 60 percent half width at half height.

The proton telescope was operated in a $1+2-3$ coincidence - anticoincidence sequence. The modified form of the Dell colncidence circuit shown in figure 3.3 was used. Each input is terminated in a shorted $100 \mathrm{ohm}$ 11ne, and is connected to the comon point A through a gerkantum diode. For colncidence inputs the diode 18 normally conductine. When the colncidence blas 19 properly adjusted a coincldence to singlos ratio of 20 to 1 is possible with this circult. The diode at the anticolncidence input is nomally blased off. A nagative pulse causes the dlode to conduct and prevents a large colncidence pulae from betng formed at $A$. The negative input is obtained by inverting the limited pulses using a pulse transformer. Conventional limiter circuits using $\mathrm{E} 180 \mathrm{~F}$ valves are employed. When 1.5 setre shorted lines were used the colncidence resolving time was $5 \times 10^{-9}$ seconds. A non Inverting output from the limiter valve of counter 3 was used to determine the correct delay relative to the other counters. The principal advantage of this circult lies 1 in the separato 


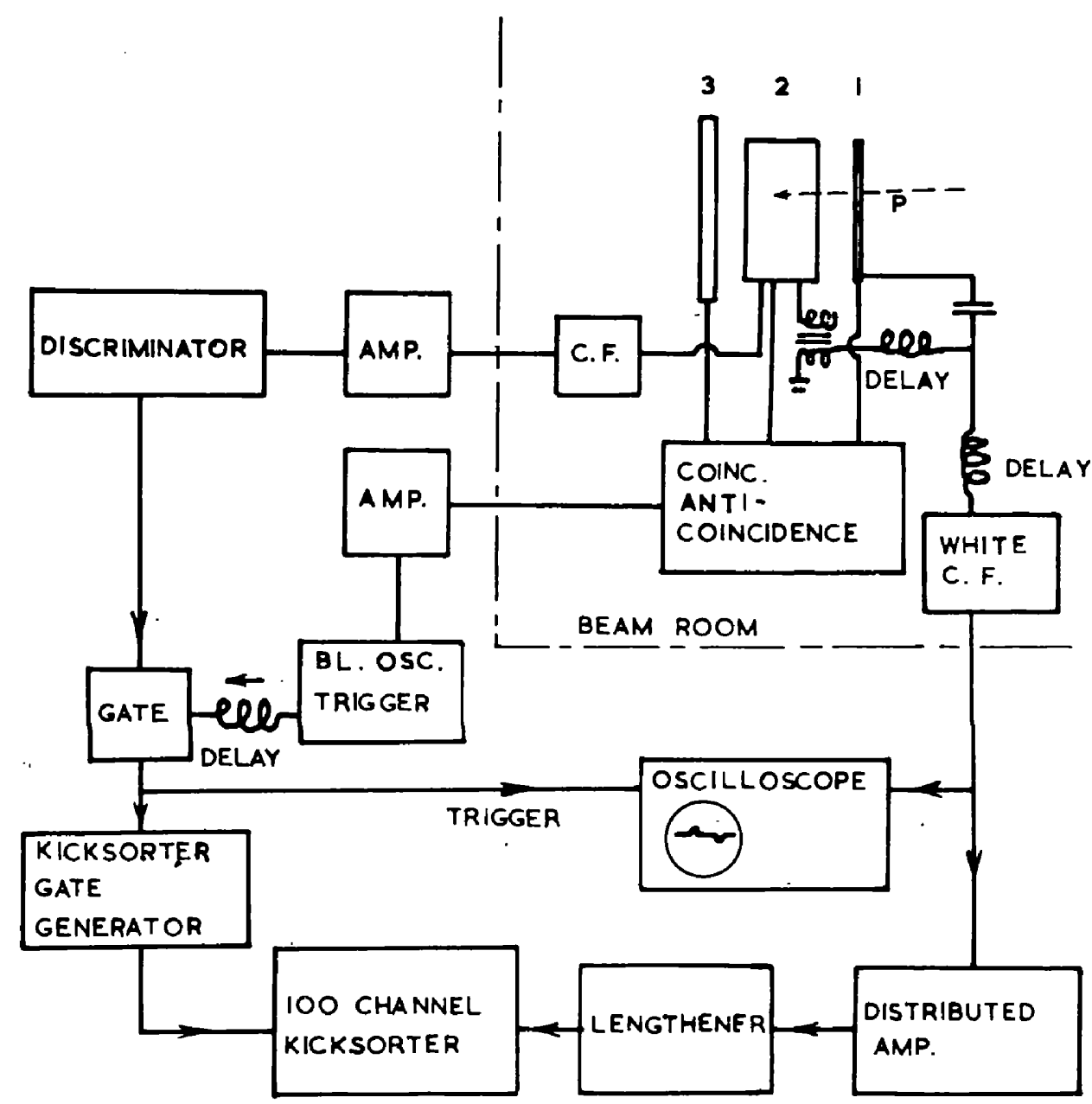

Figure 3.4. Block dlagram of c1rcult used for tosting and callbration of the proton telescope. 
termination at each input. The addition of an extre colncidence or anticolncidence input doe not involvo complicated impedance matching.

The clrcult used in the testing and calibration of the proton telescope is shown in figure 3.4. The pulsos used to measure specific lonization and energy wore taken from the 12 th and 11th photomultiplier dynodes of counters 1 and 2 respectively. The pulse from counter 2 was inverted using a pulse transformer. A $2.2 \mu$ sec delay was inserted between counter 2 and the White cathode follower. Counter 1 was counected directly Into the delay line at a point separated from counter 2 by $0.4 \mu$ seconds. When a $1+2-3$ colnctdence occurred a 541 Tektronix oscilloscope was triggered and the signals from counters 1 and 2 displayed. The oscilloscopo sweep speed was $.2 \mu$ eec per $\mathrm{cm}$. The Inversion of one pulse greatiy facilitated the Identification of pulses due to $1+2$ colnctdences from random background. The pulse holght discriminator wa used to prevent low energy particles, malnly electrons, from triggering the osc11108cope.

Counter 2 was callbrated using pulse helght distributions for thorlum $c^{\prime \prime}$ and sodium 22 gama raye. These sources 
produce Compton edges at 2.39 and $1.07 \mathrm{MeV}$ respectively. Counter 1 was callbrated using indium 114 internal conversion electrons. The counter pulses were anplified, lengthened, and the pulse helght distribution was displayed on a 100 channel kicksorter.

The pulse helght measured using the klcksorter was related to the observed deflection on the oscilloscope trace. A thorlum source was placed between counters 1 and 2 and a slow colncidence counting rate was obtained (a few counts a minute) by setting the blocking osclilator trigger level to trigger only on the largest colncldence pulses. The kicksorter was gated to accept pulses when the blocking osclilator was triggered. The oscilloscope traces were photographed and the klcksorter channel in whtch each count occurred was recorded. A dozen pulses sufficed to obtain the correlation between the pulse height displayed on tho oscilloscopo and on the kicksorter. The above procedure was used each time the counters were callbrated so that the callbration did not depend on the long terre stability of the distributed amplifiers.

The performance of the proton telescopo was tested using the $310 \mathrm{HeV}$ bremsitrahlung beam of the Glaggow 


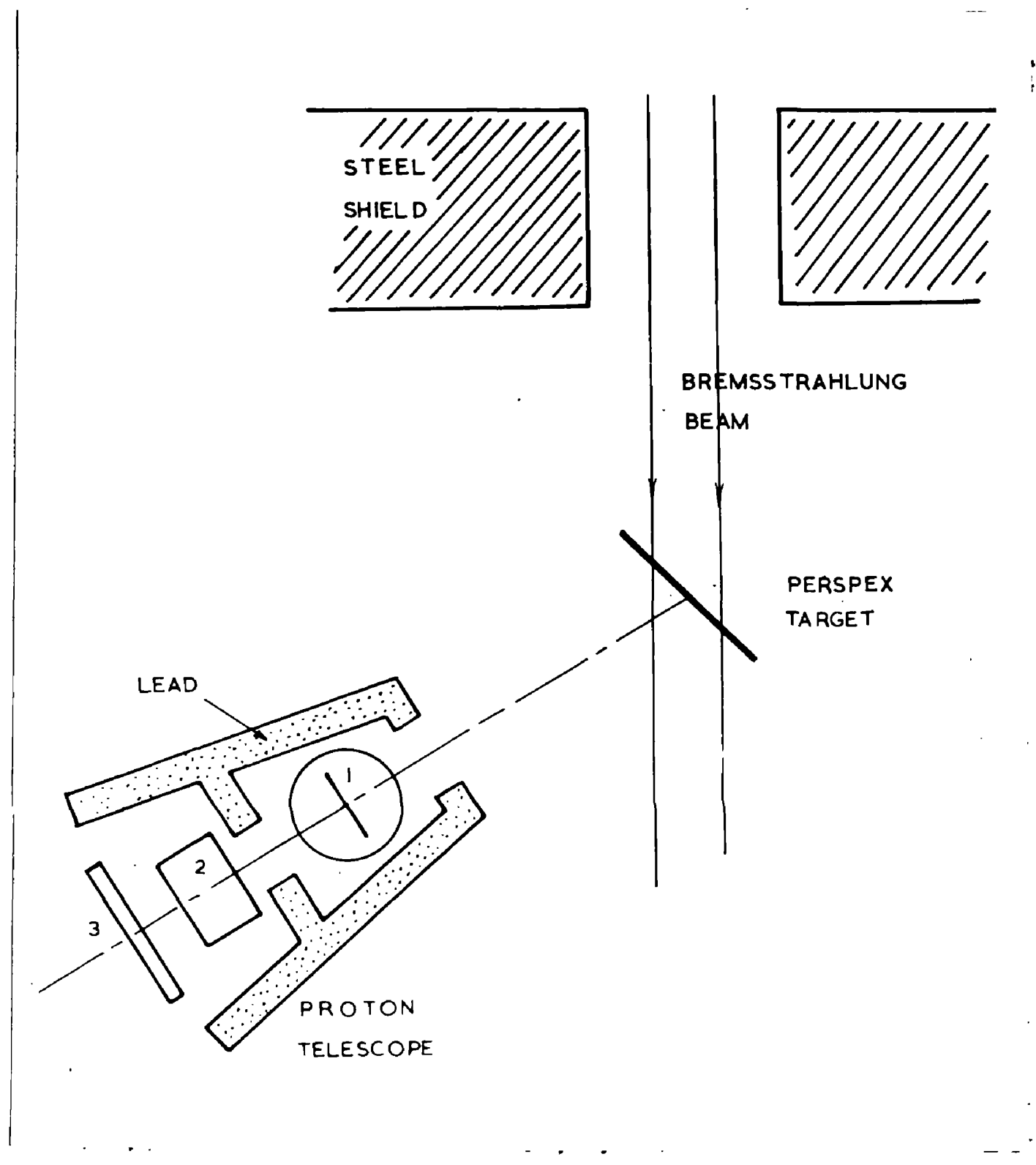

Figure 3.5. Plan of experimental arrangement used in proton telescope tests. 
electron synchrotron. The various properties of tho synchrotron and tho photon beam aro diecussed in Chapter IV. A $1 / 16$ inch perspex sheet was placed in the beam 10 metros from the synchrotron target. placing the perepex target in this position allowed the counter tests to be done at the samo time as the bear was being used for another experiment. A $1 \times 1$ inch thick eteel shield was positioned just in front of the targot to shleld the counters from the large flux of charged particlea produced at small angloa to the beam. The experimental arrangement is shown in figure 3.5. The counter telescope was positioned with 1 ts axis at 65 degrees to the incident bean direction. The lead shielding which was 1 Inch thick was provided to reduce the random background in the counters: The aperture of the counter telescope was defined by a $2 \frac{1}{8}$ inch hole in the lead block between counters 1 and 2 . For the goometry used the aperture was .015 steradians. The average bears intensity and width during this test were $3 \times 10^{8}$ equiralent quanta per minute and $400 \mu$ seconds respectively. $1+2-3$ colncidences were used to trigger the oscilloscope. The osc1lloscope traces were photographed w1th a camera having an $f 1.0$ lons ualng Ilford HPS film. The 

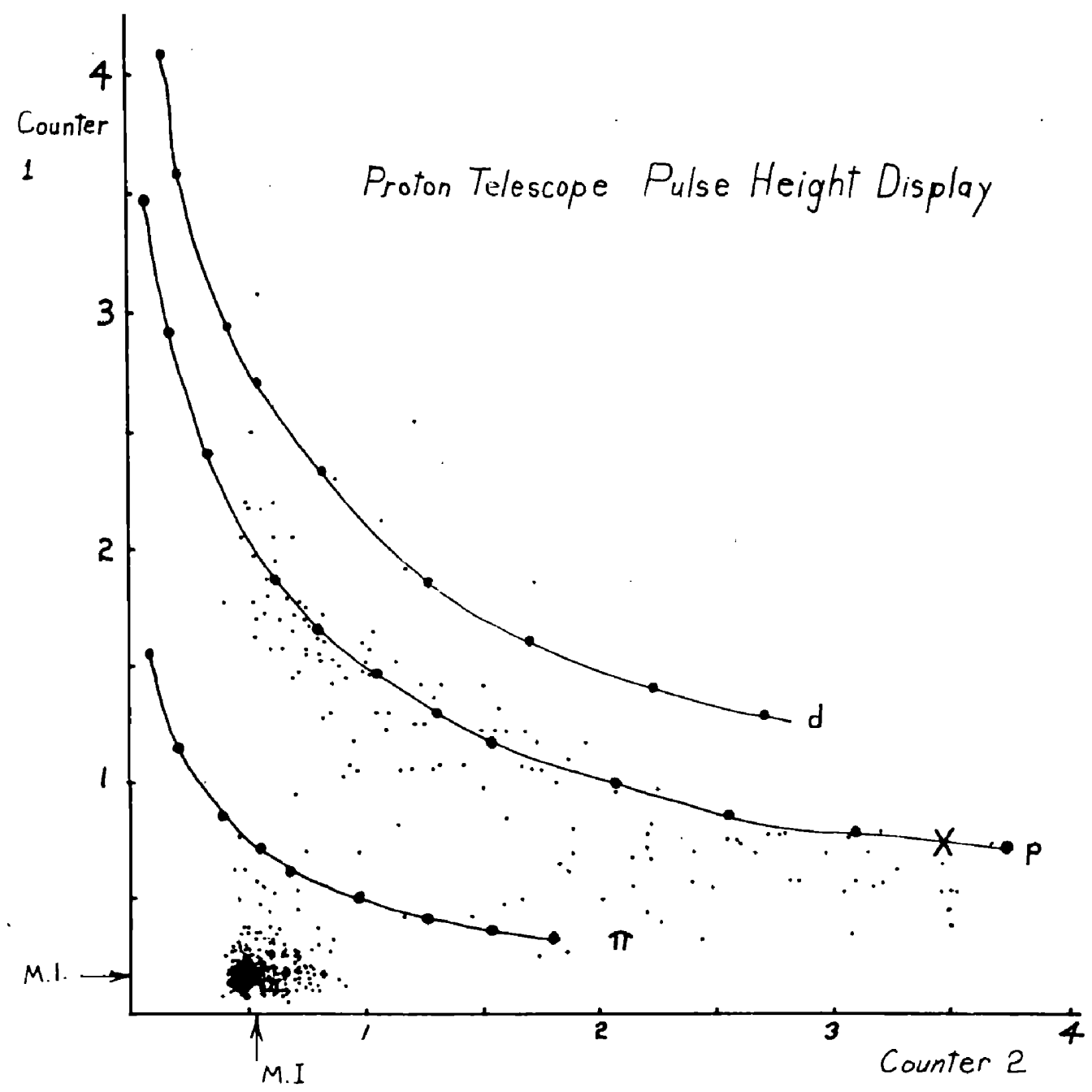

Figure 3.6. Plot of deflection in counter 1 against deflection in counter 2 showing the separation of pions, protons, and deuterons obtalned by the method of $\mathrm{dE} / \mathrm{d} \boldsymbol{x}$ and $\mathrm{E}$. 
recorded traces were projected in a microfilm reader and the position, separation, and helght of the two pulses messured. Events for which the separation or position of the pulses differed by more than 20 or 50 nanoseconds respectively from the mean wore rejected. The absence of any traces in whtch the pulage occurring in the reverse order satisfled tho postion and separation requirements indicated that the probability of random pulees simulating a true $1+2-3$ event io negliglbio. The measured deflection of the pulso from counter 1 was plotted agalnst that from 2 for all traces that satisfied the above conditions. The spots shown in figure 3.6 were obtalned in a 15 minute run. The curves were calculated using the counter calibration obtalned with the sourcso and the response of plastic scintillator for different chargod particles. A reasonable soparation between the various chareed particles is obtalned. The shape and position of the band of protons agrees well with the calculated curve. The $\mathrm{X}$ indicates the expected endpoint of the proton band at $81 \mathrm{MeV}$ corresponding to the range of counter 2 . The points lying between the proton and pion curves may be attributed to negative plons stopping in the socond scintillator. Nuclear 


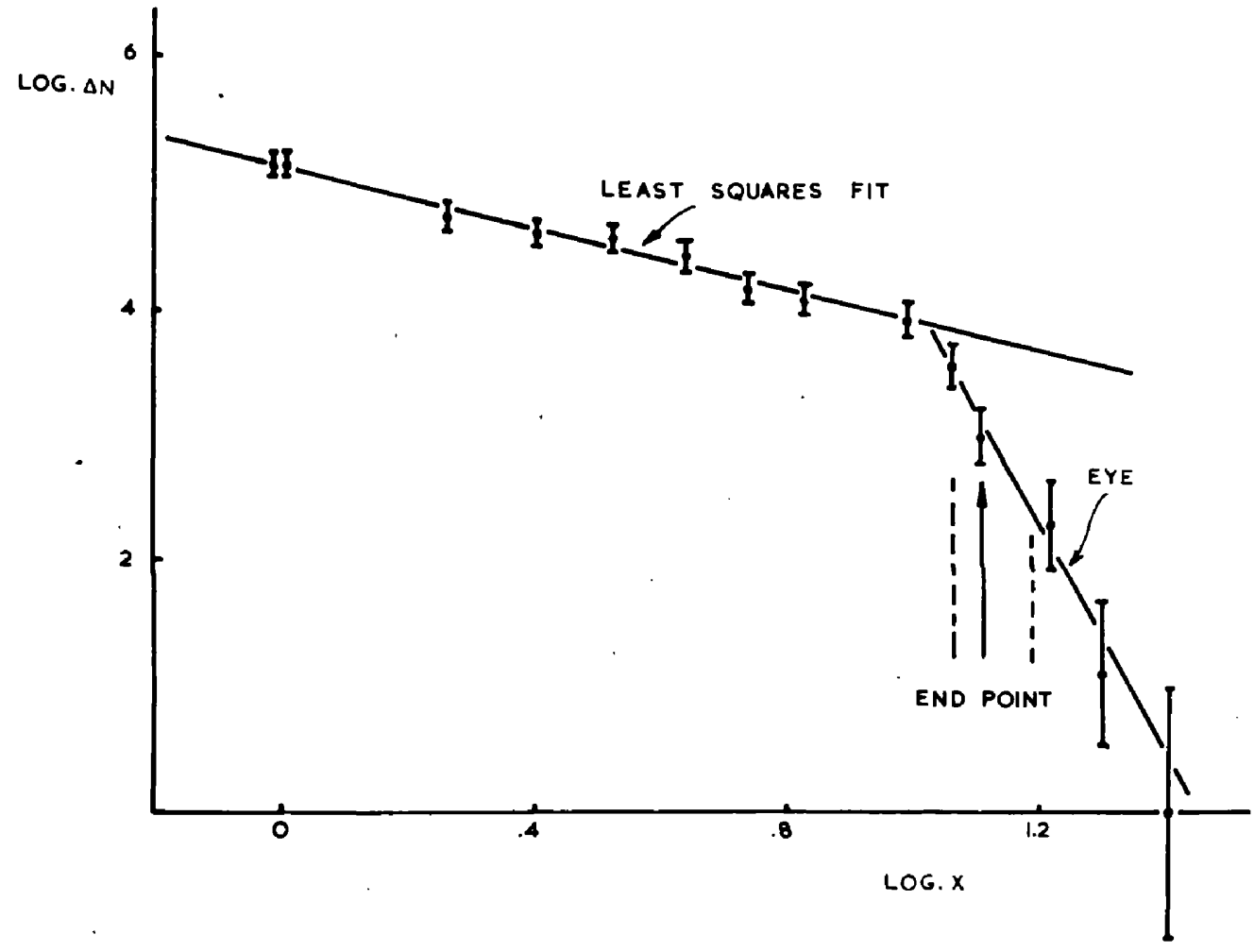

F1gure 3.7. Graph of $10 \mathrm{~g} \Delta \mathrm{N}$ ve $10 \mathrm{~g} X$ used to obtain end point calibration of the protion telescope. The arrow indicates the end point adopted and the dashed lines, the estimated limit of error. 
disintegration resulting from the capture of the negative plons produces a varying number of charged particles. Since this process happens very quickly tho pulse height due to tho charged nuclear particles w111 be added to that due to the pion kinetic energy. The arrows Indicate tho deflection expected for alniram lonizing particles traversing the scintillators.

The endpoint of the proton spectrum may bo used to obtain a calibration of tho counter telescopo at high energy. In the test run described above a total of 740 protons wero identified. The uncertainty in this number was of the order of \pm 20 due to the difficulty of separating protons from plons and deuterons. A eraph of log $\Delta N$ rs $10 \mathrm{~g} x$ was plotted where $\Delta N 18$ the number of spots in the proton band in an interval $\Delta x$ about the deflection $x$. Figure 3.7 shows a typical log $\Delta N$ ro. log x plot. A straight lino least squares fit was mado to the points for $\log x<1$. The stralght line through the points above $\log x=1$ was draw by oye. The ond point was defined as the deflection where the ordinate on the second Iine equalo $\log (\Delta N / 2)$ as defined by the first 11ne. The energy calibrations, deternined using sources and the end point of the proton spectrum, egreed to within 
5 percent.

The procedure outlined above may be justified by considering the known energy spectrum of protons produced In photodisintegration. Keck (1952) measured the energy spectrum of protons from carbon and cadmium produced by 300 MoV bremsstrahlune. He found that

$$
d \sigma / d E \propto E^{-\gamma}
$$

where $\mathrm{E}$ is the proton energy in MeV and $\gamma$ depends on the nucleus and the angle at which the protons are detected. For carbon he found $\gamma=1.7$ up to $130 \mathrm{HeV}$ at 67 degrees. Since a perspex targot (composition $\mathrm{C}_{5} \mathrm{H}_{8} \mathrm{O}_{2}$ ) was mistakenly used in the proton counter tests a direct comparison with Keck's measurement is not possible. However the proton spectrum from porspex may be expected to show an approximate exponential onergy depondence. The pulse helght in counter 218 proportional to the proton energy to a first approximation so that the $10 \mathrm{~g} \Delta \mathrm{s}$ may reasonably be expected to show a linear dependence on $10 \mathrm{~g} x$. To check this assumption the energy spectrum of protons from perspex was obtalned from the pulse height distribution using the average of the two calibrations. After correcting for energy $108 \mathrm{~s}$ in the target, the energy 
spectrum was best fitted by^ $\mathrm{E}^{-\gamma}$ dependence with $Y=1.5$. The test of the proton counter telescope indicated that the separation of protons from the other charged particles is adequate to allow tholr Identification by the method of simultaneous measurement of specific iontzation and energy. The close agreement between the energy callbrations done at 2.4 and $81 \mathrm{MeV}$ Indicates that the pulse height in counter 2 may be used to measure proton energles between 15 and $81 \mathrm{MoV}$. The ability to reglster protons over the ent1re energy range that is of Interest is very Important in an experiment where low counting rates are expocted.

(c) The Plon Telescope

The method of stmultaneous measurement of spectflc Ionization and energy is unsultable for the detection of negative plons. The difficulty due to production of charged particles in negative pion capture by nuclel is arolded when specific lonization and range are used to identify pions. The energy lost by a charged particle traversing a counter which is thin with respect to the particle range may deviate substantially from the most probable energy 10ss. In particular largo deviations 


\section{$-63-$}

towards higher enerey $108 \mathrm{~s}$ are observed. The distribution of energy loss has been described by Landau (1944) (see also Cranshaw, 1952). The loss in resolution in the measurement of speciflc fonlzation due to this effect may bo largely avolded by measuring the specific Ionization in two or more counters. The gain In tho counters 15 adjusted so that the most probablo pulse helghts are equal and the smallest pulse selected. The counter telescope described below makes use of this nethod.

A scintillation counter telescope (herafter called the pion telescope) consisting of four counter was used to detect plons by the specifio lonization and range method. Plastic scintillator NE 101 was used in counters 1 and 2, and NE 102 in counters 3 and 4. The ocintiliators 1.2, 3, and 4 were 3, 3, $25 / 8$, and 5 inches $1 \mathrm{n}$ diameter and $\frac{3}{4}, \frac{1}{2}, \frac{1}{4}$ and $\frac{1}{2}$ Inch thick respectively. The aperture of the counter telescope was deflned by counter 3. Particles which atopped in counter 3 produced a $1+2+3-4$ colncidence - anticoincidence in a Boll type colncidence circuit having a resolving time of 20 nanoseconds. This circuit has been described by Rutherglen and Valker (Rutherglen, 1960, Walker, 1960). 
The pulse helght at the collector of counters 1 and 2 was measured using a display system described later. Absorbers were introduced into the counter teloscope (see f1G. 3.8). Absorber $A_{3}$ served to Increase the width of the particle range defined by the telescope. $A_{2}$ prevented charged particles produced by negative pion capture stars in counter 3 and $A_{3}$ from entering counter 2. $A_{1}$ was chosen so that the counter telescope detected plons in the required energy range. When $A_{1}, A_{2}$, and $A_{3}$ were 1, t. and 1 inch thick perspex sheets respectively, the telescope detected pions in the range 45.8 to 60.0 MeV and protons in the range 102 to $132 \mathrm{MeV}$. The effect of negative plon star particlea may be shown to be small. When $A_{2} 18 \frac{1}{2}$ inch thick only protons with energy $35 \mathrm{MeV}$ can enter counter 2. It 1s known that 10 percent of all negative pion captures in carbon produce protons of energy $30 \mathrm{MeV}$ (Ammiraju and Lederman, 1956). From a consideration of the counter telescope geometry it was estimated that less than one percent of the negative plons produced otar particles that onter counter 2. Counter 4 was placed as far behind counter 3 and $A_{3}$ as was consistent with efficient anticolncldence operation to reduce the number of particles from negative pion stars that enter counter 4. When th1s happens the event w111 not be reglotered. 


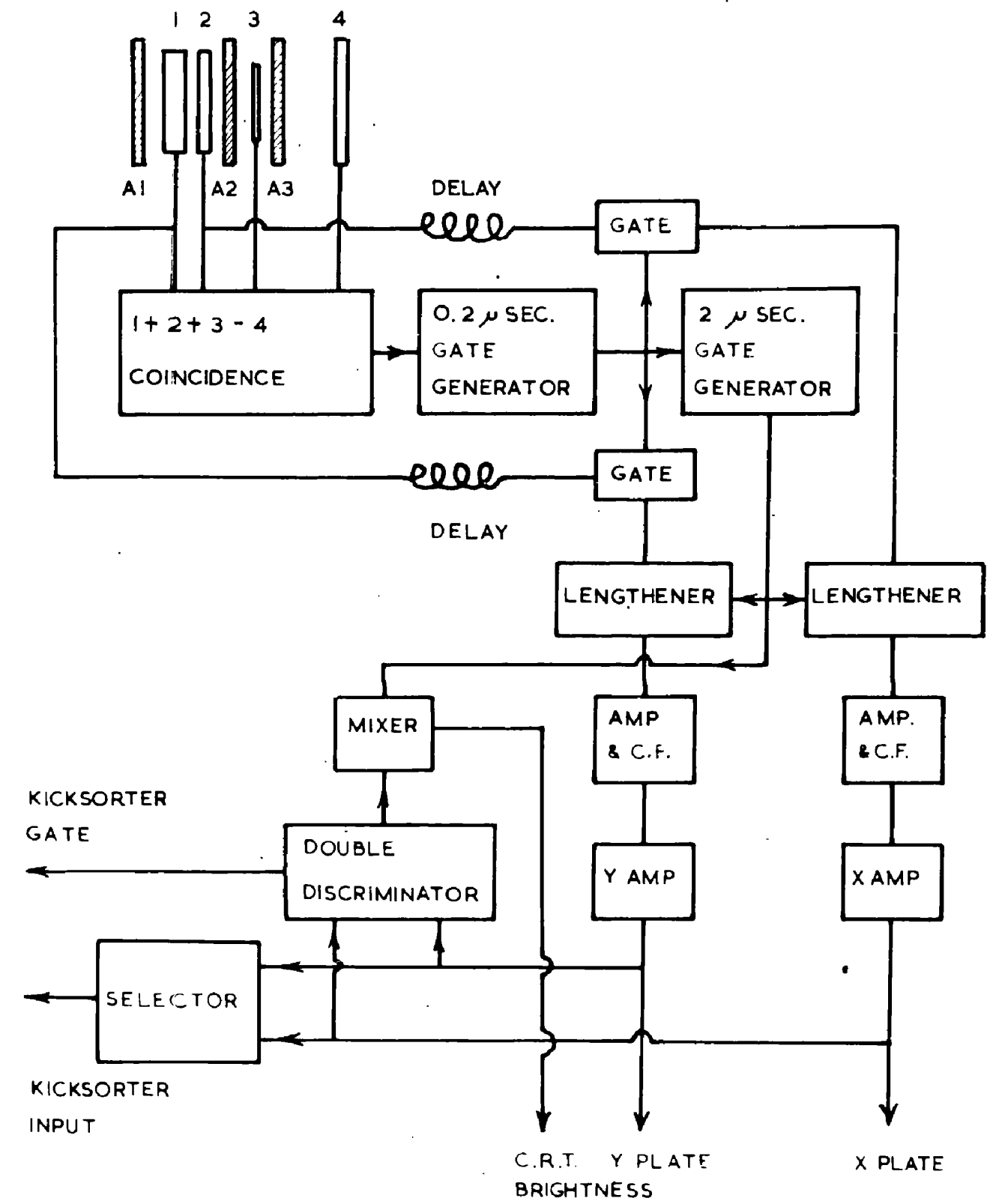

Figure 3.8. Block diagram of the clrcult used with the pion telescope. 
The pulees from the collector of counters 1 and 2 and a pulse olentrying a $1+2+3-4$ colncidence anticotncldenco were fed through 70 oba cables to the display system. A block diagrara of the display systera facilities used in this experiment is show in figuro 3.8. The complete display system has been described by Rutherglen and Walker (1960) and by Walker (1960). Tho coinoldence pulse trigzers a blocking oscillator trigger circult which produces a 20 volt pulso - $2 \mu$ seconds long. This pulse was ued to operate a linear gate whtch allowed the collector pulses fron counters 1 and 2 to pass through to tho lengthener circult. The lengthoned pulses are rectangular, $2 \mu$ seconds long and proportional in height to the input pulses. They are amplified by two paraphase amplifiers and fed to the $X$ and $X$ doflection plater of a cathode ray tube. A negative 40 volt pulse is simultaneously fed to the cathode of the C.R.T. This system produces a spot on the C.R.T. face which has $X$. and $Y$ deflections proportional to the puloe helght in counters 1 and 2. The doublo discriminator 1 s used to prevent the "bright up" occurring for $X$ or $X$ deflections less than a minimum deflection. This elininates a large number of spots due to low energy electrons. The 
Information is recorded by photographing the C.R.T. alsplay. The selector is a conventional diodo colncidence circult whlch was designed to give an output proportional In helght to the snalier of the two input pulses. Tho selector output was displayed on a 100 chennel klcksorter. The kicksorter was gated by the double discrininator to provent a large number of electrons from introducing large dead time losses. The klcksorter display was used as a continuous check that the systen was operating satisfactorily.

The porfomance of the pion telescope was tested using the 307 IfeV bremstrahlung beam of the Glasgow electron synchrotron. A $1 / 16$ inch perspex target was placed In the bean 6 metres from the synchrotron target. The pion telescope was 12 inches from the target. The telescope aperture subtended an angle of .019 steradians in this position. The beam passed through a hole in a steel screen which shielded the counters from charged particles produced by the beam in air. Signals from the counter telescope were fed to the display system located in the beam research room.

The E.H.T. supply voltages to tho countera were adjusted so that collector pulses produced by $2.6 \mathrm{HeV}$ 


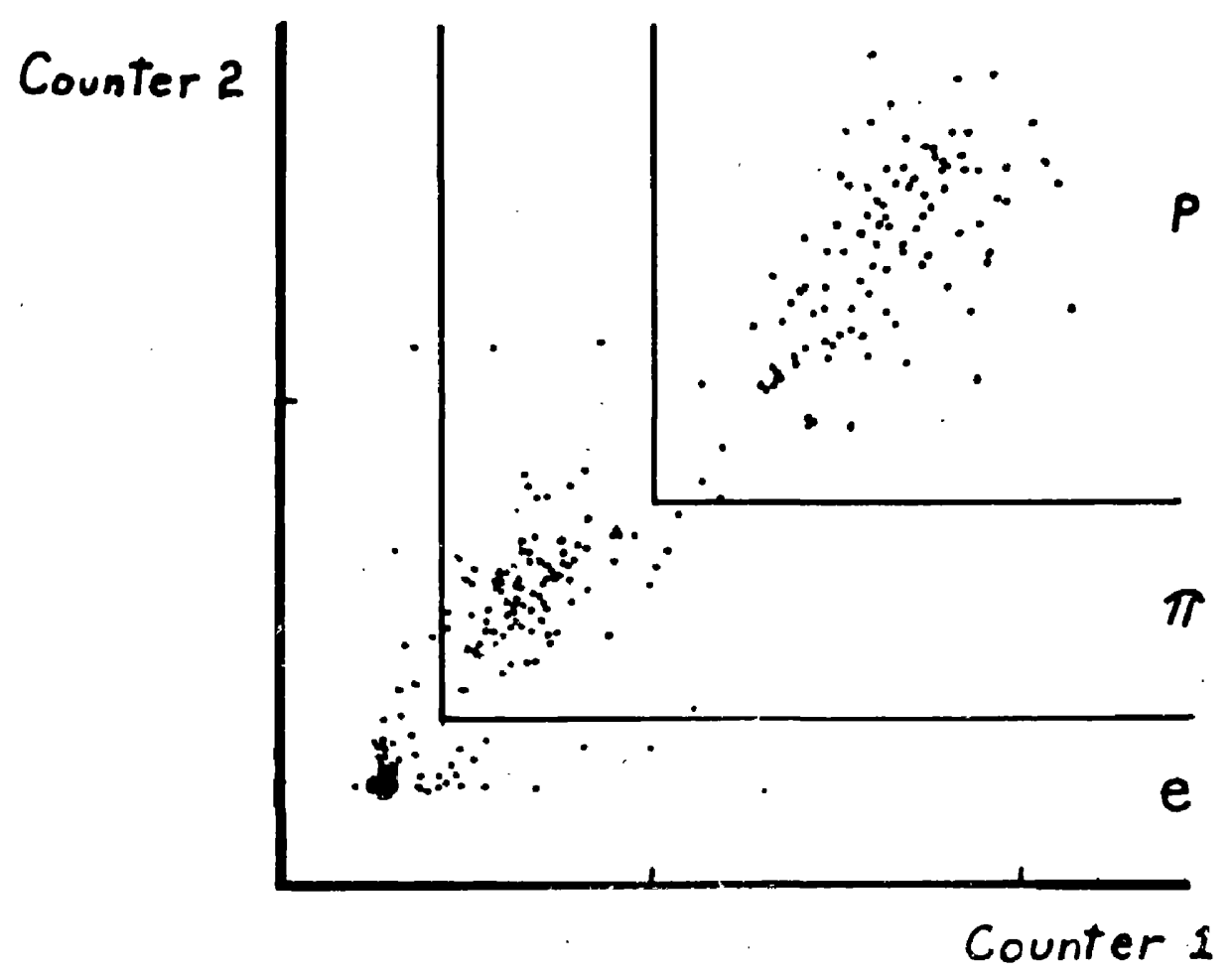

MESON TELESCOPE PULSE HEIGHT DISPLAY

Figure 3.9. Cathode ray tube display of pulse height from counters 1 and 2 of the pion telescope. 
thorium $c^{11}$ gamma rays fully cut off the limiter valves of the colncidence clrcult. The E.H.T. supplies to counters 1 and 2 were then set so that the pulse helght due to particles produced in tho perspex targot and stopping in counter 3 produced equal pulae helght at the $X$ and $Y$ deflection plates of the display unt cathode ray tube. The C.R.T. display of pulses from counters $I$ and 2 was photographed.

A typical spot picture 18 shown in figure 3.9 . Host of the spots lie close to a line blsecting the angle between the $X$ and $Y$ axes. Spots that appear well of this line are produced when the energy $108 \mathrm{~s}$ in one counter Is large with respect to the mean enorgy $108 \mathrm{~s}$ for tho particle. The spots are seen to 110 in 3 eroups corresponding to electrons, pions, and protons. A thorius source was placed behlnd counter 2 so that energetio beta particles could penetrate counter 2 and enter counter 1 . In the rooulting C.R.T. display the spots coincided with the part of the electron group in figure 3.9 closest to the origin. It was concluded that the spot group have been properly attributed to electrons, pions, and protons.

A typical pulse helght distribution obtalned using 


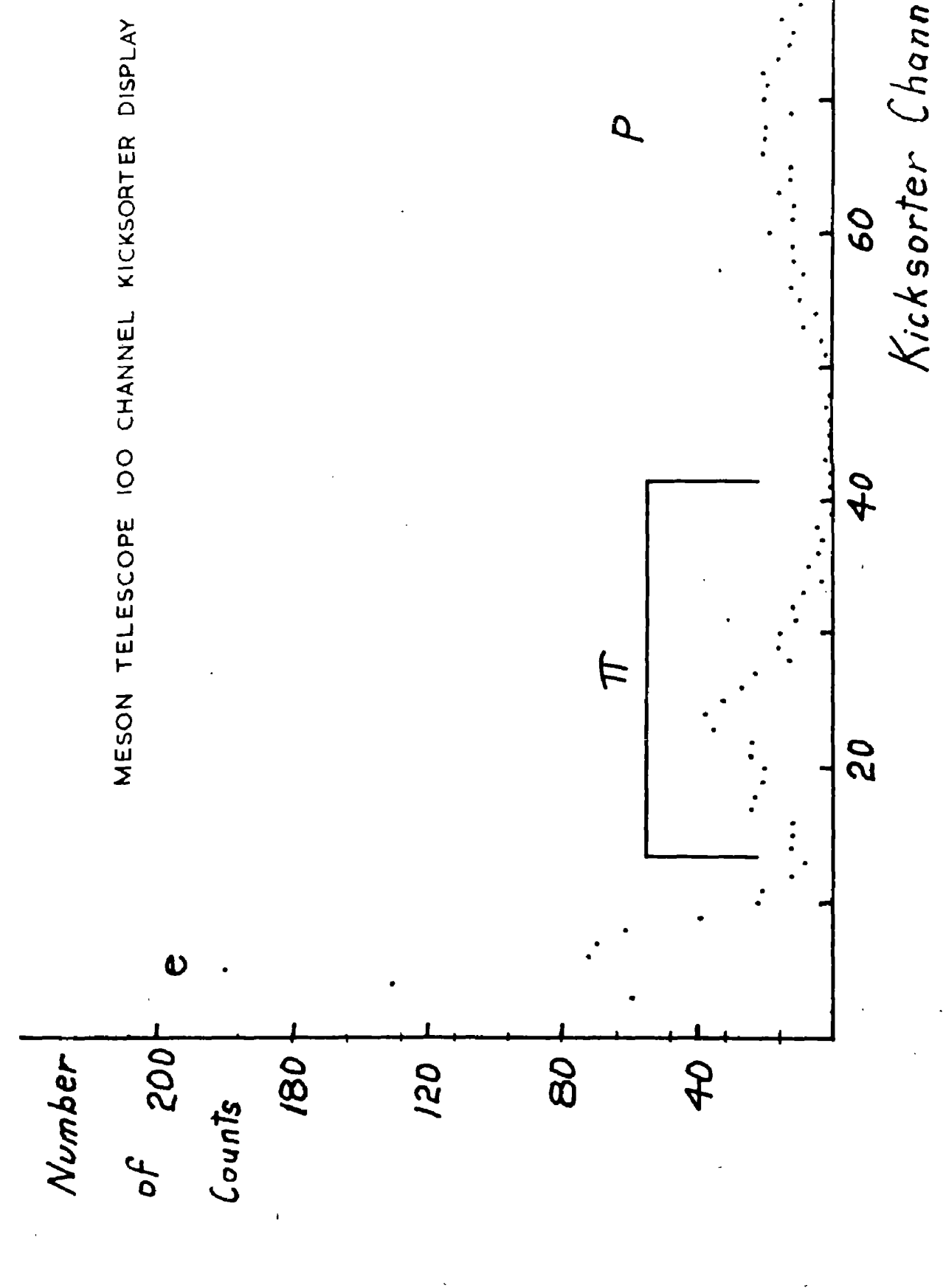

0
0
0
4
4
4 
the 100 channel kicksorter is shown in figure 3.10. A distinct separation into three groups ta observed, The C.R.T, and klcksorter displays were correlated using a pulse generator. The helght of pulses fed to the two slgnal inputs of the display unit wero varled Independentiy. The loc1 of C.R.T. deflections corresponting to a glven klcksorter channel was obtained. They were found to be "L" shaped. Typical loct are the lines separating the electron, jion, and proton reglons in f1gure 3.9. Tto brackst in figure 3.10 corrosponds to the pion region in Iigure 3.9. It was concluded that the three groups shown in the kicksorter display corresponded to electrons, plons, and protons as indicated. The work described above indlcated that the plon telescope was capable of detecting and identifying pions by the wethod of specific lonization and range..

(d) Detection of Protons in Colncldence with Negative Pions.

The simultaneous detection of negative pions and protons fion deuterium was accomplished using the counter telescopes described in the preceding sections. A block diagram of the complete electronic system 18 shown 


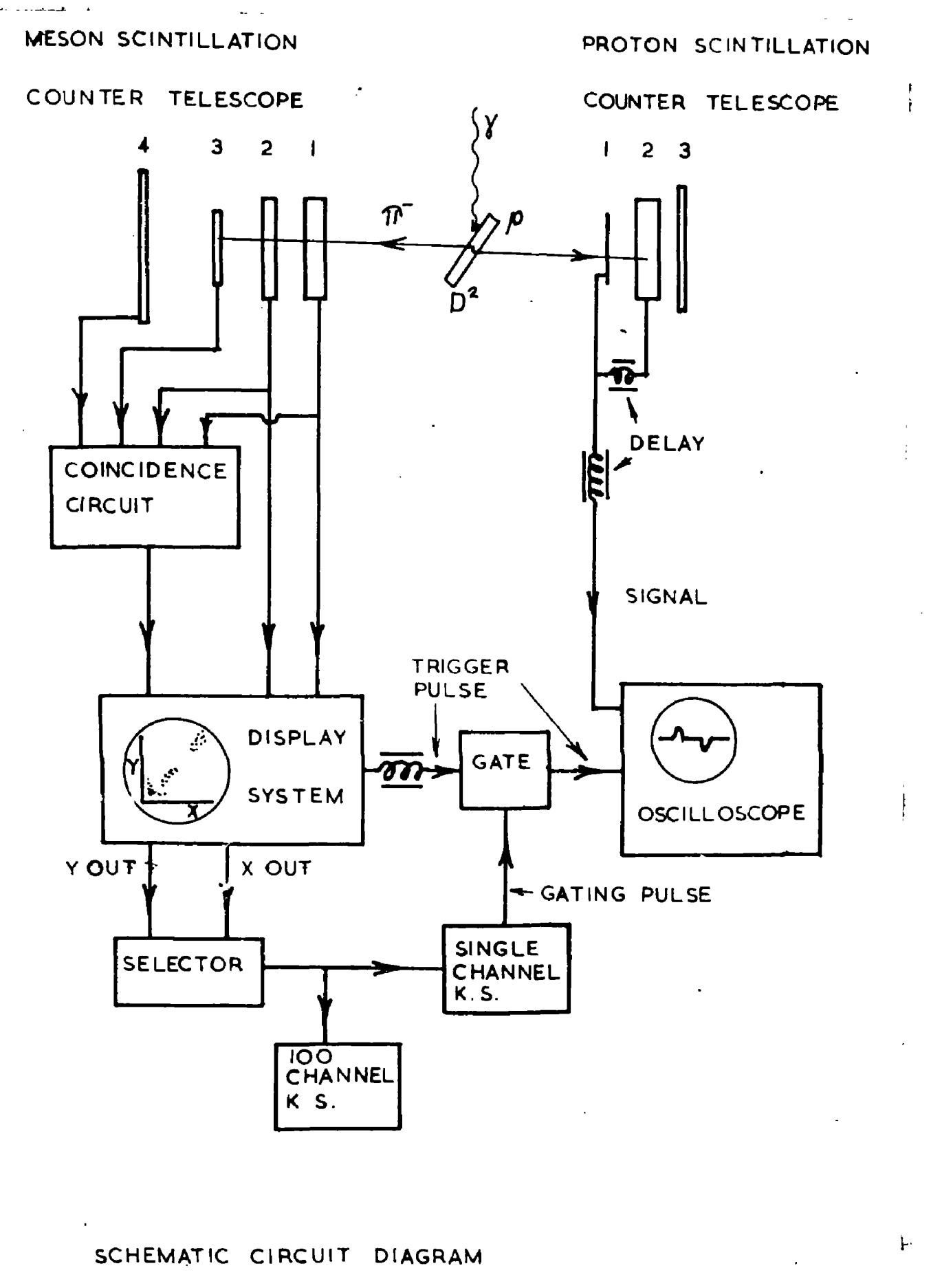
F1gure 3.11. Block diagram of c1rcult usad to detect protons in colneidence with negative plons from deuterium.


In figure 3.11. A $1+2+3-4$ coinctiencoonticolncidence is formed in the coincidence circuit. The pulse helghts from counters 1 and 2 are displayed on the cathode ray tube display system and a pulse proportional in height to the smaller of 1 or 21 s fed to the 100 channel kicksorter. A single channel kicksorter is set to select pulses in the pion group. When a pulse occurs in the pion group the single channel kicksorter opens the gato and a trigger pulse from tho display system blocking oscillator is fed to the trigger 1nput of a 541 Tektronix osc1110scope. The signal pulses from counters 1 and 2 of the proton telescope are displayed on the oscilloscope trace. The signal delays are adjusted so that the stenal pulses appear in the midde of the oscilloscope trace. The trigger pulse is delayed to allow the gate to open fully. No difficulty in distinguishing negative and positive plons arioes since protons w111 only be produced in colncidence with the former.

The operation of a coincldence counter telescope at small angles to the bremstrahlung beam is difficult. The large number of charged particles (malniy electrons) produced at forward angles produces high counting rates. 
Large doad time $1058 \theta$ and high random colncidence rates may then be encountered. The negative plon-proton detection system aroids these difficulties by demanding colncidences from the pion telescope only. It was sltuated at 90 degrees to the beam.

A preliminary test of the entire detection syotem was made uoling a heavy water target. An envelope was constructed by folding and welding 2 thou mylar sheet and was f1lled with 10 gas of heavy water. The heavy water target was suspended in the $307 \mathrm{MeV}$ bremsetrahlung beam of the Glasgow electron eynchrotron with the normal to the target at 45 degrees to the beam. The average thickness of heary water in the beam was $\frac{f}{4}$ inch. The pion telescope was placed at 90 degrees to the beam with counter 3. which definad the counter/aperture. 17 Incheo from the target. The proton telescope was placed at 30 degrees to the incldent beam. A 2 inch diameter hole In a $\frac{1}{2}$ Inch thlck lead block, placed between counters 1 and 2 and 16 inches from the target, defined the proton telescope aperture. Lead blocks 1 Inch thick were placed either side of the proton telescope to enield the counters from the general room background. The photon beam passed through a hole in a 6 inch thick steel screen 
which shlelded the counters from charged particles produced in the alr. The arrangement was Identical to that shown in figure 4.6 except for the target. The total photon flux was monltored using a Cornell thickwalled copper lonlzation chamber.

The oscilloscope ras triggered when a plon was detected in the pion telescope and the oscilloscope traces were photographed. A single channel kicksorter was set to accept pulses whlch were reglstered botween channels 11 and 45 of the 100 channel kicksorter. Tho upper end of the electron group was included (see figure 3.10). Thls was done to ensure that plons were not m1ssed. It was not expected that protons would be observed in colncidence with the extra eloctron triggers.

A total of 556 traces were recorded on film corresponding to a total beam flux of $8.0 \times 10^{10}$ equivalent quanta. The filn was analysed as described above. Seventeen traces were found whlch satisfiod tho criteria of pulso separation and position. The pulse holghts from counters 1 and 2 were measured for these traces and a diagram simllar to flguro 3.6 was plotted. Comparison with the calculated response curve for protons Indicated that 12 of the plotted points were consistent 
with the particles being protons. The remalning 5 points lay well below the proton curve. The background of random pulses that occurrad on these traces was not large and there was no amblguity in the 1dentification of the 17 colncidence particles.

The number of pion-proton coincidence events expected in this run was calculated. Freo nucleon kinematics wero assumed and the $-/+$ ratio and differential cross section for positive pion production at a proton were obtalned from Morarcelk' paper (1957). Th1s gave 70 negat1re plons. It was assumed that $1 / 5$ of the recoll protons would enter the proton telescopo (detalled calculations later showed $1 / 10$ to be the correct fraction) Indicating that 14 pion-proton colncidence events were expected. The detection system has been shown to operate satisfactorily under more serious background conditions than are expected when a liquid douterium target is used. An unambiguins identification of plon-proton colncidenco events was obtalned. The cathode ray tube and kicksorter displays provide a useful oinck that the system was functioning properly. The number of plon-proton coincldence events observed in this short run was of the order of magnitude expocted. The detoction systen way 
be expected to provide a satisfactory measurement of the energy distribution of protonsobserved in colncidence with negative pions. 


\section{CFAPTER IV}

Photoproduction of Negative Plons in Deuterium.

(a) The Synchrotron.

The scintillation counter toloscopos described in Chapter III were used to determine the angular distribution and energy spectrum of protons detected in colncidence with negative pions from deuterium. The bremsetrahlung beam of the Glasgow electron synchrotron (HcFarlane et al., 1955) provided the source of photons. In the Glasgow Eynchrotron the electrons are accelerated In a clrcular orbit $123 \mathrm{~cm}$ in radius. The gulde fiold 1s provided by $20 \mathrm{C}$ sect10:l magnets which are pulsod by discharging a condenser bank through the nagnet colls. Electrons are infected at 70 to $80 \mathrm{KoV}$ by a diode gun and are accelerated to relativistic velocity by betatron action. Synchrotron acceleration 1s obtained using two quarter wave resonators. The maximum energy of the clrculating electron beam depends on the guide field and energtes up to $340 \mathrm{HoV}$ are obtained by varying the voltage on the condenser bank. The recent addition of D.C. blas to the magnet allows the maximum energy to be extended to $440 \mathrm{MeV}$. Tho bremsstrahlung bear $1 \mathrm{~s}$ produced by allowing the naximum energy electrons to 
spiral in and strike a .06 inch tungaten w1ro. Tho photons produced in the synchrotron target pase into an adjacent experimental beam room. The nature of the photon bean and the experimental conditions that obtein necessarily play a large part in the design of experiments using the synchrotron beam.

The bremsetrahlung boam contalns photons of all energles between $E_{\max }$ and zero, whore $E_{\max }$ is the maximum energy of the circulating electron bean. Orer a considerable range of energy the number of photons 18 inversely proportional to thelr energy. There is a sharp cut off at $\mathrm{E}_{\max }{ }^{\circ}$ The energy spectrum has been calculated by Schiff (1946) for an Infinitely thin target. For targets arallable in practice, multiple scattering of the electrons 18 an important effect. In circular accelerators multiple traversals of the target also occurs. The bremsetrahlung spectrum of the collimated beam from the Glaggow eynchrotron operated at a maximum energy of $314 \mathrm{MeV}$ has been measured by Rutherglen and Halker (Walker, 1960) using a magnetic palr spectrometer. Th1s instrument used 30 degree deflection. The electron-positron palrs were detected In colncidence using scintillation counters. The results 


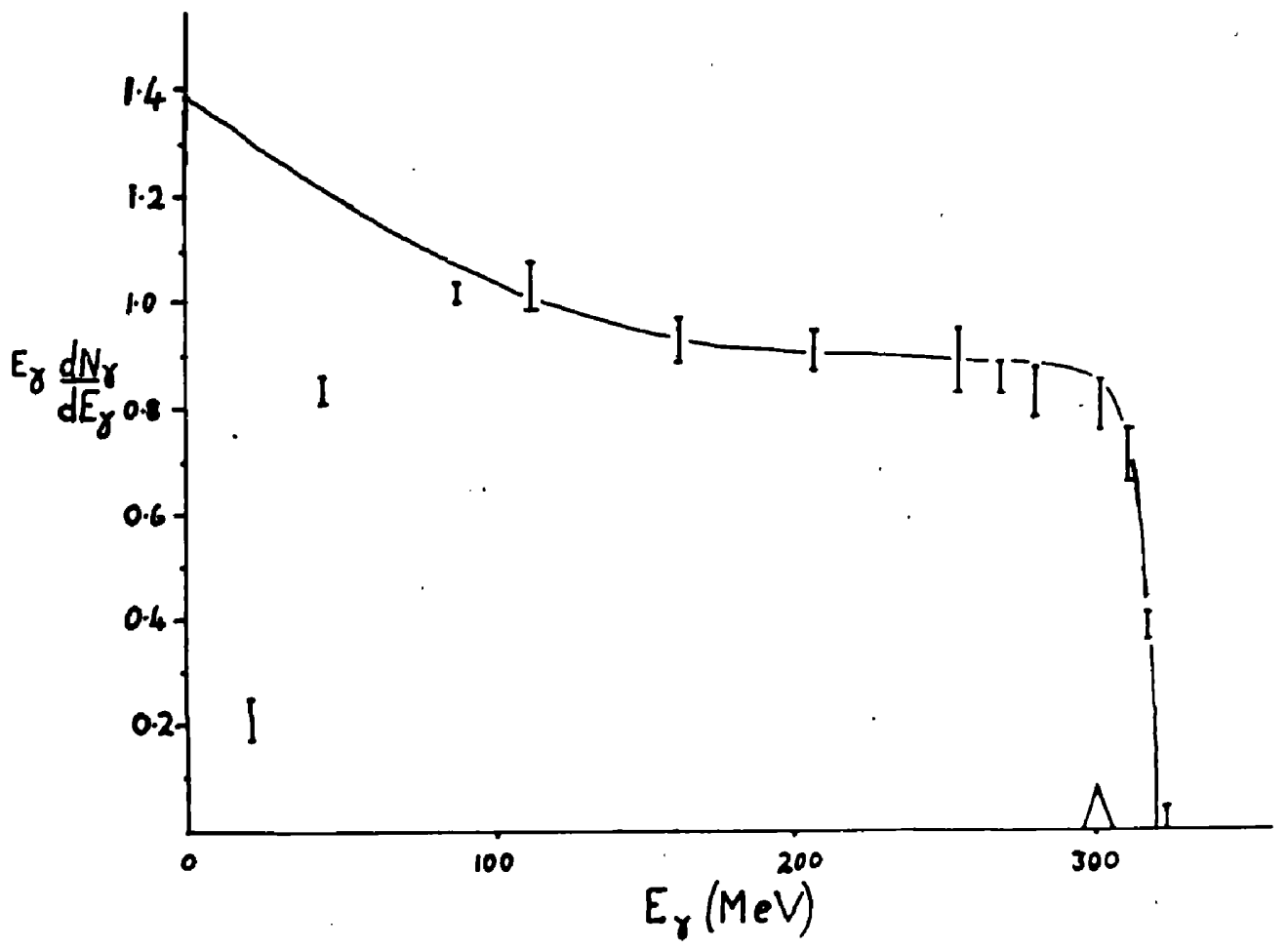

F1gure 4.1. Bremsetrahlung pectrum. The curvo Is tho Schiff thin target opectrum. The experimental points are due to Rutherglen and Walker (Walker 1960). 
of this measurement are shown in figure 4.1. The energy resolution 1 s shown at $300 \mathrm{MeV}$. The curve $1 \mathrm{~s}$ the Schiff thin target spectrum, and the experimental points are in good agreement with it above 100 HeV. At lower energy multiple scattering of electrons introduced large errore.

Photons produced in the bremsetrahlung process are emitted in the direction of the incident electron with an angular spread $\sim \mathrm{mo}^{2} / \mathrm{E}_{\max }$ where mo ${ }^{2}$ is the electron reat wess and $\mathrm{E}_{\max } 1 \mathrm{~s}$ the incident electron energy. For $300 \mathrm{MeV}$ electrons the angular spread $10^{1 / 10}$ degrees. The angular width of the beam is increased by multiplo scattering of the electrons in the target and by variation of the initial direction of the electrons due to multiple traversals of tho target. The intensity distribution of the bremsitrahlung beam from the Glasgow synchrotron 1 a bell shaped and has an angular full width at half maximum of .46 degreos (Atkinson et al.. 1957). The width of the ream 18 thus mainly determined by multiple scattering. To improve the geometry of the boam a collimation oystem was developed and is described by Atkinson et al. The primary collimator is a $\frac{1}{\text { inch }}$ hole in a 9 inch long lead cylinder placed 125 cm. from 

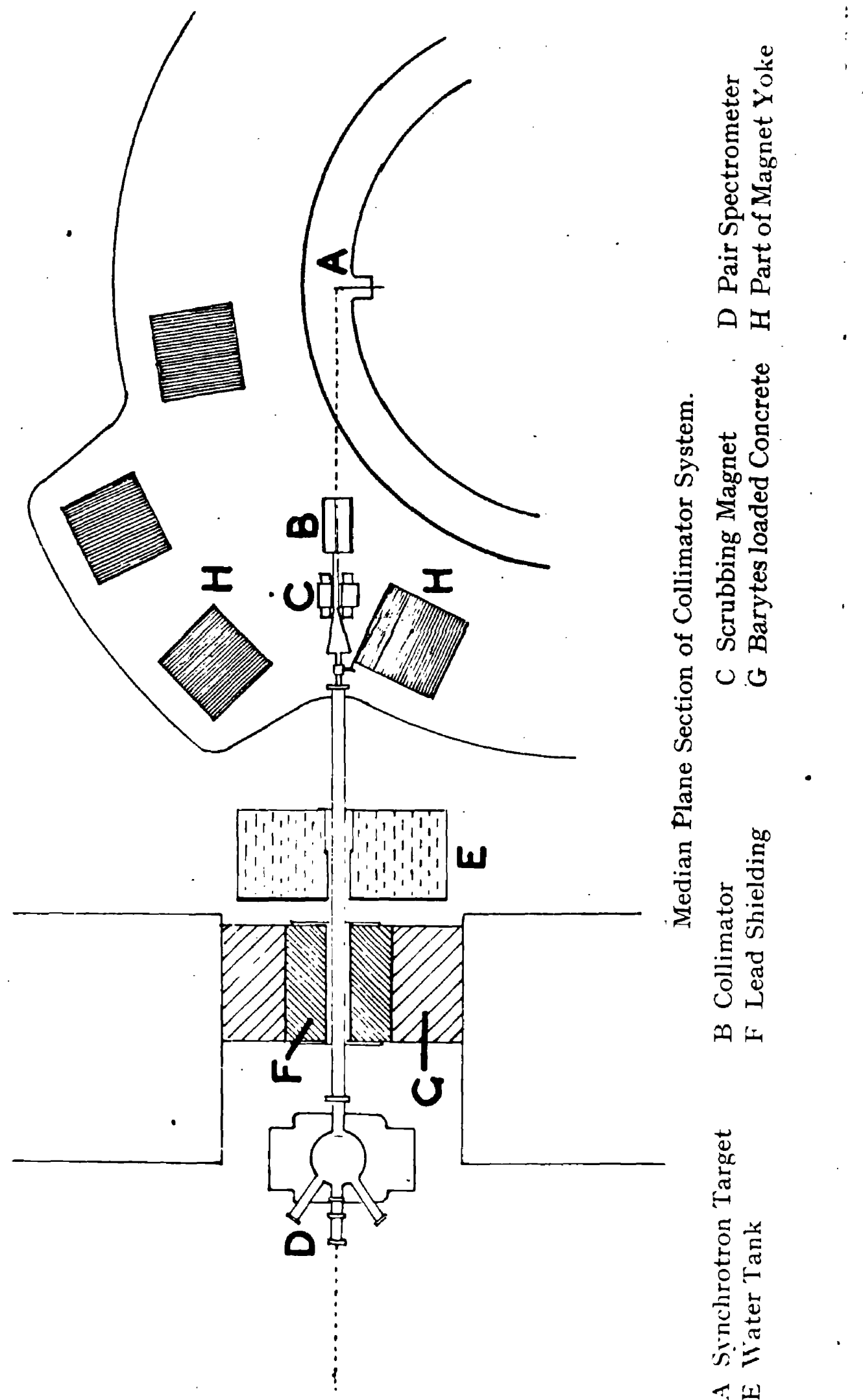

范

虹

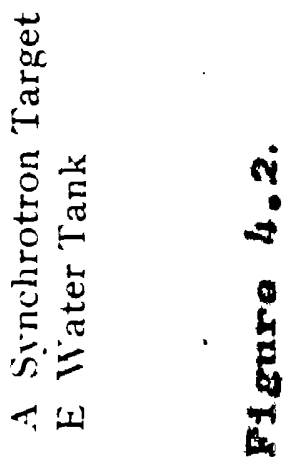


the synchrotron target. The median plane section of the coll1mation system 18 shown in f1gure 4.2. The contamination of chareed particles produced at the collimator is removod by a scrubber magnet, C. A secondary lead collimator serves to remove photons and electrons scattered in the primary collimator. The palr spectrometer magnet, $D$, may bo used as a secondary scrubber. The beam tubo is evacuated. The full width of the collimated beam 180.20 degrees. An X-ray photograph of the collimated beam at 6.5 metres from the target is shown to scale in f1gure 4.5.

A bremsstrahlung beam is usually described by 1 to maximum energy $\mathrm{I}_{\max }$ and the number of equivalent quanta, Q. per undt t1me where.

$$
Q=U / E_{\max }=\int_{0}^{E} E / E_{\max } N(E) d E
$$

where 0 is the total energy in the beam, and $N(E) d E$ is the number of photons between $E$ and $E+d E$ per unt t1me. When $Q, E_{\max }$ and the spectral shape are known $N(E)$ is defined.

The bremsitrahlung beam of the Glasgow synchrotron is monitored using a Cornell thick-walled copper Ionization chamber (Corson et a1., 1953). The thickness of the 
copper walls is chosen so that the charge developed 1s largely due to lonlzation by electrons of a ehower near the shower maximum. The number of electrons at the shower maximum is nearly proportional to the photon enerey. The total charge collected is then roughly proportional to the total enorgy in the bean. The eensitivity of the chamber is expressed in MeV per coulomb and 1 s dependent on $E_{\max }$. The Cornell chamber 1s open to the atmosphere and tho calfbration 1 s referred to normal temperature and preseure. Several of these chambers have boon calibrated at Cornell, the agreement between the different chambers is good. Tho Corne11 calibration 1s assumed for the Glasgow chamber. An Ionization chamber construoted from the quantameter design of Vilson (1957) is also avallable but was not used in the work described here.

The maximun energy of the Glasgow synchrotron 18 dotermined by measuring the maximum magnet current, the guide field being known as a function of magnet current. Measurement of $\mathrm{E}_{\max }$ made using thopalr spectrometer showed good agreement with $\mathrm{E}_{\max }$ obtalned from magnet current measurements (McFarlane, private communication). then the breasstrahlung beam is used in counter 
experiments it is desirable that the ratio of Instantaneous intensity to the average intensity be as low as possible. The random colnctdence rate, p110 up, and dead time losses depend on the Instantaneous intensity. The width of the bean from the Glasgow synchrotron may be extended to 2 milliseconds by sultable modulation of the radio frequency power supplied to the resonators. The beam shape is monttored by a thin scintillator placed directly in the beam.

\section{(b) The Target}

The thin Ilquid deuterium target used in this experiment was constructed by D. M1ler and has been described by Bellamy et al. (1960). A section through the cryostat is shown in 1gure 4.3. The target chamber is in good thermal contact with a l litre reservolr contalning liquid hydrogen refrlgerant at atmospherio pressure. The target and 11quid hydrogen reservolr are surrounded by a radiation shleld at liquid nitrogen temperature $\left(77^{\circ} \mathrm{K}\right)$. The vacuum in the cryostat was malntained at less than $10^{-6}$ m. He by an oll diffusion pump.

The target chamber is shown in Iigure 4.4. The 


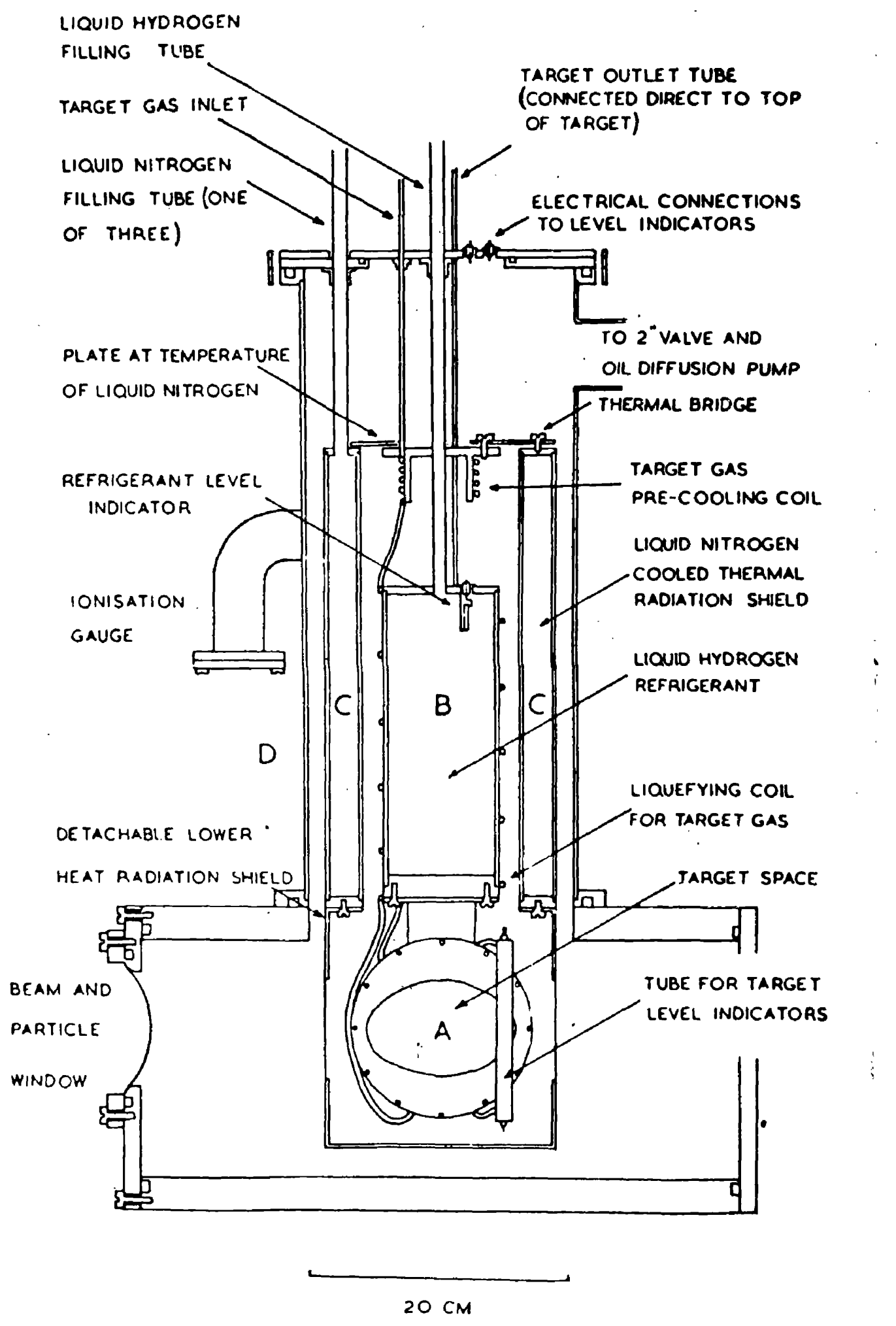

Figure 4.3 Vertical section through cryostat. 


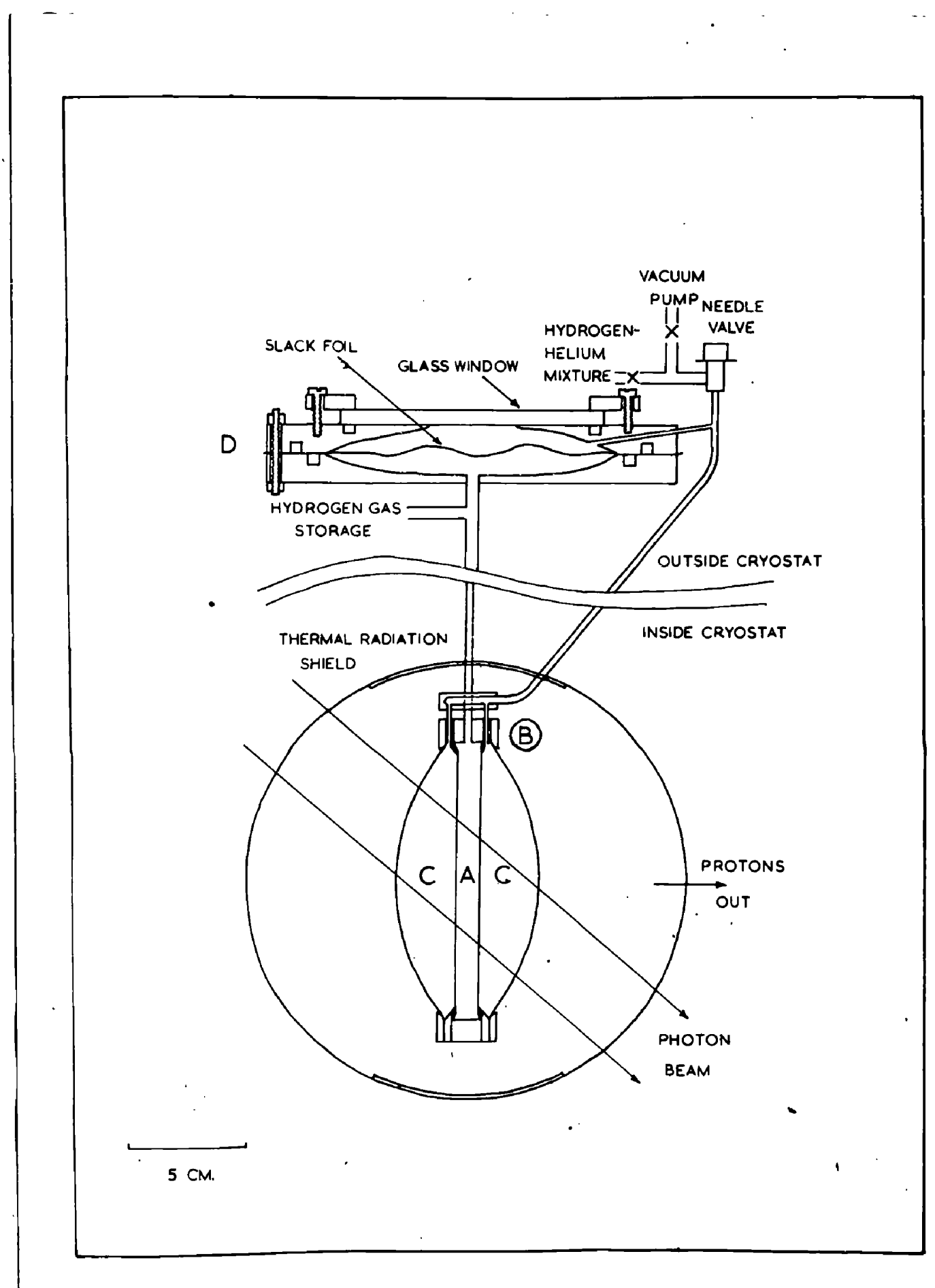

Pigure 4.4. Liquid targot.
A Ilquid douterium
C hydrogen gas
B level Indicator
D prossure compensating device


thin target walls are .001 Inch mylar. The contral section. $A$, contains the liquid deuterium: The outer sections, C, are connected together and filled with hydrogen gas. A zero pressuro differenco 10 maintained across the Inner target walls so that the liquid target is flat and of uniform thickness. Slow changes in deutertum vapour pressure are compensated for by the slack fotl device D. The target thickness was measured at room temperature using a microscopo and found to be $1 \pm .003 \mathrm{~cm}$. Heslstance type level indlcators are used to show whether the target was empty or full.

The thicliness of material traversed by the incident photon beam and by particles emitted from the target was sma11. The total target wall thickness was .004 1nches. Ports cut in the radiation sileld wero covered with .0002 Inch alumintum fo1l. Mylar windows .004 inch thick were provided in the outer vacuum jacket. Two of these windows were largo $\left(4 \frac{1}{2} \times 16\right.$ inches) to allow the dotection of emitted particles over a largo angular range.

A wooden ring was attached to the top of tho roctangular part of the outer vacuum jacket (see figure 4.3). The centre of this ring was located above the centre of the target to within 2 my a complicated 


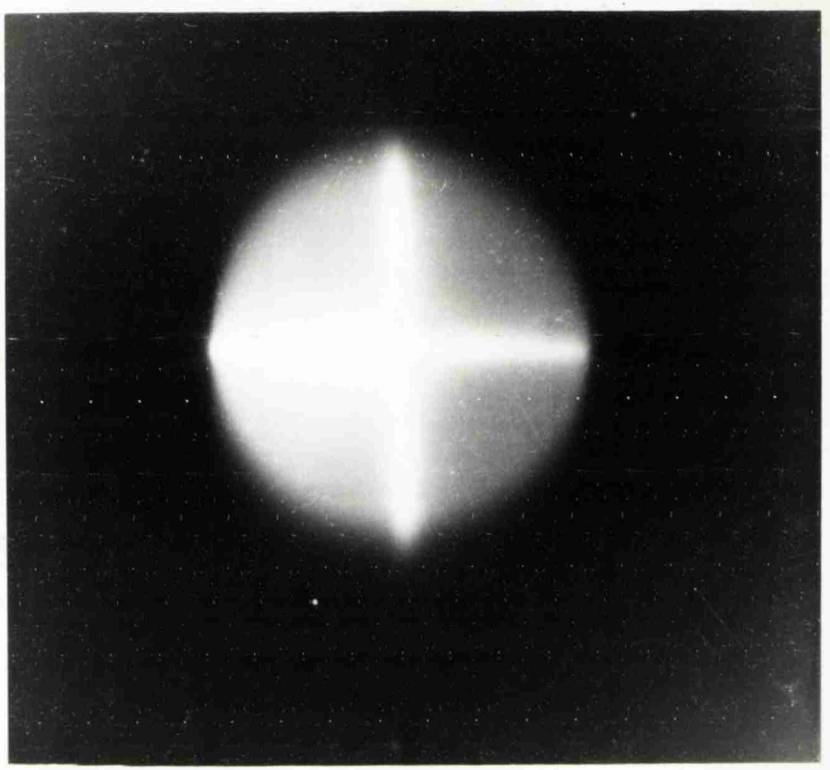

Figure 4.5. X-ray photograph of bremsstrahlung beam showing one of the crosses used to line up the target. 
procedure using, marks on the target viewed through small holes in the radiation shield, and plumb lines suspended from the wooden ring. Since it was necessary to move the proton telescope to different angles durlng the experinental run a system was devised to ald the lining up of this telescope. A bracket attached to the proton telescope trolley fitted loosely around the cyllndrical part of the target vacuum jacket. It was located by 4 scrows so that the axis of the counter telescope passed through, and was constrained to rotate about the centre of the target.

The douterium used to f1ll the target was produced by electrolysis of heary water and was stored in a 160 litre tank at $80 \mathrm{~cm} . \mathrm{Hg}$.

(c) Exper1mental Procedure.

The deuterium target was placed in the $307 \mathrm{MeV}$ bremsstrahlune beam 6 metres from the synohrotron target with the normal to the target surfaces at 40 degrees to the beam. The target was located in the beam using crosses suspended from the wooden ring. The alignment was checked by obtatning $x$-ray photographs. The final alignment is shown in figure 4.5 


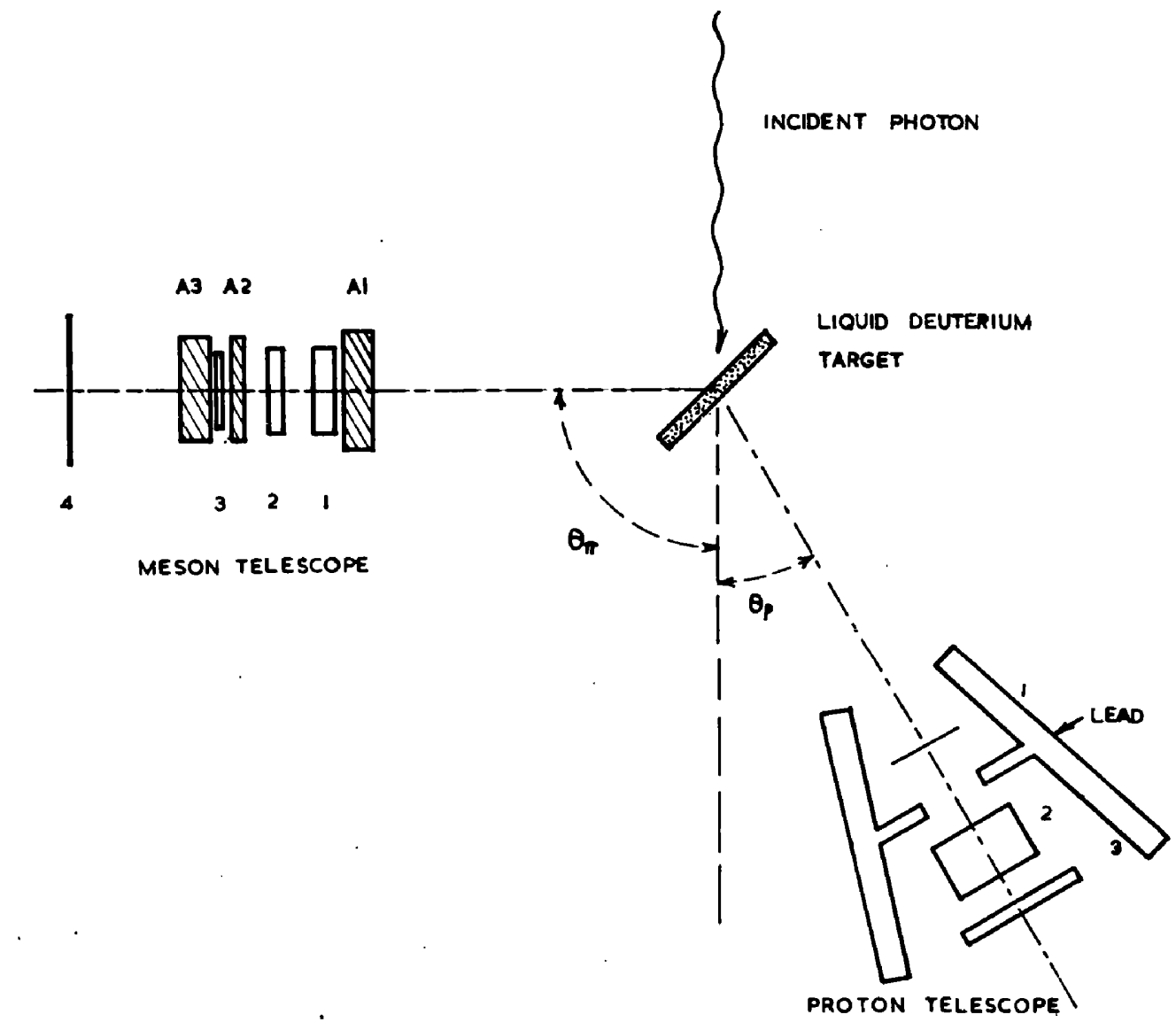

SCHEMATIC PLAN OF EXPERIMENTAL ARRANGEMENT

Fieure 4.6. 
The bean passed through vacuum botwoon the primary collimetor and the target except for 1 inch of air between the beam tube and the target vacuum. The experimental arrangement is shown in figure 4.6. A general view of the apparatus in the beam room is shown in figure 4.7 . The boun tube passed through a 6 inch steel screen placed between the target and pair spectrometer. This provlded extra shlelding agalnst charged particles swept out of the boam by the pair spectrometer magnet. The scrubber and pair spectrometer magnets were always on whon data was being rocorded.

The pion telescope was placed with 1 ts axis at $90 \pm 1$ degreos to the Incident beam airection with conter 3, which defined the telescope eperature $17 \pm .2$ inches from the target. In this position it subtended an angle of $.0187 \pm .0005$ steradians at the centre of the target. The angular accoptance was $\$ 3.7$ degrees. The pion telescope was operated in a $1+2+3-4$ coincidenceanticolncidence sequence and dotected plons incident on 1t. between 45.8 and $60.0 \mathrm{MeV}$.

The energy distribution of protons detected in colncldence with the plons was obtalned. The proton telescope was positioned with its axis at $30 \pm 2$ degrees 


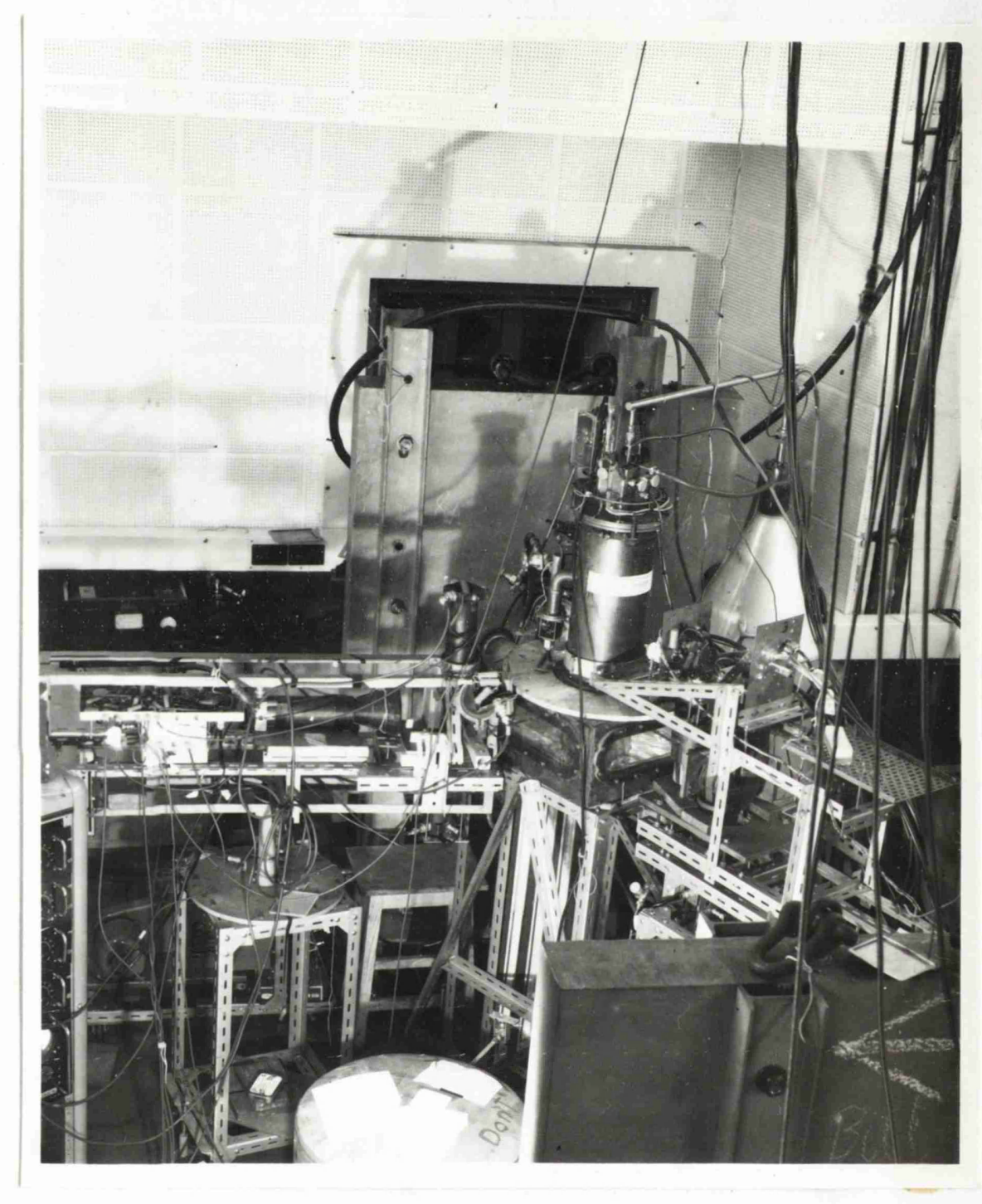

Figure 4.7. General view of apparatus in the beam room showing the target and the two counter telescopes. 
to the incldent beam. The telescope aperture was defined by a 2 inch diameter hole in a half inch thick lead block placed between counters 1 and 2 . The central plane of this block was $16.5 \pm .2^{\prime \prime}$ from the centre of the target ard defined a solid angle of .0113 \pm .0003 steradians at that point. The angular acceptance of the proton telescope was $\$ 3.5$ degrees. Lead blocks 1 inch thick were placed elther side of the proton telescope to shield it from charged particles produced by the beam in the target window and in the alr near the counters. Pulees from counters 1 and 2 were displayed on an oscilloscope whenever a plon was detected. The oscilloscope traces were photographed.

The angular diatribution of the protons detected in coincidence with the negative pions was measured. Protons were detected at 4 angles, 22, 30, 38, and 46 degrees measured from the incident beam direction. The uncertainty in the position of the proton telescope was \pm 1 degree in each case.

The experimental run lasted 33 days in which time a total flux of $5 \times 10^{12}$ equivalent quanta passed through the target. The empty target background was measured at the beginning and end of the experimental run. Tho 
proton telescope $81 \mathrm{HeV}$ endpoint callbration was obtained at the beginning and end of the run using protons produced at 65 degrees in a perspex target, and once during the run using protong produced in the deuterium target. The proton telescope was callbrated at the beginning and end of each day's run using thortum $c^{11}$ $2.62 \mathrm{MeV}$, and sodium $221.28 \mathrm{HeV}$ gamma rays, and $160 \mathrm{KeV}$ internal conversion electrons from Indium 114. At least one hour was allowed after switching on for the electronics to become stable before calibration.

The performance of the pion detection eysten was checked several times each day by photographing the cathode ray tube spot display (seo figure 3.9). The 100 channel kicksorter diaplay (figure 3.10) was used as a continuous monitor of the pion detection system. The operation of the single channel klcksorter and the oscllloscope trigger system was monttored by checking that the oscilloscope was triggered whenever an event was recorded in the pion group on the 100 channel k1cksorter d1splay. The E.H.T, voltages and the varlous trigger levels were checked each day before data was recorded. The operation of the amplifierintegrator system which was used to record the total 


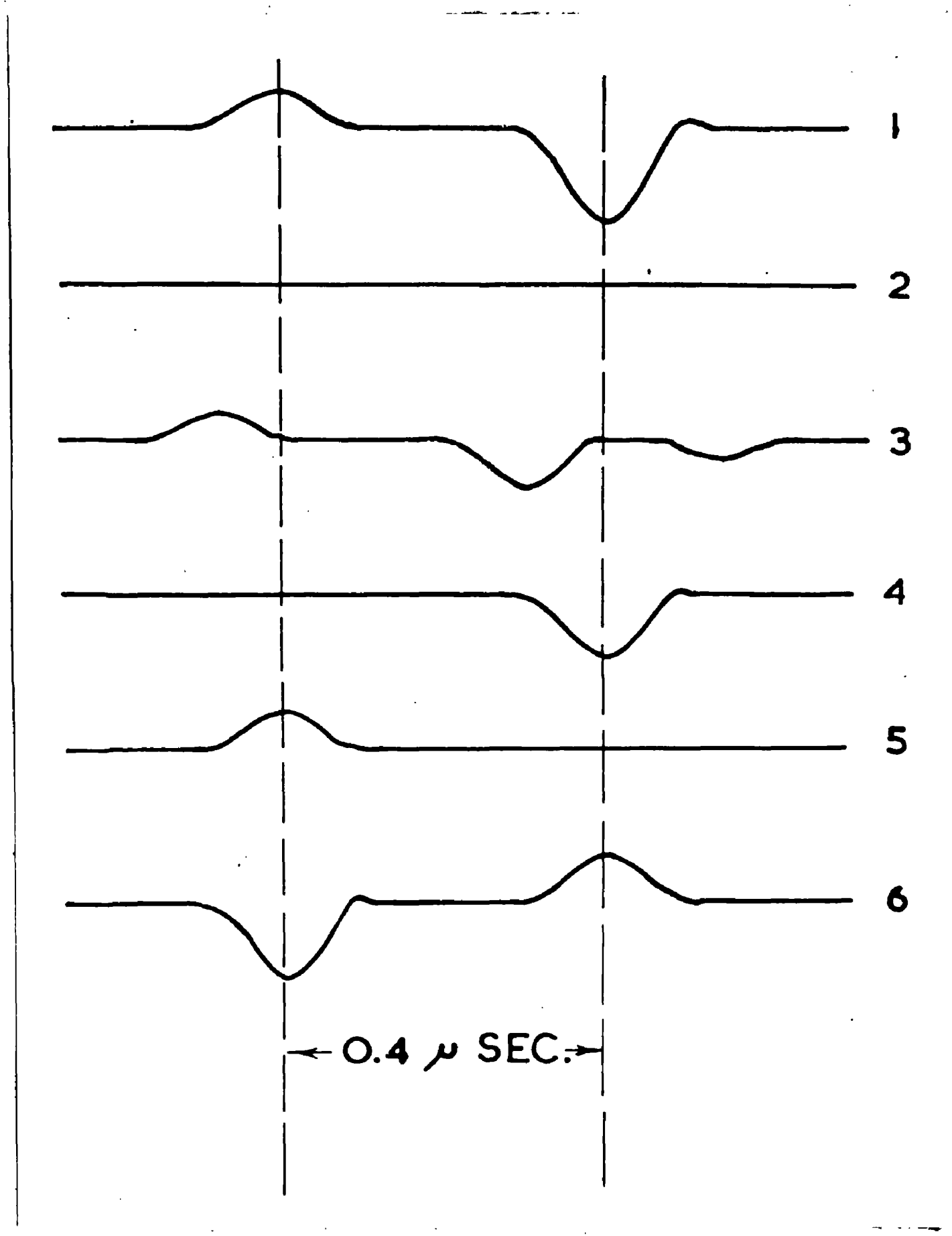

Figure 4.8. Typical oscilloscope traces. The dashed lines indicate the delay between counters 1 and 2 . 
charge collected by the beam nontor was cheched several tizes onch day. Tho varlous checks gave a good Indication of the operation of the detection systex end allowod fault to be found quickiy.

Data recorded when tho operation of the dotoction system of the boaxi monltor wore suspoct were rejected. The remaining filn was analysed to select colncident protons. Tho posttion and separation of pulsos fron counters 1 and 2 woro used to solect colncident particlea. The traces show in ricure 4.8 wore selected to 1liustrate tho various typos of tracoo that vere found. Positive defloctions are producod by counter 1, nogativo ones by oounter 2. The first trace is due to a colncident particle entering the telescope. The majortty of the tracos vere 11ke 2 in which no particlos soro detected In elther counter: In 3 the trace produced by a random particle entoring tho tolescope is shown. Tho last pulso 10 not assoclated vith a pulso fron counter 1 and may be attributed to a photon or to a charced particlo that alssed countor 1. Four 11lustrates tho traco oxpected when a colncident noutron produces a knock on proton in counter 2. Since the plon telescopo does not diet1ngulsh botween nogetive and positivo plons, thero is 
a high probability of traces like 4 occurring. The counter geometry provents particles produced in the target from entering counter 2 directly without traversing counter 1 . The bachground runs indleated that traces of this type were due to particles from tho target. All traces like 4 were attributed to neutrons produced in reaction (1.3). Colncident charged particles which traverse counter 1 only produce traces ilke 5. The probablitty of random background pulses producing traces 11ke 1 and 6 is expected to bo equal. Since no traces like 6 were found 1t has been assumed that all traces like ( $(1)$ were due to colncident particles. The helght of pulses from counters 1 and 2 were reasured for all colncldent traces. Tho pulse height from counter 1 was plotted against that from 2 as shown In figure 4.9. The specific lontzation and onergy selection of the proton telescope was used to eliminate events not due to protons. In all 17,000 traces were scanned and 453 colncidence protons were tdentifiod at a11 angles. In figure 4.9 the colncidence ovente observed with the proton telescope at 30 degrees are plotted. The expected response to plons protons and deuterons $1 \mathrm{~s}$ also shown. The bottom edge of the proton 


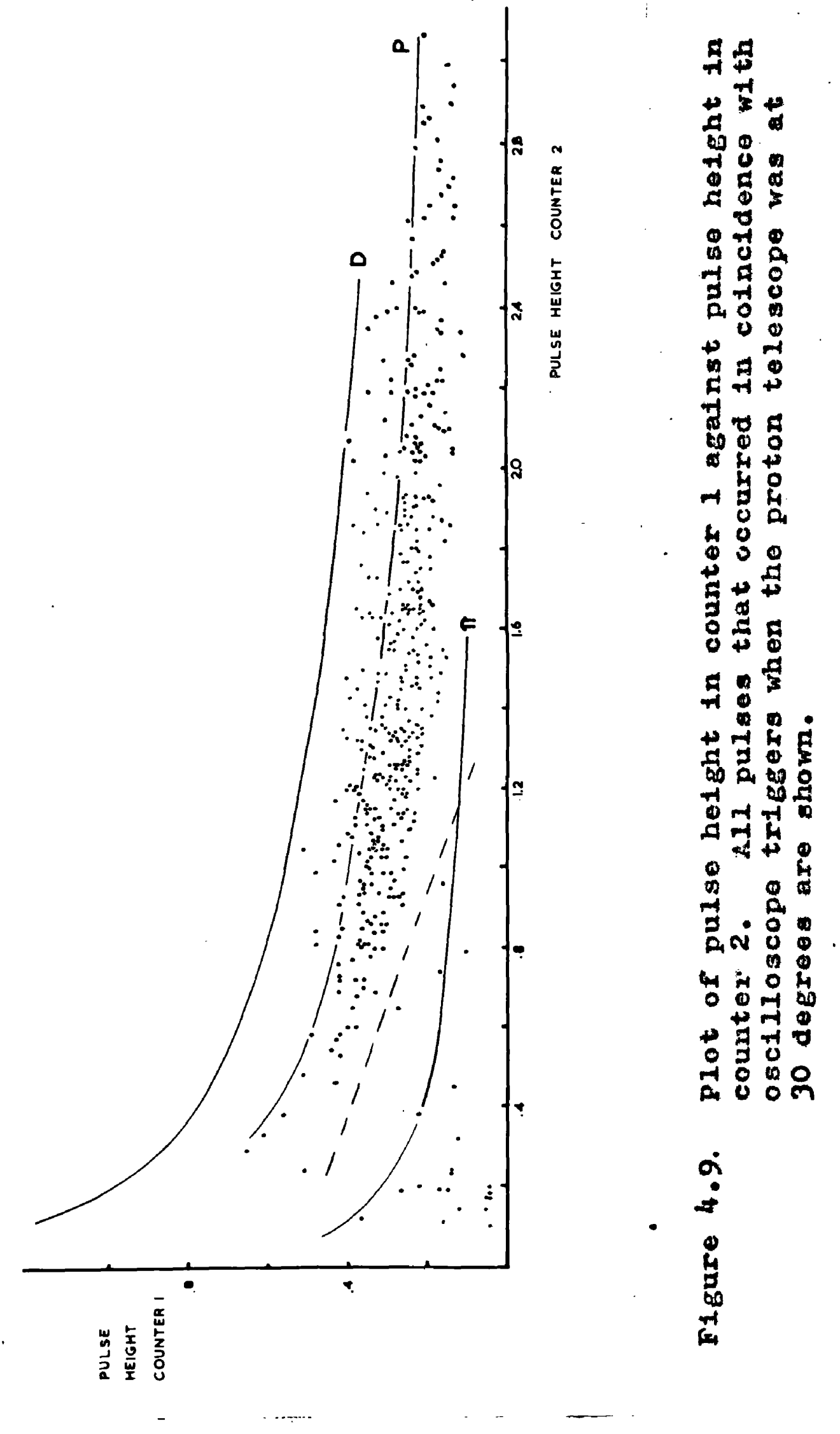


band is more sharply defined than the upper edge. This is a consequence of the Landau distribution of energy 10ss in the thin scintiliator. All spoto above the dashed I1ne were attributed to protons.

The callbration of the proton telescope changed by about $8 \%$ durine the xun. W1thin the uncertainty of the calibration the pulse heleht from both counters 1 and 2 decreased untrormly throughout the run. The pulse height resolution did not change. The decrease in pulse helght was most likoly due to change in gain of the distributed amplifier in the oscilloscopo. The gatn in this type of amplifier is very dependent upon valve characteristlcs. A direct check that the change in gain occurred in the oscilioscope could not be made since the inftial sensitivity was not known to better than 10 percent. The mornting and evening calibrations done each day never differed by more than 6 percent, which was within the uncertainty of the individual calibrations. To allow for the change in callbration the measured pulse heights were normalized using the averace source calibration each day before they were plotted in figure 4.9. After the normalization the proton end polnt calibrations done at the beginning and end of the run agresd to within 
0.5 percent, and differed from the average eource calibration by 6 precent. The average of the source and endpolnt calfbrations was adopted. Expressed in deflection measured in the f1Im reador 1 t was $.0483+.0035$ inches/1 liev.

Ar an additional check on tho energy calibration of the proton telescope, the pulse height produced by fast electrons traversing counter 2 was measured. A .005 inch copper sheet was placed in the bremsstrahlung beam. The oscliloscope was trigfered by $1+3$ colncidences and the pulses from counters 1 and 2 fere displayed on the oscilloscope trace. The discrininator ras sot using a thorium source to select particles loosing more than $2 \mathrm{MeV}$ in counter 2. A $\frac{1}{2}$ inch thick perspex absorber was placed botweon counters 2 and 3 so that only eloctrons leaving counter 2 with energy $>2$ MeV were selected. The oscliloscope traces were photographed and the helghts of pulses from counters 1 and 2 were seasured. A histogram of the pulse helght distribution for counter 2 is shown in figure 4.10 . The nost probable pulse helght estlmated from the reletive numbers in the two nost probable intervals is shown by the arrox. Followting the suggestion of Cranshaw (1952) 1t 


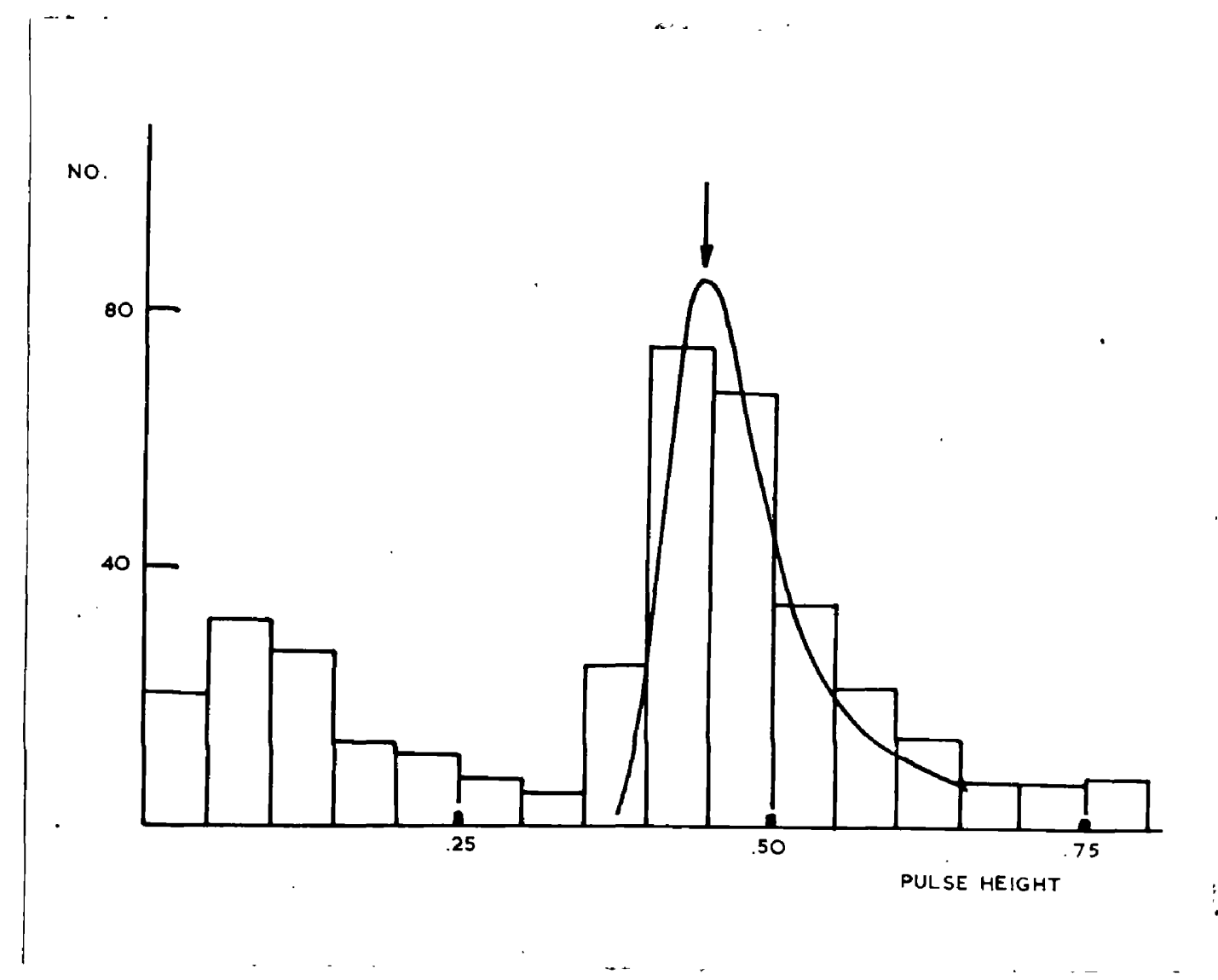

F1gure 4.10. Ilistogram of pulse height produced in counter 2 by polativistic electrons traversing the proton toloscope. The arrow Indicates the probable pulso helght. The curve 1.s the Landau distribution including counter resolution. 
was assuned that fublished values of spectric lonfation refer to the most probable energy 10ss. The most probable energy 1038 for the electrons in counter 2 , $9.5 \mathrm{MeV}$, was obtained using $1.8 \mathrm{MeV} \mathrm{cm}^{2} / \mathrm{gm}$ as the speciflc lontzation for mintmum lonizing particles. The curre in figure 4.10 is the Landau distribution of energy loss with counter resolution (assumed 10 percent full width at half helght) folder in. The Landau distribution was obtained using the prescription of Rosil (1952). The pulse helght distribution Implies the enerey calibration $1 \mathrm{~s} .0462+.007$ inches/MeV in good agreement wh the adopted calibration.

The onergy measured in the cornter tolescopes must be corrected for enerey lost by the particles escaping from the target to obtain the particle energy at creation. As the production occurs unf formly throughout the target volume a single energy for particles entering the telescope w111 corrospond to a range of energy at creation. Thus 15 and $20 \mathrm{MeV}$ protons produced at the near and far sides of the target will have the same energy entering the counter telescopo. At higher energy the spread $1 \mathrm{~s}$ less belng 2.5 and $1.6 \mathrm{MoV}$ for 40 and 70 MeV protons respectively. The creation enercy of both 
protons and pions have been related to measured particlo energy by assuring that production occurred at the redian plain of the target.

In the backeround runs a total of $6.49 \times 10^{11}$ equivalent quanta passed through the empty target. No colncident recoll protons wero observed.

The continuous spot distribution in figure 4.9 wa divided into bins corresponding to $10 \mathrm{MeV}$ intervals for frotons produced at the redian plane of the target. The energy Intervals are given in column 1 of table 4.1. The number of frotons in each interval wes obtalned by counting the spots in the proton band and is given in column 2. The R.M.S. deviations are given in the third column.

The expertmentally observed angular distribution is presented in table 4.2. The number of protons observed at each angle is elven in column 2 and the corrosponding total flux at eack arsie in colum 3. The exrors ars R.M.S. deviations only. The exror due to relative monitoring of the photon flux vere $5 \%$ and are small compared with the R.M.S. deviations. The angular resolution is indicated in column 1.

Figure 4.11 shows the energy spectrum for recoll 
Table 4.1

Energy Spectrum of Reco11 Protons from Negative P1on Photoproduction in Deuterium

$\begin{array}{ccc}\begin{array}{c}\text { Proton Energy } \\ \text { Interval }\end{array} & \begin{array}{c}\text { No. of } \\ \text { Protons }\end{array} & \begin{array}{c}\text { R.M.S. } \\ \text { Deviation }\end{array} \\ 17-27 & 15 & 3.9 \\ 27-37 & 82 & 9.0 \\ 37-47 & 133 & 11.6 \\ 47-57 & 84 & 9.2 \\ 57-67 & 54 & 7.4 \\ 67-77 & 23 & 4.8 \\ >77 & 5 & \end{array}$


Table 4.2

Angular Distribution of Recoil Protons from Negative Pion Production in Deuterium.

Angle No. of Protons Total Photon degrees $\pm 3.5$

${ }_{10}^{\text {Flux }}{ }_{Q}^{11}$
23

396

38

46
32

2
3.59

26.7

3.44

1.73
No. of Protons

per $10^{11}{ }_{Q}$

$6.4 \pm 1.3$

$14.8 \pm .74$

$9.3 \pm 1.6$

$1.2 \pm .83$ 


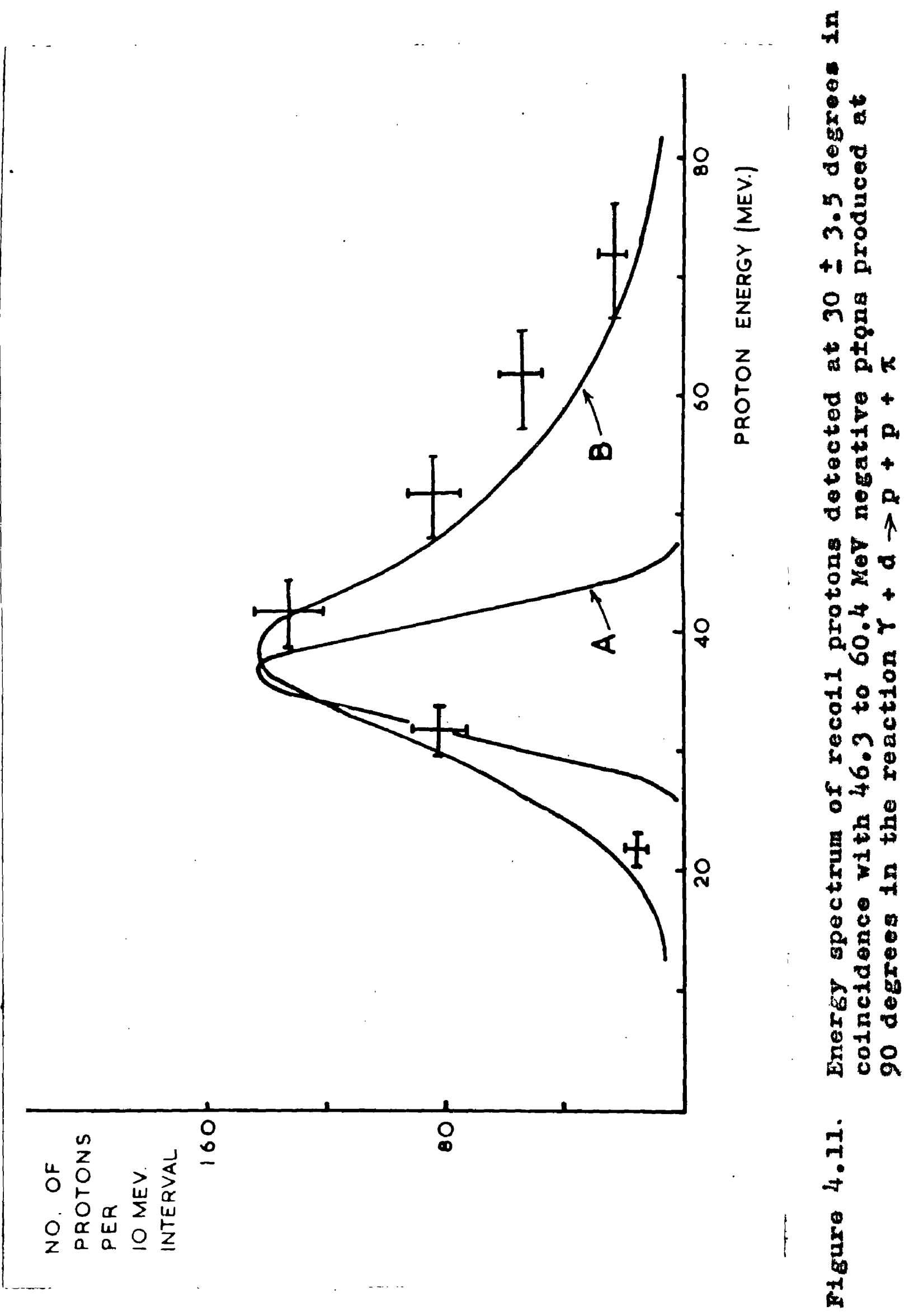




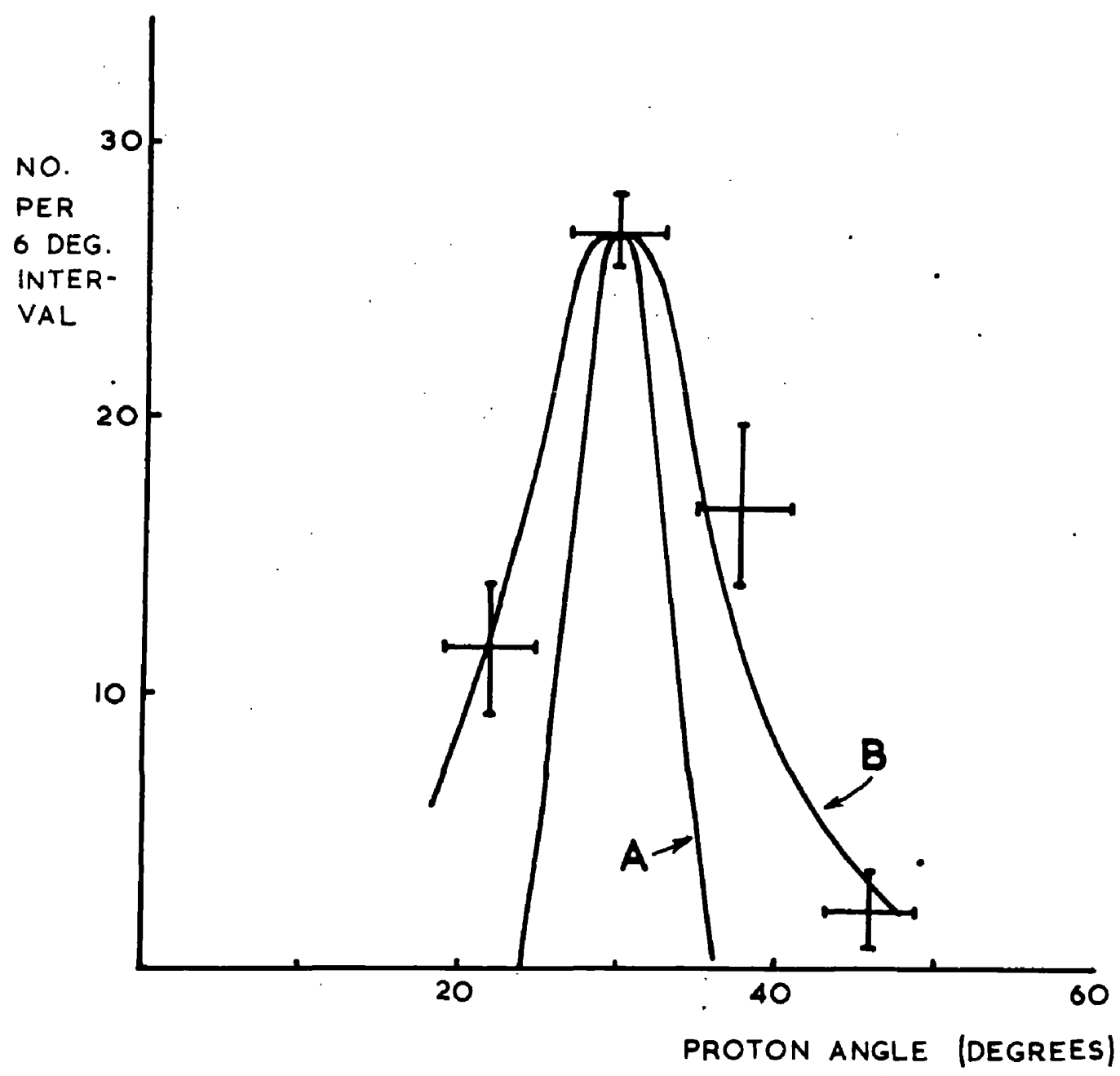

Figure 4.12. Angular distribution of recoll protons detected in coincidence with 46.3 to $60.4 \mathrm{MeV}$ negative pions produced at 90 degrees in the reaction $\gamma+d \rightarrow p+p+\pi^{-}$. 
protons measured at $30 \pm 3.5$ degrees 1 in colnoidence with 46.3 to $60.4 \mathrm{MsV}$ negativo pions detected at $90 \pm 3.7$ degrees. The experimental points aro takon from table 4.1. Tho vertical barg Indicato R.M.S. deviations. The horizontal bars Indicate the uncertainty due to the energy callbration which was $+7.2,-6.2$ percent. Curro A is the energy opectrun calculated for negative pion production at a froe neutron at rest. Curve $B$ is the enerey spectrum obtained in the spectator model calculations. Curve $D$ was normalized to tho area under a histograi drawn through tho experimental points.

The angular distribution of recoll protons detected In colncidence with the negative plons is shown in figure 4.12. The experimental points were obtalned from table 4.2. The vertical bars are R.M.S. deviations. The horizoutal bars ropresent the angular resolution, \pm 3.5 degrees, of the proton telescope. The curves $A$ and $B$ are the angular distributions calculated for ingattvo pion producti'n at a free neutron at rest, and for the epectator model description of pion production in deuterium. The curves were normalized to the experimental point at 30 degrees. 


\section{CHAPTER $\mathbf{V}$}

Calculation of Energy and Angular Distributions.

Tho experimental angular and energy distribution, for recoll protons detected in colncidence with negative plons from deuterium are compared with the distributions caiculated when the process is described by the spectator mode1. The agreement between the experimental and calculated distribution furnishes the toat for val1dity of the spectator model. The simpler reaction $\gamma+n \rightarrow p+\pi^{-}(1.2)$ is also considered, although $1 \mathrm{t}$ is not expected to give good description of the proton energy and angular distributions. The comparison of the distributions calculated in the two approximations 11lustrates the effect of nucleon momentum on the observed distributions.

The energy and momentum conservation conditions for negative plon photoproduction at a free nucleon are

$$
\begin{aligned}
& v=\mu+P \\
& v_{0}+M_{M}=\mu_{0}+T_{p}+M_{p}
\end{aligned}
$$

where $v$ and $v_{0}$ are the photon momentum and enerey. $\mu$ and $\mu_{0}$ are the pion momentum and energy. and $P$ and $T_{p}$ are the proton momentum and k1netio energy. 


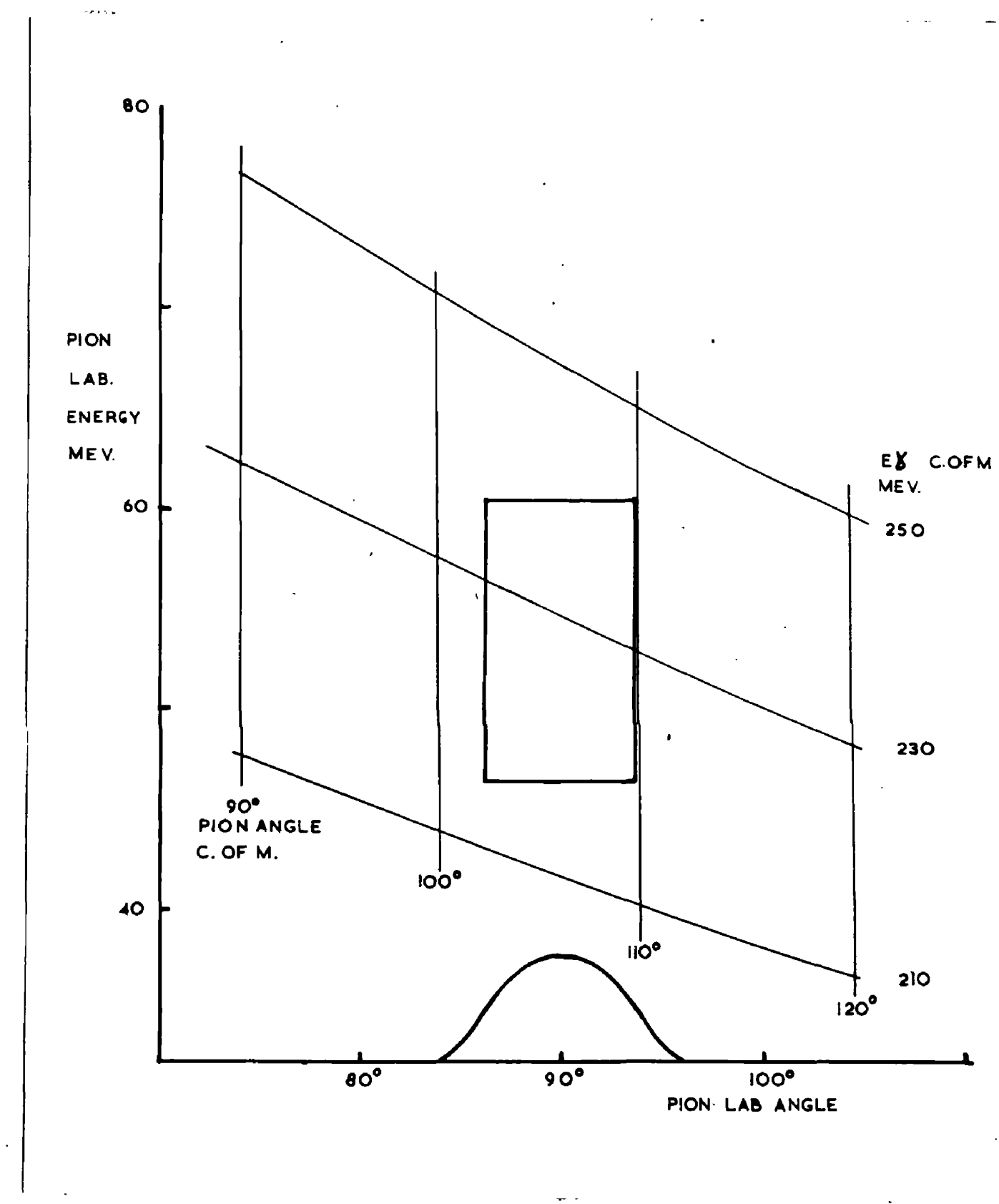

Figure 5.1. Diagram of pion kinematics for negative pion production at a free neutron. The angular resolution of the pion teloscopo Is shown. 


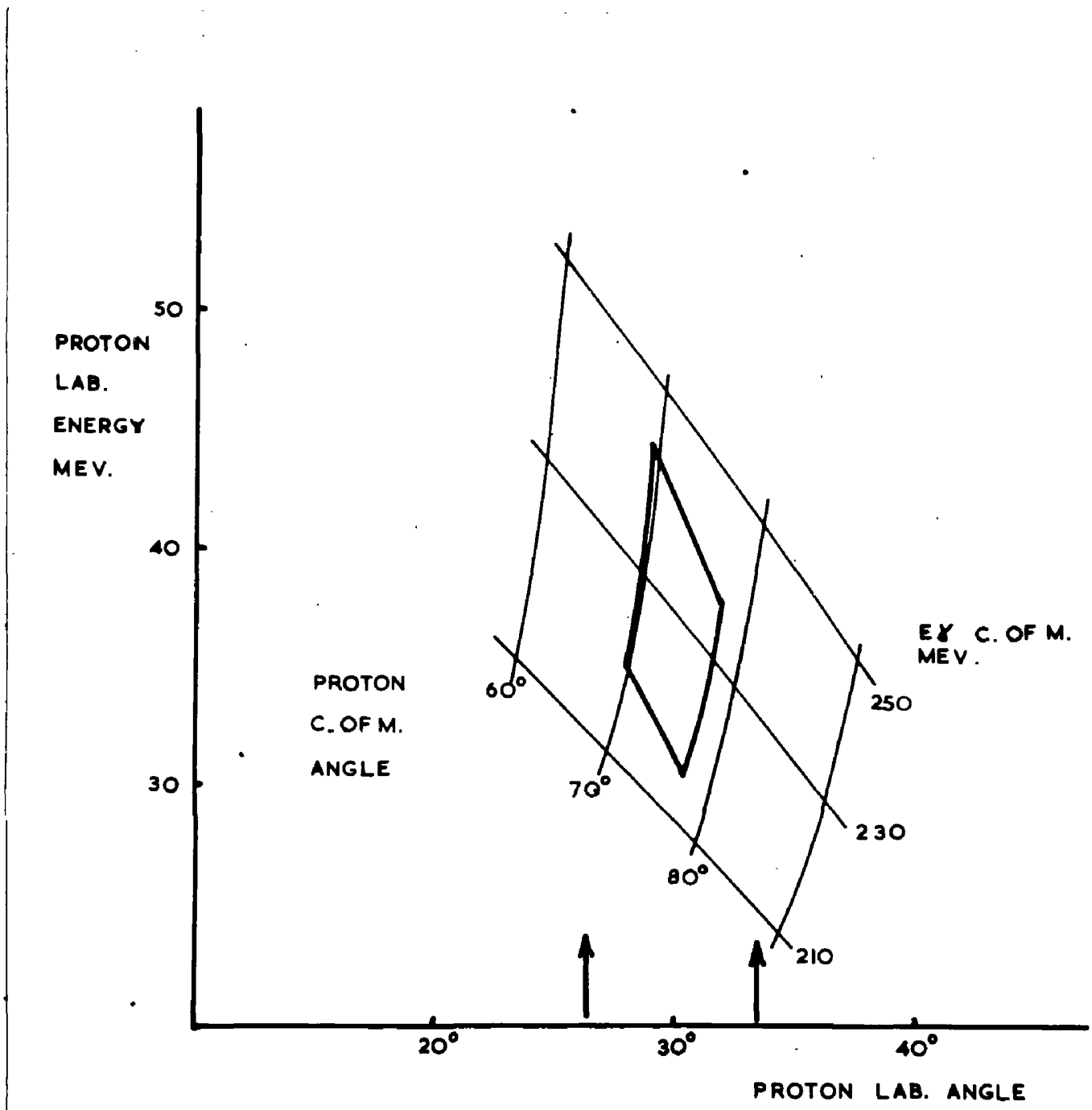

Figure 5.2. Diagram of proton kinematics for nagative pion production at a free neutron. The angular accoptance of the proton telescope 18 indicated by the arrows. 
$M_{n}$ ard $M_{p}$ are the neutron and proton rest mesees. Equations $(5.1)$ are a special case of the general two-body erergy and monentum conservation condltions that have been used to compute tables of kinematic relations for many reactions. Reaction (1.2) can not be observeddirectly and kinematical tablea for this reaction have not boen published. A desk calculator was used to compute the kinematical relations for reaction (1.2) for the small energy and angular range of Interest here. The solutions given by Malmberg and Koester (2953) were used to $601 v$ for $T_{p}, \theta_{p} T_{T}$ and $\theta_{p}$ for various values of $v_{0}$ and $\theta_{p} *$ and $\theta_{\pi}^{*}$, where $\theta_{p}$ and $\theta_{\pi}$ are the proton and pion production angles measured from the incident photon direction and $\boldsymbol{T}_{\pi}$ is the pion kinetic enorgy. The asterisk indicates quantities expressed in the centre of mass syotem. The conventional kinematical diagrams are shown in f1gures 5.1 and 5.2 . Pion (proton) laboratory angle and energy are plotted on the $X$ and $Y$ axes respectively. Lines of constant photon energy and pion (proton) centre of mass anglo are drawn on these diagrams. The two dlagrams and the relation between pion and proton centre of mas angles, $\theta_{\pi}^{*}=180-\theta_{p}^{*}$. may be used to obtain laboratory angle 
and energy for the plon and proton for any particular. centre of mass angle and incident photon energy.

A graphical mothod using I1gures 5.1 and 5.2 has been used to calculate the angular and energy distributions expected for recoil protons observed in coincidence with 46.3 to $60.4 \mathrm{MeV}$ plons produced at 90 degrees. The angular resolution of the plon telescope is shown in figure 5.1. The effect of a finite target and the counter aperture have been considered. The angular acceptance of the pion telescope, 7.3 degrees, is the full width at half helght Given by the angular resolution curve. The pion energy and angular range accepted by the telescope is indicated by the rectangle in figure 5.1. The corrosponding energy and angular range for the rocoll protons 16 represented by the "dlamond shaped" area in figure 5.2. If the crose section for pion production 1 s assumed to be constant over the range of pion energy and angle accepted by the pion telescope, then to a good approximation the relative probability of a recoll proton being observed at a particular angle $1 \mathrm{~s}$ given by the length of a line of constant $\theta_{p}$ which $110 \mathrm{~s}$ inaide the "diamond shaped" area. The effect of finlte target volume is considered by replacing the target by a number 
of sources and adding the contribution from the various sources at each angle. The angular resolution of tho proton telescope was folded in to obtain the expocted experiaentally observed angular distribution. Curve A In figure 4.12 is the angular distribution expected for recoll protons detected in coincidence with negativo pions produced at 90 degrees and 46.3 to $60.4 \mathrm{lieV}$ at a free neutron at rest.

The onergy distribution of recoll protons was obtalned In a simllar way. The length of a line of constant $T_{p}$ lying inside the "dlamond shaped" area in figure 5.2 was used to obtain the relative probabllity of a recoll proton beling produced at a particular energy. The energy resolution of the proton telescope was taken to be $10 \mathrm{MeV}$ wide, the ridth of the bins used to obtain the expertmental enerey distribution. The effect of the enerey resolution was included in calculating the energy spectrum by taking the probability of detecting a pion at an energy $T_{p}$ to be proportional to the area under the energy distribution between $T_{p}-5$ and $T_{p}+5 \mathrm{MeV}$. The observed energy distribution calculated for recoll protons from pion photoproduction at a freo neutron is curve A in flgure 4.11. Since the angular acceptance of the 
proton telescope was wider than the distribution of recoll protons shown in figure 5.2 no restriction on proton angle was required in calculating the observed energy distribution.

Spectator Model Calculation

The energy and momentum consorvation conditions for negative pion photoproduction in deuterium ere

$$
\begin{aligned}
& v+D=\mu+P+S \\
& v_{0}+H_{D}=2 M_{p}+T_{p}+T_{B}+\mu_{0}
\end{aligned}
$$

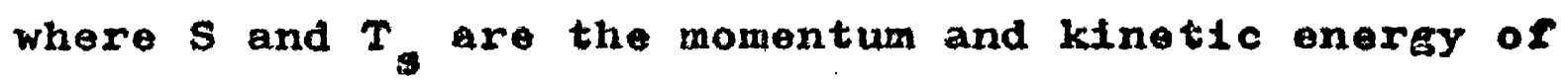
the spectator proton, and $D$ and $M_{D}$ are the momentum and mass of the dauteron. Although there are only two particles in the Initial state, there are threo in the final state and moasurement of the angle and energy of one final state particle does not allow a solution of 5.2. The spectator model assumption 1s that the pion is produced at the neutron and the proton monentur is the same in the Initial and final states. Since the deuteron is at rest

$$
D=N+5=0
$$

where $N$ is the noutron momentum. 


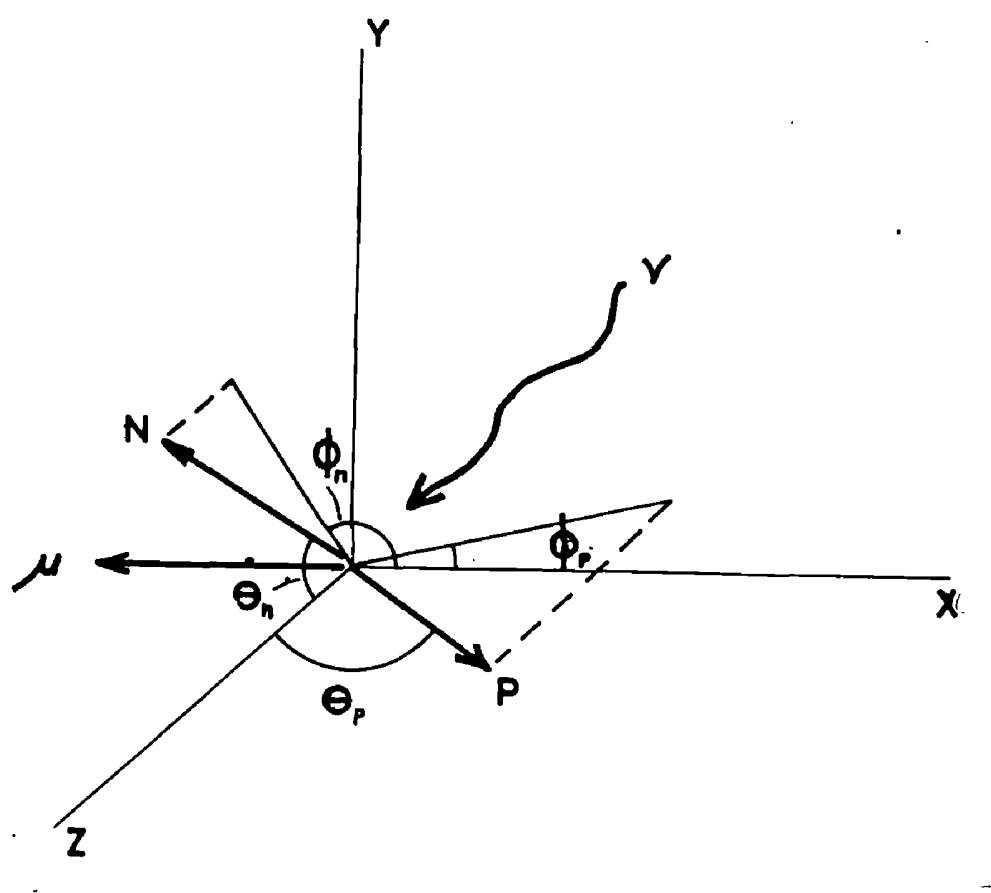

Figure 5.3. Ceometry of opectator model description of negative pion photoproduotion in deutorium. 
from (5.2) and the epectator proton energy, $T_{0}=N^{2} / 2 M_{p}$ In the non relativistic limit. The binding energy of the deuteron $B$, is included since $M_{D}=M_{p}+M_{n}-B$. Pion production in deuterium has now been reduced to a two body reaction in which nelther of the particles in tho inftial state are at rest. Tho geometry of the spectator model reaction is 1llustrated in figure 5.3 . The photon 18 incldent along the z-axis. The pion momentum is shown directed along the negative $X$-axis corresponding to the detection of the pion at 90 degrees. Tho Initial neutron and recoll proton momenta are shown. Equations (5.2) have been solved in the spectator model for proton energy $T_{p}$ angles $\phi_{p}$ and $\emptyset_{p}$ and for the laboratory and centro of mass photon energy. The solutions $a=0$.

$$
\begin{aligned}
& T_{p}=A-\left\{A^{2}-\left[M_{p}-A\right]^{2}-\left[|N| \sin \theta_{n} \sin \phi_{n}\right]^{2}-\right. \\
& \left.\left[\left(\mu_{0}^{2}-M_{\pi}^{2}\right)^{1 / 2}+|N| \sin \theta_{n} \cos \phi_{n}\right]^{2}\right\}^{1 / 2} \\
& \theta_{p}=\cos ^{-1} \frac{\left(M_{p}-A\right)+T_{p}}{\left(2 M_{p} T_{p}\right)^{1 / 2}} \\
& \sin \phi_{p}=\frac{|N| \sin \theta_{n} \sin \phi_{n}}{\left(2 M_{p} T_{p}\right)^{1 / 2} \sin \theta_{p}}
\end{aligned}
$$




$$
v_{0}=M_{p}-M_{n}+B+T_{s}+\mu_{0}+T_{p}
$$

$$
\begin{gathered}
v_{0}^{*}=\frac{v_{0}}{\left[1-\frac{|N|^{2}+2|N| v_{0} \cos \theta_{n}+v_{0}^{2}}{\left(v_{0}+M_{n}\right)^{2}}\right]^{y_{2}}} X \\
\left\{1-\frac{v_{0}+|N| \cos \theta_{n}}{v_{0}+M_{n}}\right\}
\end{gathered}
$$

where $A=M_{n}-B-T_{a}-\mu_{0}-|\lambda| \cos \theta_{n}$,

$\nabla_{0}^{*} 1$ s the centre of mass photon energy, and $c=1$. The varlous angles are defined in figure 5.3. The non relativistic relation botween proton energy and momentum has been used.

The numerical computation of $T_{p}$ etc. requires that the pion energy and the inttial neutron romentum be known. The pion energy was defined by the pion telescope. The probability distribution for nucleon momenta in the deuteron was obtalned from the llulthén wave function. It is

$$
P(|N|)=\frac{K N^{2}}{\left[\left(N^{2}+\alpha^{2}\right)\left(N^{2}+\beta^{2}\right)\right]^{2}}
$$

where $a=(\mathrm{IBB})^{\frac{1}{2}}=45.7 \mathrm{MeV}$ and $\beta=260 \pm 2 \mathrm{MeV}$ (Ihite et a1.,1960. Tho nucloon momentum distribution is 1sotropto 
In space. The numerical computation was done for the range of nucloon monenta appropriato to the doutoron. The Glasgow Univeralty Deuce computer was used and $T_{p}$ ' $\theta_{p} \cdot \sin \varnothing_{p} \cdot \nabla_{0}$ and $\nabla_{0}$ * were computed for 10 values of $\mathrm{N}$ from 10 to $190 \mathrm{MeV}$. 7 values of $\phi_{n}$ from 0 to 180 degroes, 5 values of $\theta_{n}$ from 30 to 150 degrees. 3 values of $\mathrm{E}_{\pi}$ from 188.2 to $197.6 \mathrm{MeV}$. a total of 1050 combinations in all. The reaction to symetrical about the $x-Z$ plano in figuro 5.3.

The plon centre of mass anglo $\theta^{*}$ in the photon neutron centre of mass system corresponding to plon emission at 90 degrees in the laboratory system is

$$
\theta_{\pi}^{*}=\tan ^{-1} \frac{\left[\cos ^{2} \theta \cos ^{2} \phi_{n}+\sin ^{2} \phi_{n}\right]^{1 / 2}}{-\gamma\left[\sin \theta \cos \theta_{n}+v_{c m}\left(\mu_{0} / \mu\right)\right]}
$$

where $v_{c m}=\left(r^{2}+2|x| v_{0} \cos \theta_{n}+v_{0}^{2}\right)^{\frac{1}{2}} /\left(v_{0}+u_{n}\right)$ 13 the relocity of the centre of mass in the laboratory system.

$$
r=1 / \sqrt{1-v_{c m}^{2}}
$$

$\cos \theta=\left(v_{0}+|N| \cos \theta_{n}\right) /\left(N^{2}+2|N| v_{0} \cos \theta_{n}+v_{0}^{2}\right)^{\frac{1}{2}}$ 
and $\ln \theta=|N| \sin \theta_{n} /\left(N^{2}+2|N| v_{0} \cos \theta_{n}+v_{0}^{2}\right)^{\frac{1}{2}}$

$\theta_{\pi}$ was calculated for each combination of $\theta_{n}$ and $\phi_{n}$ for a fow values of $|N|$ and $\mu_{0}=193 \mathrm{MeV}$ and graphs of $\theta_{\pi}^{*}$ vs $|\mathrm{s}|$ drawn.

The probability of a plon being produced by a photon of energy $v_{0}$ at a noutron with momentur if is proportional to tho weighting function

$$
W=\rho(|n|) \rho\left(\phi_{n}\right) \rho\left(\theta_{n}\right) \rho\left(v_{0}\right) d \sigma / d \Omega\left(v_{0}^{*} \theta_{\pi}\right)(5.10)
$$

where $\rho(|s|)$ is the area under the nucleon momentum probability distribution $(5.8)$ between $N-10$ and $N+10$ MeV.

$$
\rho\left(\phi_{n}\right)=1 \text { and } \rho\left(\theta_{n}\right)=\sin \theta_{n} \text { for an 1sotropic }
$$

distribution.

$\rho\left(v_{0}\right)$ was obtalned from the schiff thin target apectrum with $\mathrm{E}_{\max }=307 \mathrm{MeV}$. and $d \sigma / d \Omega\left(\nabla_{0} * \theta_{\pi}^{*}\right)$ is the differential cross section for negative pion production at a free noution expressed as a function of centro of mass photon enerey and the pion production angle.

The appropriate weight $W$ was assigned to each calculated recoll proton energy and angle. The energy 
spectrun was obtained fron the assigned trelghts. The probability of a recoll proton being produced in an energy interval $\Delta E_{p}$ about $E_{p}$ is glven by the sum of the weights $W$ assigned to protons in the interval. In calculating the proton energy spectrum to be compared with the experimentaliy observed spectrum the requirement that the recoll proton enter the proton telescope was imposed by considering the calculated $\theta_{p}$ and $\sin \varnothing_{p}$. The effect of the finite target was included by considering that protons were produced at a number of sources. The limits on $\theta_{p}$ and $\sin \phi_{p}$ depended on the proton telescope aperture and the source position in the target: The relative probability of detecting a proton at energy $E_{p}$ was then proportlonal to $\Sigma W$ where the sum was taken from $E_{p}-5$ to $E_{p}+5 \mathrm{MeV}$, corresponding to the width of the energy bins used to obtain the experimental spectrum. Curve $B$ in figure 5.2 shows the energy spectrum calculated in the spectator model for recoll protons detected at $30 \pm 3.5$ degrees in coincidence with 46.3 to $60.4 \mathrm{MeV}$ plons produced at 90 degreos.

The engular distribution of the recoll protons was calculated in a simllar way. Only protons for which $\sin \phi_{p}$ Indicated that the proton entered the proton 
telescope were included. The telescope angular resolution was included by strming $\left[W\right.$ from $\theta_{p}-3$ to $\theta_{p}+3$ degrees. The calculation was don for the centre of the target only. The angular distribution calculated in the spectator model for the recoll proton detected in colnciderse with a negative pion at 90 degrees 1 shown in figure 5.1 curve $B$.

The differential cross section for plon photoproduction was obtalned from Moravcsik's paper (1957). Graphs were dram of positive pion production cross sections as a function of centre of wass photon energy $v_{0}$ f for different contre of mass pion angles $\theta^{*}$. The $-/+$ ratio was assumed constant over the range of $v_{0}^{*}$ and $\theta_{\pi}^{*}$ involved and was not used in calculating $W$. Apert from the $-1+$ ratio the use of cross sections for pion production at a nucloon at rest is not strictiy correct since the transformation of the cross section from the centre of mass to the laboratory system depends on nucleon monentum $N$.

The efficiency of the detection system may be checked by calculating tho cross section for negativo pion production. The number of recoll protons $n$, is related to the pion photoproduction cross section by 


$$
n=\left[\begin{array}{lllll}
\frac{d \sigma^{2}}{d \Omega d E} & \frac{\Delta v_{0}}{v_{0}} & Q & \Delta \Omega & N
\end{array}\right] \times F
$$

where $Q$ is the total rlux expressed in equivalent quanta $\Delta \Omega$ is the solid angle subtended by the pion telescope at the centre of the target. and $N 1$ the total number of nuclel in the bean per $\mathrm{cm}^{2}$. The photon energy and interval $V_{0}$ and $\Delta V_{0}$ aro detexmined by the kinematics for negative pion photoproduction at a free neutron at rest. The quantity in brackets is the usual exprastion for the number of plons detected. F 1s the Iraction of the recoll protons expected to enter the proton telescope. The spectator model calculation Gives $F=.097$

Tho number of recoll protons detected was corrected for counting $108 s e s$ due to multiple scattering and absorption of plons in the counter telescope and for pion decay in flight. The multiple scattering correction was calculated using the Eraphs of sternholmor (1954). The data of Shaplro (1951) and Byfleld et al. (1952) for negative pion aboorption in carbon Including olastic and Inelastic scatterling was used. It was assumed that all pion decays in flight resulted in the $\mu$ meson being 
scattered out of the pion telescope. The corrections were,
multiple scattering
+3 percent
absorption
+13 percent
decay in flight
+8 percent.

The cross section for negative pion photoproduction calculated from $(5.11) 18$ then $15.8 \times 10^{-30} \mathrm{~cm}^{2} /$ steradian $\mathrm{MeV} \pm 12$ percent.

The error assigned to the cross section was obtained from the errors listed below
beam ranttor
20 percent
R.R.S. deviation
5 percent
definition of photon
energy interval
4.5 percent
determination of $\mathrm{E}_{\max }$
2 percent
pion tolescope solid angle
1.5 percent

The error in $F$ depends on the inpulse approximation calculations and was not included. The largo orror assigned to the beam monltor was largely due to instability in the amplifier integrator syotem used. The cross section for negative pion production in 
$-105-$

deuterium may be calculated using the experimentally measured positive pion cross section from hydrogen and the -/t ratio from deuterium. The value obtained by interpolation of the experimental points given in Morarcsils's paper (1957) was $17.5 \times 10^{-30} \mathrm{~cm}_{1}^{2} / \mathrm{steradian}$ MeV. \pm 10 percent. The cross section obtained from the experiment $18 \sim 10$ percent lower. This may be due to the competing photodisintegration process. 


\section{CHAPTER VI}

Discussion and Conclustons.

The agreenent botween the experimentally observed angular distribution for the recoll proton from negative pion photoproduction in deuterium and the distribution calculated in the spectator model 18 good. Figure 4.12 Indicates that the width of the angular distribution is soveral timos that expocted from negative pion production at a free neutron at rest. The additional width of the spectator model angular distribution is due to the noutron momentum. The angular distribution, 11ke that obtained by Keck and Littauer (1952) supports the opectator model description of negative pion photoproduction in deuterium.

The energy spectrum observed for the recoll proton from negative plon photoproducting in deuterium differs from the spectrum calculated using the spectator model approximation. The disagreement between individual experimental points in figure 4.11 and the curve $B$ is not large but the fact that all the experimental points are shifted towards higher enerey is algnificant. The "ohift" is approximately 8 percent with respect to curve B for all pointa, and 18 slightly larger than the estimated uncertainty in the energy calibration. The 
shape of the observed spectrun 18 well represented by the spectator model calculation. In particular the excess of protons above the most probable energy agrees with the experimental pointe.

It is tempting to speculate that tho"shift" is due to an error in the energy callbration of the proton telescope. The energy calibration has been done using, h1 gh energy protons, and thortum $\mathrm{C}^{11}$ and sodium 22 gama ray srurces. The callbrations agreod to within \pm 3 percent. The 1ndependent check of the calibration using relativistic olectrons agreed with the adopted calibration well within the accuracy of the measurement. There is no evidence that the error in the energy calibration 18 larger than indicated in figure 4.11. It was concluded that the ohift" can not be entirely due to errors in the energy callbration.

The possibility of Including random events or particles which were not protons has been considered. The single channel klcksorter was not to Include pulse helghts that extended well above and below the pion group to ensure that no plons were mlssed. The osc1110scopo was triggered on large electron pulses and the probability of dotecting electron palrs was considerable. The 
electrons were vell separated from protons by the $\mathrm{dE} / \mathrm{dx}$ and $\mathrm{I}$ measurement of the proton telescope. The spots occurring close to the ortgin in figure 4.9 vere attributed to electron pairs.

The separation between the pion and proton eroups in the kicksorter display was large and few protons wore expected to triggex the oscilioscope. Consideration of the kinematics Indicates that protons from pion production are not expected at 90 degrees. The dotection of a colncident negative pion in the proton telescope was very improbable.

The probablitty of detecting a recoll deuteron from elastio noutral pion production in deuterium was small. The correlation botween a $\pi^{\circ}$ docay photon and the recoll deuteron $1 \mathrm{~s}$ weak and the efficlency for the pion telescope detecting such photons is emall. The two partioles, plons and deuterons, most $11 k e l y$ to bo confused with protons in the proton telescope are thus very unlikely to occur in coincidence with an osc1lloscope trigger.

The total absence of inverted coincldence events (trace 6 figure 4.8) is good evidence that the probability of a random particle being included in the energy 
spectrum 1. small.

Colncident recoll neutrons from positive plon photoproduction in deuterium were exoluded by the lack of a $d E / d x$ pulse. A total of 32 ovents of this typo woro found. Host of the pulses produced by counter 2 for these events corresponded to proton energies between 20 and 35 MeV. An appreciablo distrotion of the observed recoll proton epectrum would have occurred if the $d E / d x$ and $I$ proton Identification had not been used.

Multiple scattering of the protong in the deuterium target was a small efrect and was not strongly energy dependent. Scattering in the thin front sointiliator In the proton telescope may be negleoted. The counter geometry indlcated that the number of protons striking the edges of the lead eollimator equallod 6 percent of the number passing cleanly through it. An inolastic proton ocatter in the odges of the collimator or penetration of the edges would produce a distortion in the proton spectrum. Since only a few apots occur in flgure 4.9 that are not clearly electrons or protons it was assumed that effects due to the collimator edges were small. The counting losses calculated for the plon telescope were nearly independent of plon energy in the 
energy Interval defined by the telescopo.

The energy resolution of the detection system due to counter resolution and particle energy 1088 in the target, was typlcally $\pm 3 \mathrm{HeV}$. It was narrower than the $10 \mathrm{MeV}$ intervals used to obtain the experimental spectrum. The width of tho intervals was mainly dictated by tho need to have sienificant statistical accuracy for the experimental points.

The consideration of the experimental technlque outlined above did not reveal any effect likely to produce a significant distortion in the energy spectrum.

The calculation of the energy spectrum in the spectator model approximation necessarily involved a number of approximations. The pion $-/+$ ratio was assumed constant. The data lncluded in Horarcsik!s paper (1957) Indicate that it may be expected to vary by about 10 percent in the energy and angular region that was expected to make the rain contribution to the proton enerey spectrum. The relation between the centre of mass and the laboratory cross section for pion production was assumed to be independent of the neutron monentum $\mathbb{N}$. The error introduced by this approximation 18 difficult to estimate. It was considered that the 
Eeneral accuracy of the spectator model calculations did not warrant detalled consideration of the $-/+$ ratio or the cross ection transformation. The errors Introduced by the other assumptions made in the apectator nodel calculation are expectod to be smaller than those discuseed above. It was concluded that the Curve $B$ in figure 4.11 gives a good representation of the recol1 proton energy spectrum predicted by the spectator rodel.

A small discropancy between the recoll energy opectrum predicted by the spectator model and the observed spectrua exists. Although it is unlikely to be entirely due to experimental errors or errors in calculating the rocoll proton energy spectrum, this possiblity can not be completely ruled out. The apectator model neglects the interaction or the particles In the final state. The impulso approxination which Includes the final state interaction has been shown to describe accurately pion photoproductio: in deaterium near threshold (Adamovic et a1.,1959). It 1s expected to be valid at higher energy ale0. The Impulse approximation calculations of Thio (1952) for the recoll proton enerey spectrum (curve C figure 1.10) Indicate that the impulse approximation predicts an energy distribution shifted 
towards higher energy with respect to the spectator model calculations. The final state interaction $1 \mathrm{~s}$ consldered to be the most probable cause of the discrepancy observed between the spectator model spectrum and experiment.

Although the energy and angular acceptance differed slightly, the results of the present experiment may be compared with those of Keck and Littaner (1952). The energy spectra of the recoll proton obtalned in the two experiments differ. In particular the peak of the energy spectrun obtalned by Keck and Littauer was shifted towards higher energy by 10 to $12 \mathrm{MeV}$ compared with tho spectator model predictions. In the present experiment the peak to shifted towards higher energy by 3 to $4 \mathrm{MeV}$. Keck and Littauer did not obtain an excess of protons above the most probable enerey whlch was obtalned in the prosent experiment and is predicted by the spectator model calculation. The experimental technique used in tho present Investigation was superior to that of Keck and Littauer in that a liquid deuterlum target was used and the Identification of particles included in the energy spectrum was more complete. It is considered that the large discrepancy observed by Keck and LIttauer 
was due to an experimental effoct. This viow is supported by the differenco between the measured cross sections. In the present experiment a value of $15.8 \pm 1.9 \times 10^{-30} \mathrm{~cm}^{2} /($ ateradien $\mathrm{MeV}$ ) was obtalned in good agreement with the cross section predicted by recent experimental values of the $-/+$ ratio and positive pion production cross section. Keck and Littauer quote $10.8 \pm 1.0 \times 10^{-30} \mathrm{~cm}^{2} /($ oteradian MeV). for the same cross section. Unless the difference 1 s due to errors In beam monitoring the two values indicate that a substantial number of events wore not detected in the earlier experiment.

It may be concluded from the present worl that the spectator model provides a reasonable description of negative pion photoproduction in deuterium for photon energies about $230 \mathrm{MeV}$. There is some evidence that the interaction between particles in the final state has a sma11 effect at this energy. A largo ilscropancy betwoen the experimental enexgy spectrum for the recoll proton and that predicted by the spectator model is ruled out. The present findings agree with those of White ot al. (1960) that the spectator model description of pion photoproduction in deuterium is justified at energies 
$-114=$

well above threshold.

The differential cross section for negative pion photoproduction in deuterium at $90 \pm 3.7$ degrees and $53 \pm 7 \mathrm{MeV}$ is $13.8 \pm 1.9 \times 10^{-30} \mathrm{~cm}^{2} /($ steradian MeV). This is $\sim 10$ percent below the value calculated from tho $-/+$ ratio in deuterium and the positive pion photoproduction cross section in hydrogen. Although the difference can be accounted for by the Wilson (1956) model for photodisintegration of the deuteron the errors are too large for the difference to be significant. 


\section{PUBLICATIONS.}

The Response of Plastic SeIntillators to Protons. H.C. Evans and E.H. Dellamy, 1960, Proc. Phys. Soc. 74. 483.
A Level controller fox Liquid Hitrogen,
D. Mil1er and H.C. Evans. 1960, J. Sc1. Instrum. 38. 162 . 
REFERENCES

Adamovic, H.I.. 1959, Soviet Physics (J.E.T.P.) 35, (8), 29. Adamovic, M.I., Gorzhevskaya, E.G., Larionova, V.G.,

Popova, V.M., Kharlamov, S.P., and Yagud1na, F.R., 1960, Soviet Physics (J.E.T.P.) 38. (11). 779.

Adamovic, M.I., Kuzmichiva, G.V., Larionova, V.G., and Whatlamov, S.P., 1959, Sov1et Physics (J.E.T.P.) 35. (8), 21 .

Amiraju, P.. Lederman, L.M.. 1956, Nuovo Cim. 4. 283. Atkinson, J.R.. HeParlane, W., Reld, J.H., and Swlnbank, P.. 1957. Nucl. Instr. 1. 152.

Atkinson, J.H, Jr., and V1111s, B.II., 1957, H1gh Energy Particle Data, Vol 11, UnCL. 2426 (U.S. Atomio Energy Commission).

Baldin, A.11.. 1958, Nuovo C1m. 8, 569.

Bellamy, E.If., 1960, Prog. Nucl. Phys. 8, Parganon Presa. London.

Bellamy, E.H., Hogg, W.R., and Miller, D., 1960, Nucl. Instr. 7, 293.

Beneventano, M., Bernardini, G., Carzson-Loo, D..

Stoppin1, G., and Tau, L., 1956, Nuovo C1m. 4, 323. Benerentano, M., Bernardini, G., stoppini, G., and Tau, L., 1958. Nuovo Cim. 10, 1109. 
Beneventano, H., Carlson-Lee, D., Stopplnt, G..

Bernardin1. G., and Goldwasser, E.L., 1954. Nuovo C1m. $12,156$.

Dirks, J.B., 1953, Scintillation Countess (Londons

Pergamon Press).

Boreli, F., and Grimeland, B., 1955. Nuoro C1m. 2, 236. Byfleld, H., Kassler, J., and Lederman, L.M., 1952. Phys. Rer. 86, 17.

Casse1s, J.M., Fidecaro, Q., Wothere11, A.M., and Vormald, J.R., 1957, Proc. Phys, Soc, A70, 405. Chew. G.F.. 1950. Phys. Rev. 80, 196. Chew, G.F.. Goldberger, H.L., Low, F.E., and Narbu, Y.. 1957, Phys. Rev. 106, 1337, 1345.

Chew, G.F.. and Lewts, H.W., 1951, Phys. Rev. 84, 779. Chew, G.F., and Wick, G.C.. 1952, Phys. Rev. 85. 636. C1n1. H., Gatto, R., Goldwasser, E.L., and Ruderman, M.. 1958. Nuovo Cir. 10, 243.

Corson, D.R., DeWlre, J.W., MeDaniel, H.D., and W1lson, R.R. 1953. Cornel1 University publication. Cranshaw, T.E., 1952, Prog. Hucl. Phys. 2, Pergamon Press. London.

Evans, H.C. and Bollary, E.H., 1259. Proc. Phys. Soc.74, 483. Goodlng, T.J., and Pugh, H.G., 1960, Nuc. Phys. 18. 46. 
Hagerman, D.C.. Crow, K.H., and Friedman, R.M., 1957. Phys. Rev. 106, 818.

Ilogg. W.R., and Bellamy, E.HI., 1958, Proc. Phys. Soc. 72, 895.

Keck, J.C., 1955. Phys. Rev. 85, 410.

Keck, J., LIttauer. R., 1952, Phys. Rev. 88, 139.

Kharlamov, S.P., Adamov1c, M.I., and Larlonova, V.G..

1959. Soviet Physics (J.E.T.P.) 36. (9), 668.

Knapp, E., Imbof, H., Kenney, R.W., and Ferez-llendez, V.,

1957. Phys. Rev. 107, 323.

Knapp, E.A.. Kenney, R.W.. and Perez-Hendez, V.. 1959.

Phys. Rev. 114, 605.

Land, R.H., 1959. Phys. Rev. 113. 1141.

Landau, L., 1944, J. Phys. U.S.S.R. 8, 4, 201.

Lattes, C.M.G., Occialini, G.P.S., and Powell, C.F..

1947, Nature $160,459,486$.

Lax, M., and Feshbach, H., 1952, Phys. Rev. 88, 509.

Littauer, R.M., and Walker, D., 1952, Phys. Rev. 86, 838.

MacDona1d, H., 1960, Nuovo C1m. 15. 301.

MeFrarlane, W., Darden, S.E., and Oldroyd, D.L.. 1955.

Nature $176,666$.

MeMilian, E.M., Peterson, J.M., 1949. Science 109, 438. 
Malmberg, J.H., and Koester, L.J. Jr., 1953, Tables of Huclear Reaction Kinematics at Rolativistic Energios, Phyatcs Dept., Untr. of Illinols. Ifalmberg, J.H., and Roblnson, C.S.. 1958, Phys. Rev. 109. 158.

Moravesik, M.J., 1956, Phys. Rev. 104, 1451.

Moravc81k, H.J., 1957. Phye. Rev. 105, 267. Morarca1k, M.J., 1958, Huovo C1m. 7. 442. R1ch, M., Madoy, R., 1954, Nange Energy Tables, URCL. 2301 (U.S. Atomic Energy Commlssion).

Rosel, B., 1952, High-Energy Particles, Prentice-Hall, Ino.. New York.

Rutherglen, J.0., and Walker, J.K., 1960, Nucl. Inst. 8, 239.

Rutherglen, J.C.. Walker J., Miller, D., and Patterson, J.M., 1960, Rochester Conference Report, pg.23.

Sand., If.. Walker, R.L.. and Teasdale, J.G., 1954, Phys. Rev. 95. 592.

Sch1ff, L.I.. 1946, Phys. Rev. 70, 87. Shap1ro, A.M., 1951, Phys. Rev. 84, 1063. Sternholmer, R.M., 1954, Rev. Sc1. Inst. 25. 1070. Swanson, H.P., Gates, D.C., Jenkins, T.L., and Kenney, R.H., 1960, Phys. Rev. Letters, 5. 336. 
Thie, J.A.. 1952, Phys. Rev. 88, 420.

Tollestrup. A.V.. Keck, J.C.. and Horlock, R.M., 1955. Phys. Rev. 99, 220.

Uretsky, I.L., Kenney, R.V., Knapp, E.A., and Perez-Mendez. V., 1958, Phys. Rov. Latters, 1. 12.

Walker, J., 1960, Ph.D. Thesis, Glasgow Untversity. Valker, R.L., Teasdale, J.G., Peterson, V.Z.. and Vette, J.I., 1955, Phys. Rev. 99, 210.

White, R.S., Jacobson, H.J., and Schultz, A.G., 1952, Phys. Rev. 88, 836.

White, D.H., Schectman, R.H., and Chasan, B.H., 1960. Phys. Rer. 120, 614.

W11son, R.R., 1956, Phys. Iev. 104, 218. Wilson, R.R., 1957. Nucl. Instr. 1, 101. Wolfo, B., Silverman, A., and De H\$re, J.W., 1955, Rev. Sc1. Instr. 26, 504. Yukawa, II., 1935, Proc. Phys. - Math. Soc. Japan 17, 48. 
Summary of Ph.D. Thesis

Photoproduction of Negative Pions in Deuterium

by H.C. Evans

Deuterium provides the most suitable target for studying the basic process of negative pion photoproduction at a free neutron. For photon energies well above threshold the spectator model has been used to relate photoproduction in deuterium to photoproduction at a free neutron. Until recently no experimental test of the spectator model that clearly supported its validity for negative pion photoproduction in deuterium had been reported. The spectator model has been investigated using the $307 \mathrm{MeV}$ bremsstrahlung beam of the Glasgow electron synchrotron. The simultaneous detection of pions and protons produced in a thin liquid deuterium target was accomplished using scintillation counter telescopes. The pions were detected at $90 \pm 3.7$ degrees in the energy range 46.3 to $60.4 \mathrm{MeV}$. The angular distribution of recoil protons, and the energy spectrum of recoll protons detected at $30 \pm 3.5$ degrees were measured.

The measured angular distribution was well described by the angular distribution calculated in the spectator 
mode1. The measured energy spectrum has a broad maximum at $42 \mathrm{MeV}$. The shape of this spectrum/1s we 11 described by the spectator model calculations, / the measured spectrum appears to be shifted towards higher energy by 3 to $4 \mathrm{MeV}$. It may be concluded that the spectator model provides a reasonable description of negative pion photoproduction in deuterium for photon energies about $230 \mathrm{MeV}$. The differential cross section for negative pion photoproduction in deuterium at $90 \pm 3.7$ degrees and $53 \pm 7 \mathrm{MeV} 1 \mathrm{~s} 15.8 \pm 1.9 \times 10^{-30}$ $\mathrm{cm}^{2} /$ steradian $\mathrm{MeV}$. 